Florida International University FIU Digital Commons

FIU Electronic Theses and Dissertations

University Graduate School

6-30-2017

\title{
Processing of the English Verb Particle Construction in Persons with Aphasia
}

David Lopez

Florida International University, dlope042@fiu.edu

DOI: 10.25148 /etd.FIDC001975

Follow this and additional works at: https://digitalcommons.fiu.edu/etd

Part of the Psycholinguistics and Neurolinguistics Commons, Semantics and Pragmatics Commons, Speech Pathology and Audiology Commons, and the Syntax Commons

\section{Recommended Citation}

Lopez, David, "Processing of the English Verb Particle Construction in Persons with Aphasia" (2017). FIU Electronic Theses and Dissertations. 3356.

https://digitalcommons.fiu.edu/etd/3356

This work is brought to you for free and open access by the University Graduate School at FIU Digital Commons. It has been accepted for inclusion in FIU Electronic Theses and Dissertations by an authorized administrator of FIU Digital Commons. For more information, please contact dcc@fiu.edu. 


\section{FLORIDA INTERNATIONAL UNIVERSITY}

Miami, Florida

\section{PROCESSING OF THE ENGLISH VERB PARTICLE CONSTRUCTION IN PERSONS} WITH APHASIA

A thesis submitted in partial fulfillment of the requirements for the degree of MASTER OF SCIENCE

in

SPEECH-LANGUAGE PATHOLOGY

by

David Lopez 
To: Dean Ora Strickland

College of Nursing and Health Sciences

This thesis, written by David Lopez, and entitled Processing of the English Verb Particle Construction in Persons with Aphasia, having been approved in respect to style and intellectual content, is referred to you for judgment.

We have read this thesis and recommend that it be approved.

Ellen Thompson

Alfredo Ardila

Monica S. Hough, Major Professor

Date of Defense: June 30, 2017

The thesis of David Lopez is approved.

Dean Ora Strickland College of Nursing and Health Sciences

Andrés G. Gil

Vice President for Research and Economic Development and Dean of the University Graduate School

Florida International University, 2017 
C Copyright 2017 by David Lopez

All rights reserved. 


\section{ACKNOWLEDGMENTS}

I wish to thank the members of my committee for their support, patience, and gentle but firm direction on the completion of this project. What started out as mere curiosity has matured into a body of intellectual work. I would like to thank my thesis advisor Dr. Monica S. Hough for believing in the project since the first day and for her guidance and firm direction. I would also like to thank Dr. Alfredo Ardila and Dr. Ellen Thompson for their input and advice on the theoretical and practical issues of the project.

I would like to acknowledge The Aphasia House and Voices of Hope for Aphasia for opening the doors to me and allow their members to be a part of this project. I have met some amazing individuals who have reminded me why I chose the field of speech pathology. I would also like to thank all the brave participants who put their trust in my word to be a part of this project. I really could not have done this without you!

Lastly, I express my profound gratitude to my parents, friends, and spiritual family for providing me with unfailing support and continuous encouragement throughout my years of study and through the process of researching and writing this thesis. Thank you. 


\begin{abstract}
OF THE THESIS
PROCESSING OF THE ENGLISH VERB PARTICLE CONSTRUCTION IN PERSONS WITH APHASIA
\end{abstract}

by

David Lopez

Florida International University, 2017

Miami, Florida

Professor Monica S. Hough, Major Professor

This study examined comprehension of verb particle constructions in persons with aphasia (PWA) and young and older typical adults according to the semantic classes by Jackendoff (2002). The experimental task focused on the following three classes of verb particle constructions: idiomatic, directional, and aspectual verb particles. Movement of the object NP also was examined. The study involved a picture-matching task counterbalanced for each participant. The results revealed that PWAs showed slower than normal overall processing, slower processing of aspectual verb forms, and slower processing of syntactic form regardless of movement. Error analysis revealed a bias toward the meaning of the verb, particularly on aspectual verb constructions for all three groups. Accuracy data revealed no significant differences between groups although the aphasic group was less accurate in idiomatic verb forms. The results support current literature on the processing of syntactic structures in PWA. 


\section{TABLE OF CONTENTS}

\section{CHAPTER}

PAGE

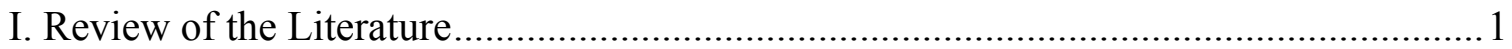

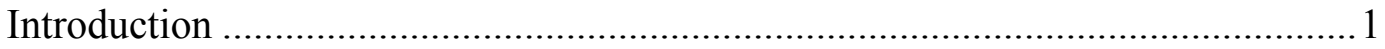

The Syntactic Structure of Verb Particle Constructions........................................2

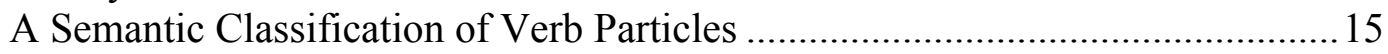

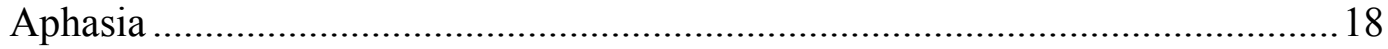

Verb and Sentence Processing and Production in PWAs.....................................20

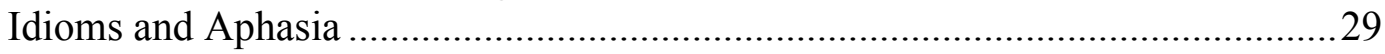

Verb Particle Constructions and Aphasia ..............................................................3

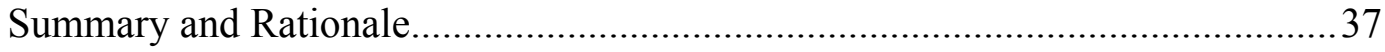

Plan of Study and Experimental Questions ..........................................................39

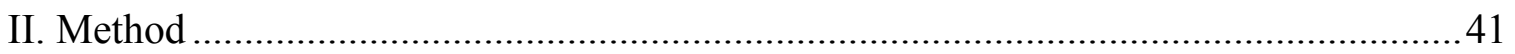

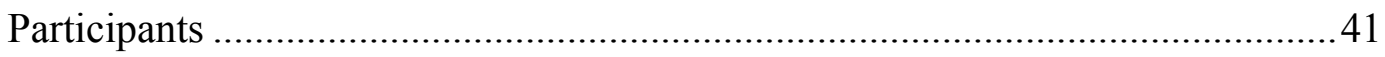

Pre-Experimental Testing .........................................................................4

General Procedures................................................................................ 44

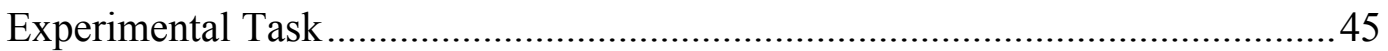

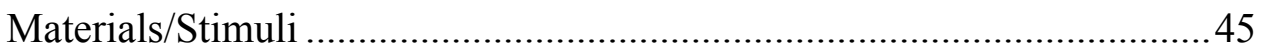

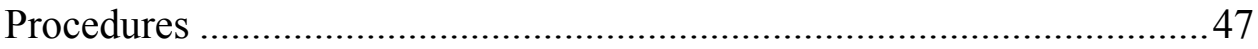

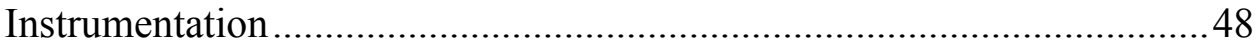

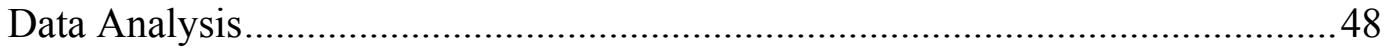

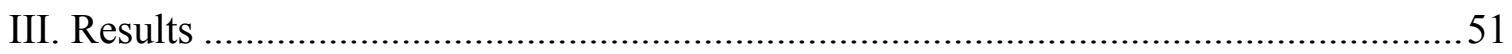

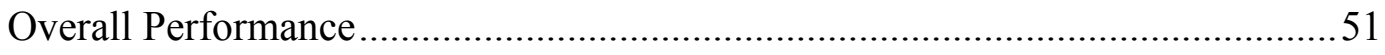

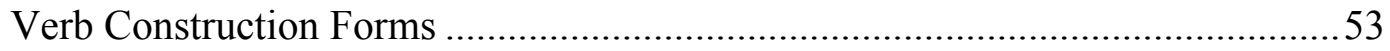

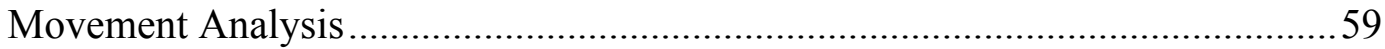

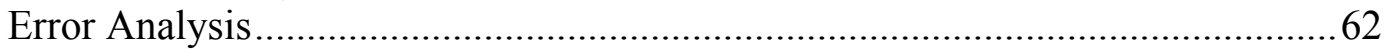

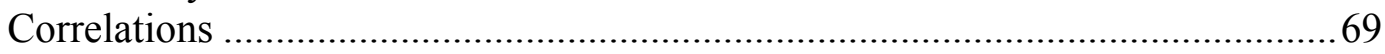

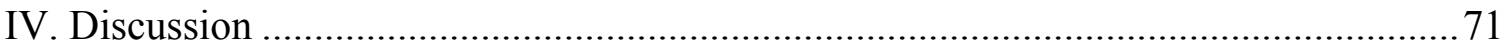

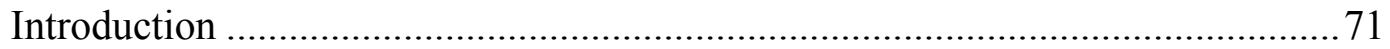

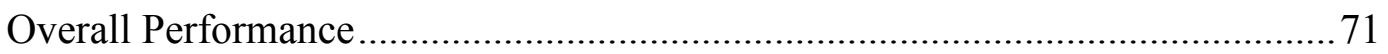

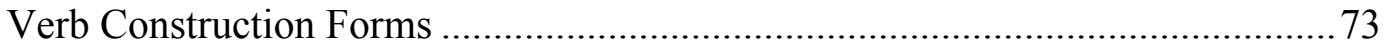

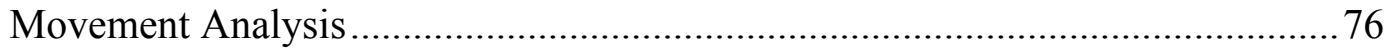

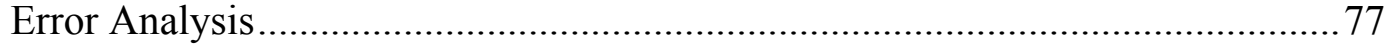

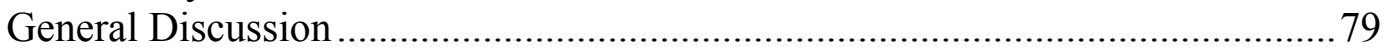

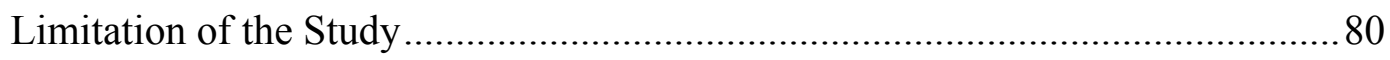

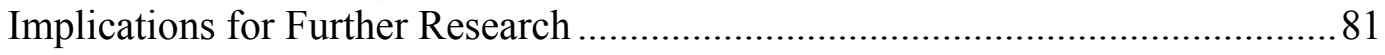

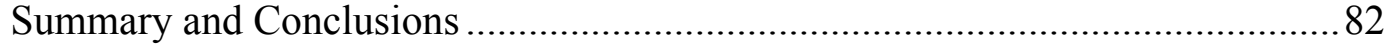

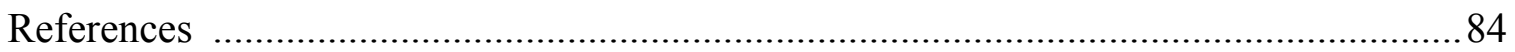

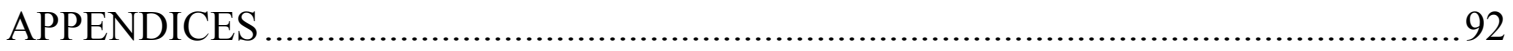




\section{LIST OF TABLES}

TABLE

PAGE

2.1 Demographic Summary

3.1 Means, Standard Deviations, and Ranges for Correct Responses for overall performance and verb construction form for all three groups

3.3 Means, standard deviations, and ranges for correct responses for movement of the verb particle per verb construction form for the three groups

3.4 Error Patterns for the Aspectual Verb Construction in Group 1 .............................67

3.5 Error Patterns for the Aspectual Verb Construction in Group 2 ...............................68

3.6 Error Patterns for the Aspectual Verb Construction in Group 3 .............................69

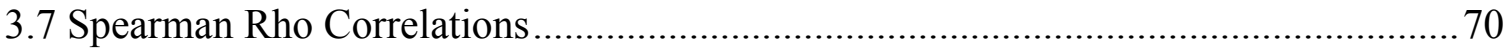




\section{LIST OF FIGURES}

FIGURE

PAGE

1. The D-Structure representation of verb particles (Johnson, 1991)............................. 6

2. The verb particle construction moves to $\boldsymbol{\mu}$ (Johnson, 1991) ......................................... 7

3. The verb particle construction moves to $\boldsymbol{\mu}$ leaving the particle in original D-structure

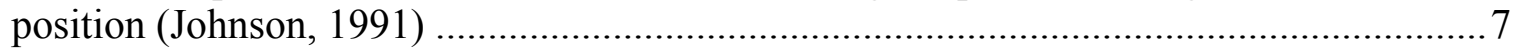

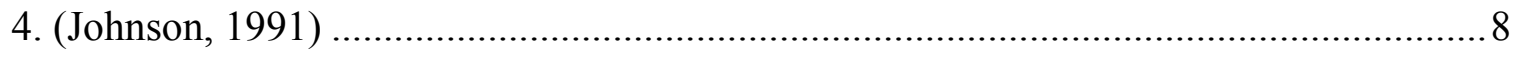

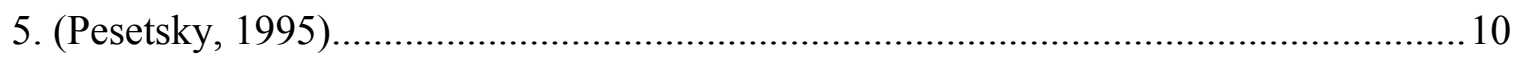

6. Syntactic Analysis of Complex Verb Particles (taken from Baker (1997)) ................. 12

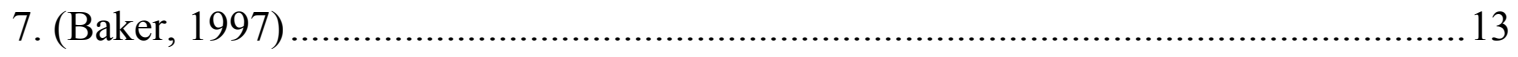

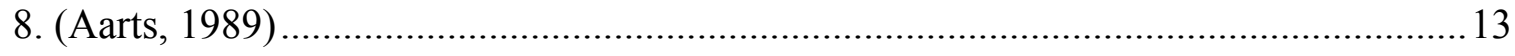

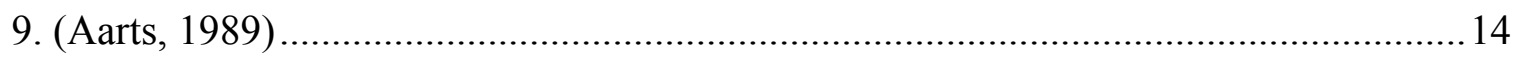

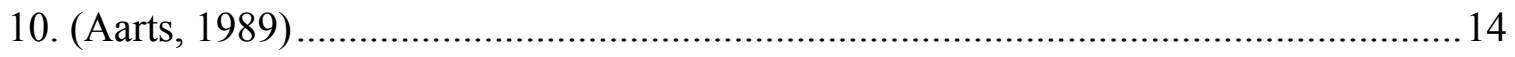

2.1 Sample stimuli for the sentence: The girl kicked the boy out ................................46

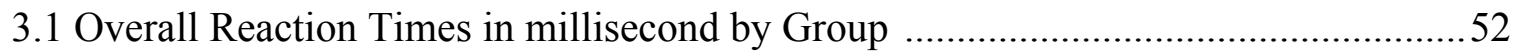

3.2 Reaction Times in milliseconds by Group for Aspectual Verb Particles ..................54

3.3 Reaction Times in milliseconds by Group for Directional Verb Particles ................55

3.4 Reaction Times in milliseconds by Group for Idiomatic Verb Particles ...................56

3.5 Reaction time for the three verb construction types for the Group with Aphasia ......57

3.6 Reaction time for the three verb construction types for the typical younger group ...58

3.7 Reaction Times in milliseconds by Group for the Condition V Prt NP ...................60

3.8 Reaction Time in milliseconds by Group for the Condition V NP Prt .....................61

3.9 Error production for the three verb construction types for the Group with Aphasia...63 
3.10 Error Production for the three verb construction types for the typical older Group .64

3.11 Error Production for the three verb construction types for the typical younger

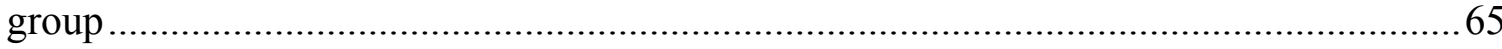




\section{CHAPTER I \\ Review of the Literature}

\section{Introduction}

Verb particles are grammatical constructions that have a unique form. Unlike most other common features of grammar, verb particles consist of two parts - a main verb such as go — and a particle—-such as out. Together, these components make up the verb particle construction go out. Another feature is their ability to occupy different positions within the syntactic structure of a sentence, as in the examples "He cut the article out" and "He cut out the article". Verb particles also tend to be generally idiomatic in nature and are said to be stored as whole units in the lexicon. Due to their seemingly complex nature, verb particles have been a topic of interest in language acquisition studies (Crutchley, 2007; Neagu, 2007; Sugisaki \& Snyder, 2002) and psycholinguistic studies of native English speakers and L2 learners (Behrens, 1998; Blais \& Gonnerman, 2013; Gonnerman \& Hayes, 2005; Dillard, 2015; Laufer, 1997; Lopez, Louis, Miles, Thompson, \& Walker, 2011; Torres-Martinez, 2015). However, there has been minimal investigation of verb particles in persons with aphasia (Kohen, Milsark \& Martin, 2011), although some individuals with aphasia have syntactic difficulties.

Thus, the purpose of this study is to examine the processing of verb particle constructions in English in typical adults and in adults with Broca's aphasia. The problem to be addressed is whether English verb particle constructions are difficult for persons with aphasia to comprehend. Past research on verb particles in persons with aphasia (PWA) has focused on their production (Kohen, Milsark, \& Martin, 2011) but not on their comprehension. The aim of the present work is to increase understanding of the 
relationships between verb argument structures and how injured brains process these constructions. To achieve this goal, the literature review will begin with a discussion of verb particle constructions followed by presentation of information on proposed syntactic structures of verb particles and their semantic analyses. This will be followed by an overview of aphasia and a general discussion on the psycholinguistic research conducted on PWA to illustrate the syntax of verbs as well as the difficulties PWA have with verb and sentence production and processing. Next, will be a discussion on the production of verb particle constructions and transitive prepositional constructions with PWA. The literature review will conclude with the summary and rationale, plan of study, and experimental questions for the current investigation.

\section{The Syntactic Structure of Verb Particle Constructions}

Verb particle constructions are composed of a verb and a preposition-like morpheme that accompanies the verb (Jackendoff, 2002). These constructions are illustrated in (1) below:

(1) a. Michelle looked up the reference.

b. They called out the lotto numbers.

c. The baby pointed out the toy.

The items in bold are the verb particle constructions. When a verb does not take a direct object as its complement, the particle is the only constituent serving as the complement as illustrated by the examples below (verb particles are italicized) (Jackendoff, 2002):

(2) The baby grew $u p$.

(3) The bomb blew up.

(4) The speech pathology students freaked out. 
When the verb takes a direct object, the direct object can appear on either side of the verb, as illustrated by the following examples:

(5) Bill put out the cigarette.

(6) The bomb blew up the city.

In the above two examples, the particle is between the verb and the direct object. When the particle appears in this position, it is said to be in the left hand position. The particle can also appear in the right hand position, as illustrated below:

(7) Bill put the cigarette out.

(8) The bomb blew the city up.

Another important feature to note is that the particle must appear in the right hand position when the object is a non-stressed pronoun, as illustrated below:

(9) Bill put it out, not *Bill put out it.

(10) The bomb blew it $u p$, not *The bomb blew up it.

(11) Mary took me out, not *Mary took out me.

Additionally, the left hand position is mandatory when the object is heavy as illustrated below:

(12) Bill put out the cigarette that he was smoking.

(13) *Bill put the cigarette that he was smoking out.

There has been disagreement in the literature in terms of whether verb particle constructions are stored as whole units in the lexicon with its corresponding verb or whether verb particles form distinct syntactic phrases in which the particle is an independent head (Aarts, 1989; den Dikken, 1995). Syntacticians who propose that verb particle constructions are stored as whole units include Johnson (1991), Pesetsky (1995), 
and Jackendoff (2002). Those who propose that particles are heads of a syntactic phrase are Kayne (1985), Aarts (1989), and den Dikken (1995).

Johnson (1991) provided an analysis whereby verb particles are inserted at deep structure (D-structure) in a single lexical position and separated syntactically. Three arguments in favor of verb particle constructions as lexical items are presented:

1) verb particle constructions undergo morphological processes such as noun derivation with -ing, and adjectival derivation with -ed:

a. Michelle's looking up of the reference is proving to be tedious

b. The calling out of my name made me blush.

c. The baby's pointing out of the toy prevented his mom from slipping.

2) the selectional requirements of particle verbs are not derived from the selectional requirements of their parts

a. The judges can't make out whether the painting is about a tiger or not.

b. Fill in whether you are single or not.

3) the verb particle in the particle verb construction cannot be stranded in instances of gapping and thus gaps with the verb:

a. Dave looked up Mary's address, and John, my address.

b. *Dave looked up Mary's address, and John, up my address.

c. *Dave looked up Mary's address, and John, my address up.

Particles enter into what Johnson (1991) identifies as a characteristic paradigm: the object of the verb particle construction is able to show up on either side of the particle unless it is a pronoun, in which case it must precede the particle. This paradigm is illustrated in (14): 
(14) a. Michelle looked up the reference.

b. Michelle looked the reference up.

c. Michelle looked it up.

d. *Michelle looked up it.

Some restrictions to the above paradigm include prepositional or clausal complements of verb particle constructions. These must follow the particle:

(15) a. Mary teamed up with the linguists.

b. *Mary teamed with the linguists up.

c. Dave pointed out that Mary was wrong.

d. *Dave pointed that Mary was wrong out.

Additionally, arguments not part of the construction may not come before the verb:

(16) a. Mary looked up the information carefully.

b. Mary looked the information up carefully.

c. *Mary looked carefully up the information.

d. *Mary looked the information carefully up.

Johnson (1991) argued that the word order alternation of the characteristic paradigm is related to Case. Thus, only those terms that are Case-marked by the verb particle construction undergo alternation, specifically, only NPs. The following deep structure (D-structure) representation of verb particle constructions is proposed: 


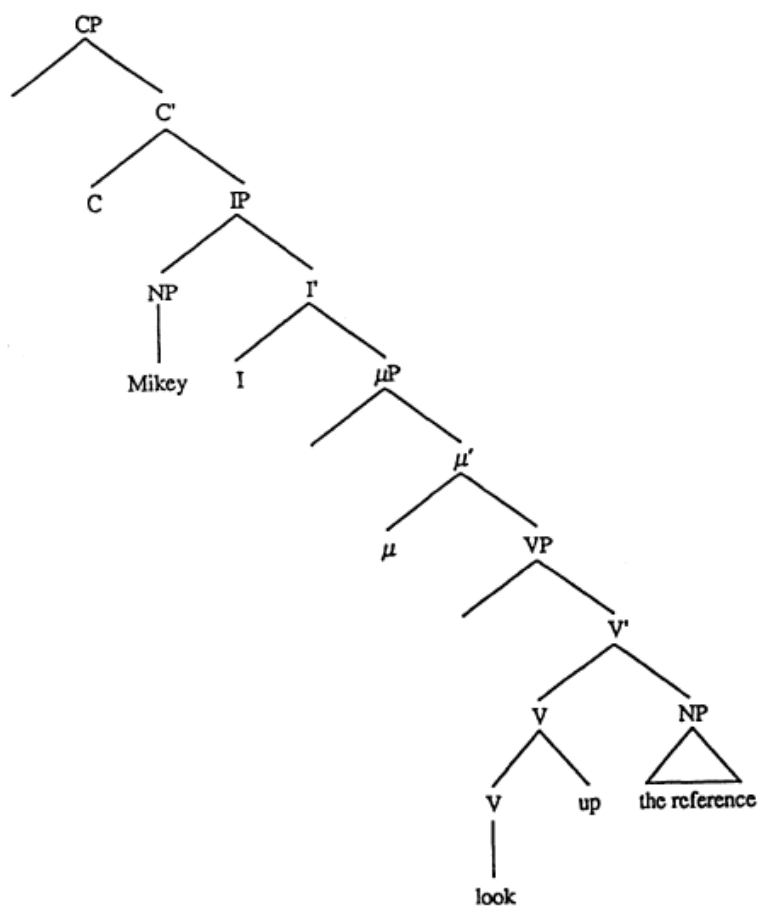

Fig. 1 The D-Structure representation of verb particles (Johnson, 1991).

In Fig. 1 above, $\mu$ represents a functional projection relevant to the assignment of case (Pesetsky, 1995). $\mu \mathrm{P}$ is analyzed as the projection responsible for objective case in all configurations. In Johnson's (1991) analysis, the verb particle construction may move to $\mu$, as illustrated below. 


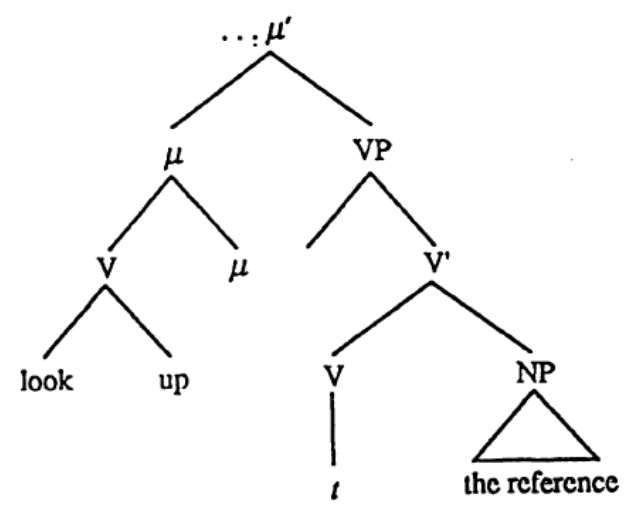

Fig. 2 The verb particle construction moves to $\mu$ (Johnson, 1991).

Additionally, Head Movement can also move the verb portion alone leaving the particle stranded. The proposed syntactic tree diagram is illustrated in Figure 3 below.

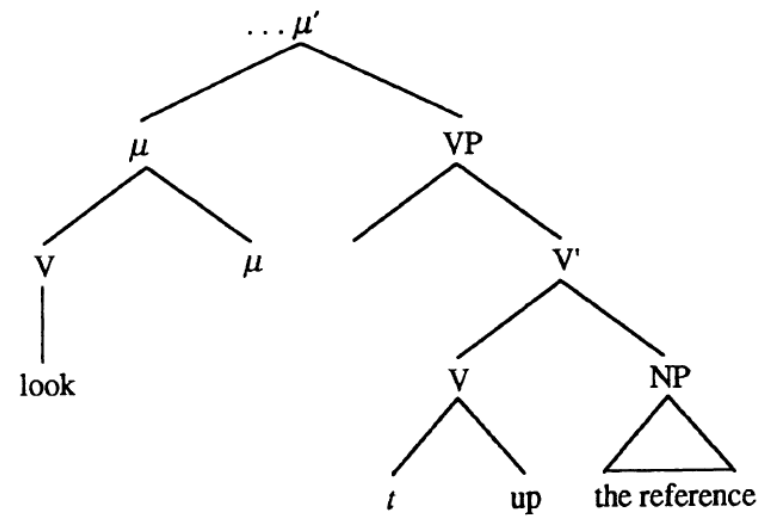

Fig. 3 The verb portion of the verb particle construction (look) moves to $\mu$ leaving the particle 'up' in its original D-structure position (Johnson, 1991).

Therefore, Johnson (1991) indicated that the syntactic force responsible for separating the particle from the verb is Head Movement. In order to account for all of the sentences in example (2), Johnson (1991) reported that if structural case is assigned after movement of the verb, then the object has to move to the Specifier position in VP. This places the NP between the verb and the particle as illustrated in Figure 4 below. 


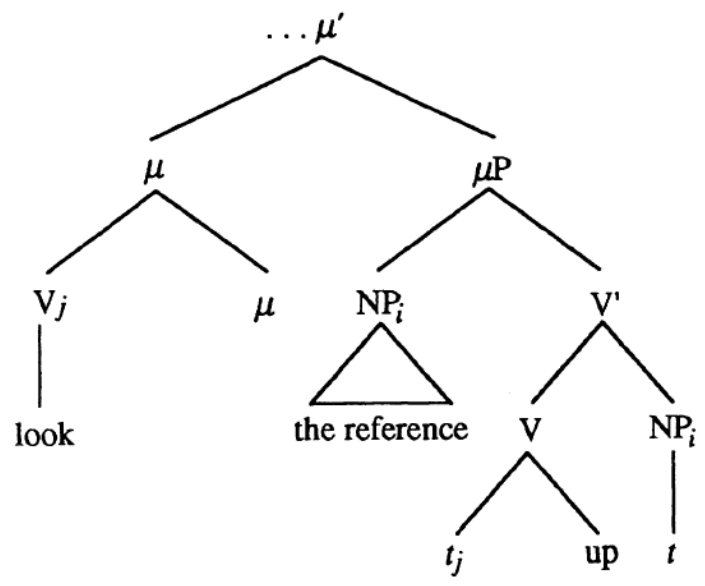

Fig. 4 (Johnson, 1991)

If, however, accusative case is assigned before the verb moves, then the predicate remains in its original D-structure position. This second option, according to Johnson (1991), is not available for weak pronouns (it, him, her). Thus, Johnson (1991) concluded that "the characteristic paradigm emerge straightforwardly if the verb and particle are base-generated together and separated by Verb Movement" (p. 608).

An alternate analysis is provided in Pesetsky (1995). In Pesetsky’s analysis, verb particle constructions have the following structure: verb particle G DP:

(17) a. Sue sent out $G$ the message

b. We threw away $\mathrm{G}$ the notice c. Ernie put down $\mathrm{G}$ the duckie.

According to Pesetsky, the DP immediately following the particle should be thematically restricted and should not bear the Goal role as the following examples illustrate taken from Pesetsky (1995): 
(18) a. The secretary sent out $\mathrm{G}$ a schedule to the stockholders.

b. The secretary sent out the stockholders $\mathrm{G}$ a schedule.

Pesetsky argued that objective case on the Goal argument in example (18) b cannot be licensed by the verb without violating the adjacency condition, but is straightforwardly licensed by G in example (18) a. Thus, Pesetsky proposed an alternative structure to mitigate example (18) b.:

(19) The secretary sent the stockholders out a schedule Pesetsky (1995) adopted Johnson's (1991) analysis without Johnson's approach to objective Case. Below is Pesetsky's analysis of the verb particle construction. 


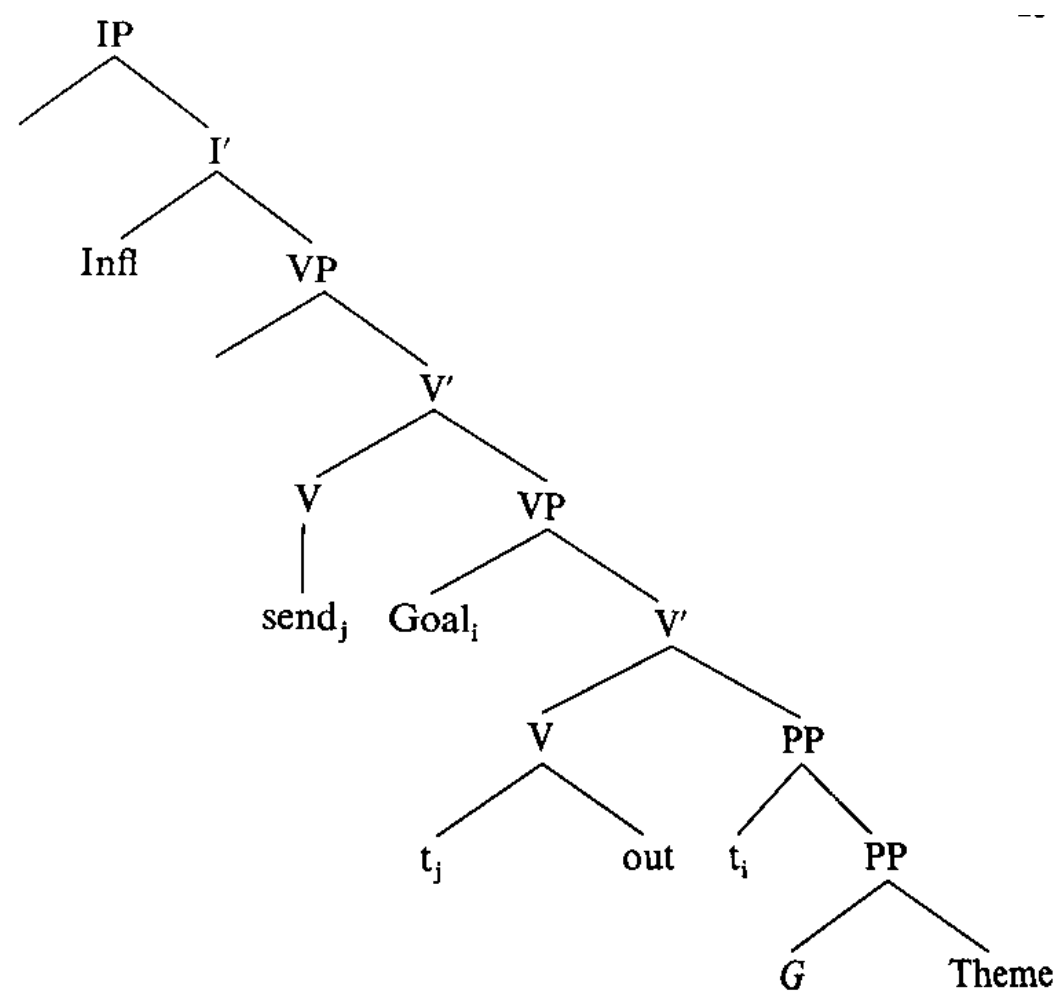

Fig. 5 (Pesetsky, 1995)

Unlike Johnson (1991), Pesetsky explained that the movement of Goal is motivated by reasons of Case. Goal bears strong case features that need to be checked. These features are checked against comparable features borne by V. In Pesetsky's analysis — verb particle G DP — the strong features of V are optionally present but the strong features of DP are obligatorily present. When $\mathrm{V}$ bears strong case features as illustrated in the diagram above, it can move if movement provides an opportunity for its features to be checked. The unique feature of the configuration proposed by Pesetsky (1995) is that the lower V can move out of the higher V. Once it leaves its particle behind, adjacency can be satisfied, as the diagram shows. Pesetsky states that this movement is what derives the order verb object particle: 
(20) a. Sue sent the message out.

b. We threw the notice away.

c. Ernie put the duckie down.

Furthermore, like Johnson (1991), Pesetsky assumed the particle forms a part of V (the verb) and extends a condition in which the particle is not detachable under coordination:

(21) *John turned up the air conditioning and down the heat.

However, Pesetsky (1995) argued that the structure produced by the analysis described in Fig. 5 yields the correct constituency for coordination. In the examples taken from Pesetsky (1995), the lower $\mu$ P may be a conjunct (as illustrated in (22) a) as may VP (as illustrated in (22) b):

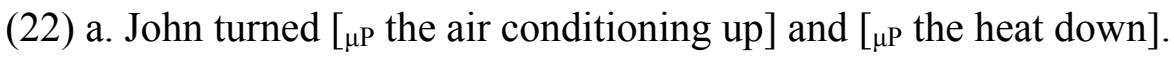
b. John turned the air conditioning [vp down on Friday] and [vp up on Saturday].

Thus, in Pesetsky's analysis, $\mu \mathrm{P}$ corresponds to VP.

In contrast to Johnson (1991) and Pesetsky (1995), den Dikken (1995) proposed the hypothesis that particles are heads of small clauses (SC), ergative, non-lexical, and prepositional. The following structure for complex verb particle constructions is proposed (the reader is referred to Den Dikken (1995) for a complete analysis and explanation of the theory): 


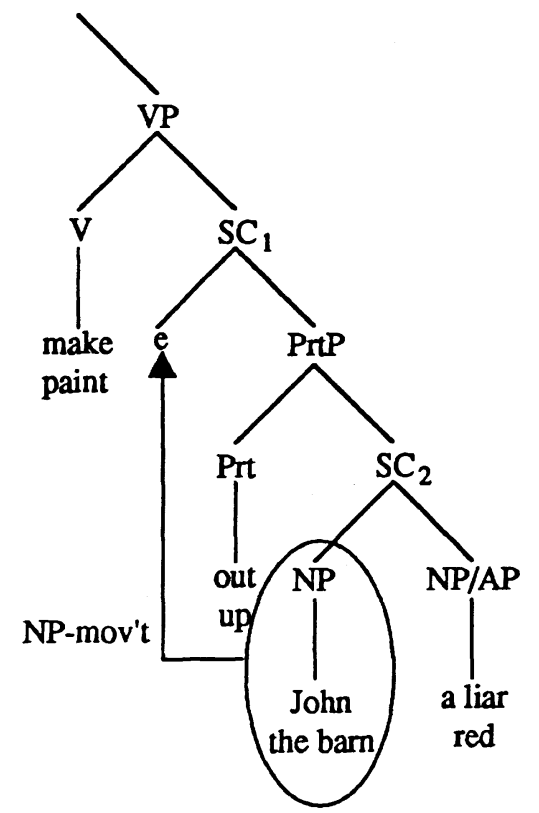

Fig. 6 Syntactic Analysis of Complex Verb Particles (taken from Baker (1997))

The tree diagram above illustrates den Dikken's view that the small clause is basegenerated as the complement of the particle. The subject of the small clause then moves into the subject position of the particle phrase in order to check Case with the verb (den Dikken, 1995; Baker, 1997). Like den Dikken (1995), Kayne (1985) also proposed that particles are heads of small clauses; however, unlike den Dikken (1995), Kayne proposed that the small clause is generated as the subject of the verb particle and is moved to the right past the particle in order for its subject to check Case with the verb (Kayne 1985; Baker 1997). Below is Kayne’s syntactic analysis taken from Baker (1997) demonstrating the rightward extraposition of the small clause predicate: 


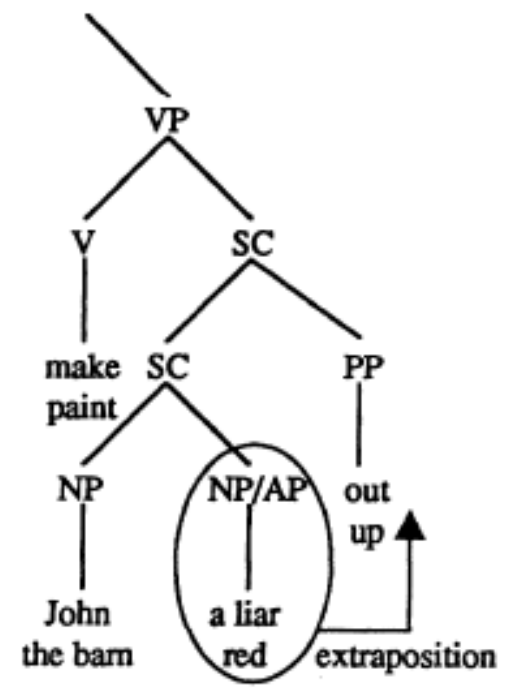

Fig. 7 (Baker, 1997).

Aarts (1989) provided an analysis that distinguishes between verb particle constructions, which he terms verb-preposition constructions, from prepositional verbs. An example of a prepositional verb construction is provided below:

(23) Peter looked at Mary longingly.

According to Aarts (1989), (23) will have the following structure:

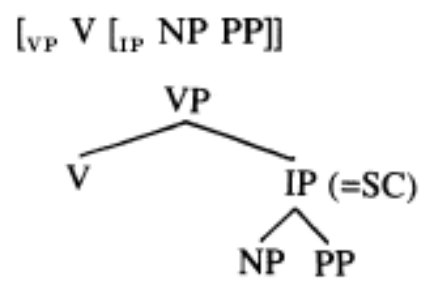

Fig. 8 (Aarts, 1989) 
In contrast, prepositional verb constructions have the following structure:

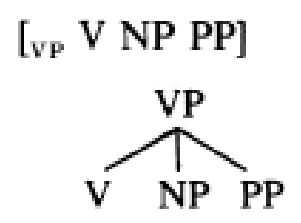

Fig. 9 (Aarts, 1989)

Aarts analyzed verb particles as intransitive prepositions heading a prepositional phrase. Prepositional verb constructions subcategorize for SCs (small clauses) which Aarts (1989) has analyzed as IPs whereas prepositional verb constructions subcategorize for a NP and PP. Aarts proposes the structure of the SC to be [ $\left.{ }_{\mathrm{PP}} \mathrm{NP}[\mathrm{PP} \mathrm{P}]\right]$. Thus, $\mathrm{SC}$ is a projection of the lower prepositional phrase. Like Kayne (1985), Aarts (1989) proposes a rightward movement of the NP; however in his analysis, the constituents adjunct to VP:

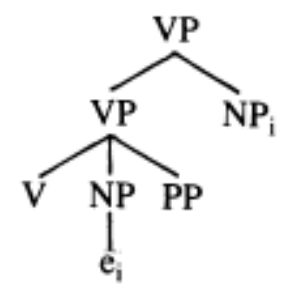

Fig. 10 (Aarts, 1989)

The common theme across all these syntactic analyses of verb particle constructions is that the constituents undergo movement from deep structure to the surface structure. A base form with the structure V Prt NP will be adopted here. 


\section{A Semantic Classification of Verb Particles}

Semantically, verb particle constructions are assumed to be stored in the lexicon as whole units (Blais \& Gonnerman, 2013; Jackendoff 1995, 2002; Wray \& Perkins, 2000). Studies on L2 learners of English have focused on the transparency or opaqueness of verb particle constructions (Blais \& Gonnerman, 2013; Condon, 2008; Gonnerman \& Hayes, 2013). Jackendoff (2002) classified English verb particle constructions into several different semantic classes. These semantic classes are idiomatic verb-particle combinations, directional particles, aspectual particles, time-away constructions, and idioms consisting of particles plus something other than the verb. McIntyre (2002) proposed that idiosyncratic verb particles are in fact compositional and that verb particle constructions such as use up and scrub down are prepositional elements with construction-specific meanings confined to the verb particle construction. In an alternative analysis to Jackendoff and similar to McIntyre, Larsen (2014) did not classify particles into the aforementioned semantic classes. Rather, he argued that all particles are compositional and that those particles classified as "aspectual" do not denote an independent aspect feature but rather they denote metaphorical spatial relations. Any aspectual relations these types of particles denote are from the spatial relations they designate. For simplicity, this paper will focus on Jackendoff's classes of verb particles, namely idiomatic verb particle constructions, directional particles, and aspectual particles. Counterarguments to these classes will also be provided.

It is widely accepted in the literature that idiomatic verb particles are said to be stored in the lexicon as complete units (e.g. Jackendoff, 2002; Wray \& Perkins, 2000). This is because the verb and its particle together are said form a meaningful unit and they 
are noncompositional. Examples of these types of verbs are look up, blow up, throw up (with the sense of vomit), bring up, and freak out (Jackendoff, 2002). However, Jackendoff (2002) stated that although the verb and its particle may be stored together they do not have to be contiguous in underlying structure. That is, the verb and its particle may be separated by an intervening noun phrase. Larsen (2014), however, dispelled a classification of idiomatic verb particles and both Larsen (2014) and McIntyre (2002) argued that the meanings of these constructions are compositional and denote abstract spatial relations.

A second class of verb particles are directional particles. These verbs select a directional prepositional phrase as their complement, indicating the direction of motion of the action. These PPs can be replaced with a particle if the phrase lacks a specifier (Jackendoff, 2002). If the phrase lacks a specifier, the particle can appear before the direct object just like an idiomatic particle. Examples of directional particles are go out, come in, and look down.

McIntyre (2002) stated that the most common type of verb particle constructions of Germanic languages express a spatial prepositional relation in which there is a theme and a reference object. The reference object, according to McIntyre, is not expressed syntactically and must be inferred on the basis of world knowledge. The example I put a record on is given to illustrate this notion (i.e. the record was placed in a record player since that is the most logical and stereotypical location). However, in contrast to Jackendoff (2002), McIntyre stated that seemingly idiomatic verb particles such as wipe down have regular meanings when one considers that the particle down occurs with many verbs of surface treatment: 
(24) brush down, clean down, dust down, hose down, rub down, sand down, scour down, scrub down, soap down, sponge down, spray down, swab down, wash down, wipe down

The third and final class of verb particles to be discussed are what Jackendoff (2002) described as aspectual particles. Aspectual particles indicate that the action is complete, as the examples below illustrate:

(25) Mary drank up the wine.

(26) The speech pathology students finished up their paper.

Or they can designate an action is on-going as the following examples illustrate:

(27) Bill read away.

(28) Dave wrote on.

Unlike directional particles, aspectual particles do not encode directionality of motion of the action (e.g. "Toss the ball up"), they can be omitted while keeping the original sense of the verb intact (e.g. "Mary drank the wine"), and aspectual markers can be redundant as in close the book up. Lastly, aspectual markers are not idiomatic: they are free to combine with a large number of verbs (Jackendoff, 2002).

McIntyre (2002) analyzed the particle 'up' similarly to the particle 'down' mentioned above. In his analysis, the particle 'up' indicates that the verb has a maximal effect on the direct object and it adds its own semantic contribution; unlike Jackendoff who argues that the aspectual markers can be redundant. In Larsen's (2014) analysis, 
contrary to Jackendoff, aspectual particles must be treated as idiomatic in order to prevent them from being productive in the grammar and from being interchangeable with other aspectual markers. Moreover, Larsen, like McIntyre, argues that aspectual particles also retain a type of abstract spatial meaning.

\section{Aphasia}

Aphasia is defined as an acquired linguistic deficit caused by brain damage that affects the ability to communicate in the modalities of speaking, listening, reading, and writing. (Goodglass, 1993; Hallowell \& Chapey, 2008; Nolte, 2009; Turgeon \& Macoir, 2008). Thus, the nature of aphasic impairment is neurogenic, acquired, and affecting language without general sensory and mental deficits. Aphasia is typically the result of left hemisphere trauma caused by either a cerebrovascular accident (CVA) or traumatic brain injury (TBI) (Ardila, 2014; Garrett \& Lasker, 2013; Hallowell \& Chapey, 2008; Helm-Estabrooks, Albert, \& Nichols, 2014). The traditional view of aphasia is that each part of the brain within the language zones performs specific tasks and these areas together form a network that results in comprehension and production of language. An alternative view argues that there are no language areas as such and that language is supported by an interactive set of neural networks and aphasia is the result of disruption within this set of networks (Helm-Estabrooks et al., 2014).

Aphasia can affect both linguistic production and comprehension or it can affect one skill more than another (Ardila, 2014; Garrett and Lasker, 2014; Goodglass, 1993; Hallowell \& Chapey, 2008; Helm-Estabrooks et al., 2014; Hough, Downs, Cranford, \& Givens, 2003). Thus, aphasia can encompass a range of impairments involving a single or multiple features of language. 
Classifying aphasia has been a difficult task and there is a lack of consensus about how the different forms of aphasia should be categorized and treated (Garrett \& Lasker, 2013; Goodglass, 1993; Hallowell \& Chapey, 2008; Helm-Estabrooks et al., 2014; Turgeon \& Macoir, 2008). Ardila (2014) indicates that "Aphasia is not a single and unified clinical syndrome, but two rather different (even opposed) clinical syndromes" (p.60). The traditional classification revolves around syndrome typology, identifying the classical categories of aphasia, namely Broca's aphasia and Wernicke's aphasia, as well as conduction aphasia, transcortical motor aphasia, transcortical sensory aphasia, and anomic aphasia (Goodglass, 1993; Hallowell \& Chapey, 2008; Helm-Estabrooks et al., 2014; Nolte, 2009; Turgeon \& Macoir, 2008). Some have classified aphasic syndromes according to types of language errors while others have classified the syndromes in terms of language impairments and related impairments of speech (Turgeon \& Macoir, 2008). It is common in the literature to refer to two broad types of aphasia: fluent and non fluent aphasia (Ardila, 2014; Goodglass, 1993; Hallowell and Chapey, 2008; Helm-Estabrooks et al., 2014; Nolte, 2009; Turgeon and Macoir, 2008). The current study will focus on individuals with Broca's aphasia, a type of non-fluent aphasia.

Broca's area corresponds to the pars opercularis and pars triangualaris of the inferior frontal gyrus (Ardila, 2014; Goodglass, 1993; Nolte, 2009). Damage to this area of the brain, and the surrounding area deep into white matter, whether caused by CVA or traumatic brain injury, typically results in a Broca's aphasia. Broca's aphasia is characterized by reduction or suppression of language production, in which there are word retrieval impairments, thought organization problems, and agrammatism. Agrammatism is the omission of grammatical morphemes and the breakdown of sentence 
structure in verbal output (Goodglass, 1993; Thompson \& Bastiaanse, 2012). Although auditory comprehension skills are often relatively intact, PWAs with agrammatism often also present with asyntactic comprehension, particularly in regard to inhibiting the processing of sentences whose meanings rely on syntactic structure (Ardila, 2014). Often accompanying Broca's aphasia is effortful articulation as the result of apraxia of speech (Ardila, 2014; Goodglass, 1993; Nolte, 2009). Persons with Broca's aphasia may show a range of severity levels relative to their limited speech production and impaired reading and writing abilities (Ardila 2014; Goodglass, 1993; Helm-Estabrooks et al., 2014; Halloway \& Chapey, 2008).

\section{Verb and Sentence Processing and Production in PWAs}

Most studies on the usage of verbs by persons with aphasia have focused on the agrammatic deficits of verb production (Bastiaanse \& van Zonnefeld, 2004; Grodzinsky, 1988; Kegl, 1995; Morean, 2012; Rochon, Saffran, Berndt, \& Schwartz, 2000; Thompson, 2003). Semantic features influencing verb retrieval also have been a focus of study (Barde, Schwartz, \& Boronat, 2006; Breedin, Saffran \& Schwartz, 1998; Kim \& Thompson, 2000).

As mentioned, agrammatism is a complex language disorder that affects the ability to produce grammatical sentences (Goodglass, 1993). Several researchers (Friedmann, 2001; Goodglass, 1993; Grodzinsky, 1988; Helm-Estabrooks, Albert, \& Nicholas, 2014; Kegl, 1995; Thompson \& Bastiaanse, 2012) concur that agrammatism is a linguistic impairment resulting from acquired brain damage to the left cerebral hemisphere, usually at Broca's area and its vicinity. It is characterized by non-fluent speech, reduced speech rate, and short utterances consisting primarily of substantive 
words with few grammatical morphemes (e.g., pronouns, prepositions, or articles). There may be comprehension deficits, particularly when the word order differs from the canonical D-structure order.

Additionally, agrammatism varies depending on the specific language used; consequently in some languages that do not have verb inflection, such as Chinese, tense and agreement omissions and substitutions are not produced by PWA (Friedmann, 2001; Goodglass, 1993; Helm-Estabrooks, Albert, \& Nicholas, 2014; Thompson \& Bastiaanse, 2012). In contrast, there are case errors on nouns and determiners in languages such as German, Finnish, and Turkish as these are morphologically rich languages (Thompson \& Bastiaanse, 2012).

Cross-linguistic research on verb production in PWA has revealed that one of the problems PWA have is movement of the verb in sentences (Bastiaanse \& van Zonnefeld 2002, 2004; Friedman 2001, 2006). In order to account for these difficulties, Friedmann (2001; 2006) proposed the Tree-Pruning Hypothesis (TPH), which suggests that differences in production and comprehension of sentences requiring movement (e.g. question formation, passives, and object relatives) can be accounted for depending on the height of the syntactic tree that the patient can access. Friedmann suggested that the higher the patient can climb the tree, the milder the impairment. This was illustrated in a study with 14 Hebrew- and Palestinian Arabic-speaking PWA in which the production of verb inflection was examined (Friedmann, 2001). The results demonstrated that the participants had difficulties with tense but not agreement. Friedmann (2001) concluded that the dissociation in verb inflections was due to the PWA being able to project to the agreement phrase (AgrP) but failing to project to the tense phrase (TP). Using the 
syntactic tree model put forth by Pollock (1989), the AgrP node is lower on the syntactic tree, and thus easier for the PWA to access than the TP node, which is higher on the syntactic tree. Thus, the participants' failing to access TP, a higher node on the tree, is responsible for the difficulty (Friedmann 2001; 2006).

Bastiaanse et al. (2002) conducted a series of studies with Dutch- and Englishspeaking patients with agrammatic Broca's aphasia focusing on finiteness and the position of the verb. A significant statistical difference between the production of verbs in matrix (main) and embedded clauses in Dutch-speaking PWA but not in Englishspeaking PWA was observed. Bastiaanse et al. (2002) concluded that these findings indicated that the production of moved finite verbs was more impaired than the production of non-moved finite verbs.

In a follow-up study on Dutch-speaking PWA only, Bastiaanse and van Zonneveld (2004) confirmed that completing a matrix clause was more difficult than completing an embedded clause. Bastiaanse and van Zonneveld (2004) hypothesized that verb-object production diminishes in a linguistically more complex construction. Within the same study, Bastiaanse and van Zonneveld conducted a second experiment consisting of a production task using verbs with alternating transitivity. Bastiaanse and van Zonnefeld found that sentence construction in the intransitive condition was significantly more difficult than in the transitive condition. The researchers concluded that the intransitive condition, although superficially less complex, was more difficult than the transitive condition. Bastiaanse and van Zonnefeld (2004) suggested that the results of both experiments indicate that when the same set of verbs is used in two grammatically different constructions, performance diminishes in the most grammatically complex 
condition. Grammatical encoding is the level affected by agrammatism and this is what leads to the impairment in verb production. Verbs have been shown to be more difficult than nouns on a single-word production task and verbs that are more complex with respect to their argument structure are harder to produce than simpler verbs. Additionally, verb production becomes problematic when movement of the verb is required (Bastiaanse et al., 2002; Bastiaanse \& van Zonnefeld, 2004).

Another series of experiments conducted by Bastiaanse et al. (2002) involved studying two other aspects of verbs in addition to finiteness. These two aspects are case and negation. Bastiaanse et al. (2002) argued that the verb plays a central role in the sentence of which one of its roles is to assign grammatical case. Grammatical case, in turn, expresses the syntactic relation between the verb and its arguments. The researchers examined the production of case marking on determiners in German patients with agrammatic Broca's aphasia. German determiners are marked for case, number, and gender. Previous studies have shown that patients do not have a problem inflecting a noun phrase for gender (Bastiaanse et al., 2002). This observation is in line with Friedmann $(2001 ; 2006)$ in which PWA can access the AgrP node on the syntactic tree since it is lower, lending support to TPH. The question that the researchers put forth was whether case as such is the problem or whether the problem is caused by issues with finite verbs (Bastiaanse et al., 2002). The results confirmed that there is a relationship between problems with the finite verb and the production of determiners. Bastiaanse et al (2002) found that there were hardly any gender errors but there were case substitutions. Thus, the problems with determiners in German speakers with agrammatic Broca's aphasia stems from problems with the finite verb. 
Bastiaanse et al. (2002) also examined negation and its relation to verb movement. As discussed earlier, PWA have problems with verb movement. This has been shown in Friedman $(2001 ; 2006)$ and Bastiaanse and van Zonneveld (2004). This problem creates impairments in verb agreement and tense. Thus, Bastiaanse et al. (2002) examined the relationship between verb movement and the PWA's ability to negate sentences. Data from four languages were collected: Dutch, Norwegian, English, and Spanish. In Dutch and Norwegian, insertion of the negation morpheme does not interfere with verb movement whereas in English and Spanish, the insertion of the negation morpheme does interfere with verb movement. Thus, the researchers hypothesized that English- and Spanish-speaking PWA should have impairments in producing negative sentences. Bastiaanse et al. confirmed that the English- and Spanish-speaking patients had significantly more difficulties with negative sentences than affirmative sentences and they performed worse than the Dutch- and Norwegian-speaking PWA when they had to construct negative sentences. As the ability to construct affirmative sentences was comparable between groups, the researchers concluded that the ability to construct negative sentences is dependent on the relationship between negation and verb movement (Bastiaanse et al., 2002).

Studies in verb retrieval in PWAs have revealed that adults with agrammatic aphasia have more difficulty retrieving verbs than nouns (Barde, Schwartz, \& Boronat, 2006; Breedin, Saffran, \& Schwartz, 1998; Kim \& Thompson, 2000). Furthermore, it has been found that naming in general is difficult in this population (Hough, 2007). Verb retrieval is argued to be more difficult due to the semantic complexity of the verb or the complexity of the verb's argument structure. Breedin et al. (1998) presented data from 
both comprehension and verb retrieval tasks in which the semantic weight of the verb was tested. The participants consisted of eight patients who had aphasia as a result of left hemisphere CVA. Three of the eight were diagnosed with agrammatism; however, all PWA had difficulty producing verbs in spontaneous speech. In verb retrieval tasks, the results demonstrated that the patient's verb retrieval was affected by the semantic complexity of the verb. The participants were more likely to retrieve verbs that incorporate a greater number of semantic features and had more difficulty with the patient vs. patient + state verb contrast. The researchers proposed that one possibility for this was that unlike the other verb contrasts, which tended to differ in perceptual, manner, or instrument features, the patient vs. patient + state contrast differed in the number of thematic roles assigned to the direct object. Breedin et al. (1998) suggested that the performance on this contrast may have been complicated by the fact that some PWAs have difficulty with this component of the verb. The researchers noted that tendency for better performance on semantically complex verbs did not appear to be tightly linked to the agrammatic speech pattern. Kim and Thompson (2000) found that their participants with agrammatic aphasia had impaired access to the lexical-syntactic entry of verbs as compared to the lexical entry of nouns. The results suggested that the participants' difficulties accessing the information in the verb's lexical syntactic entry increased as the number of arguments associated with the target verb increased in production-like tasks. 
Kim and Thompson (2000) argued that impaired access to the lexical-syntactic entry of verbs appeared to be one contributor to the sentence production deficit manifested in PWAs. Barde, Schwartz, and Boronat (2006) concluded that one of the multiple factors that hamper verb production in agrammatic aphasia is the influence of the verb's semantic complexity. Additionally, among the causal factors for agrammatism is the weakness in the syntactic input to lexical retrieval, which diminishes access to the types of vocabulary that are especially dependent on this input for their retrieval. Barde et al. (2006) supported Kim and Thompson's (2000) conclusion that weakness in the syntactic input to lexical retrieval diminishes access to the types of vocabulary that are especially dependent on this input for their retrieval. Barde et al's (2006) study also demonstrated that one of the multiple factors that hamper verb production in agrammatic aphasia is the influence of the verb's semantic complexity.

In terms of sentence production in persons with Broca's aphasia, Rochon et al (2000) found that nonfluent PWAs, whether agrammatic or not, differed from controls in the structural elaboration of the sentences they produced as well as their production of free and bound morphemes. The differences in the production of free and bound morphemes were consistent with the amount of elaboration produced. In a case study described in Kegl (1995), it was found that grammatical argument structure can differentiate between sentence complexity factors as well as predict which constructions will or will not pose problems for syntactic processing by PWAs. 
It has been found that processing of verbs may be intact in PWAs (Breedin, Saffran, \& Scwartz, 1998; Shapiro, Gordon, Hack, \& Killackey, 1993; Kim \& Thompson, 2000). In Breedin et al.'s (1998) auditory picture matching task, the results showed that broad semantic distinctions between verbs were fairly well preserved in PWAs. A noun and verb synonymy test revealed that 4 out of the 8 persons with aphasia demonstrated fairly good comprehension of verbs and showed no difference between nouns and verbs while the other four had more difficulty with verbs than nouns. This last group failed to show statistically significant results. In a lexical decision task, Morean (2012) demonstrated that both fluent and nonfluent persons with aphasia processed semantically light verbs faster than semantically heavy verbs. Morean (2012) argued that the results suggest that heavy atypical verbs may actually reside in the periphery of semantic categories which makes them more prone to error while the light verbs lie closer to the center, making them more readily accessible. Morean's (2012) findings contrast with the aforementioned results that heavy verbs were more easily retrieved than light verbs. In a second experiment addressing this, Moraen (2012) found that both semantically heavy and light verbs were retrieved identically and accurately, which refutes the heavy-better-than light claim described above.

Other studies have demonstrated difficulty processing Wh-movment, reflexivity, and unaccusative verbs (Burkhardt, Avrutin, Pinango, \& Ruigendijk 2008; Burkhardt, Pinango, \& Wong 2003; Dickey, Choy, \& Thompson, 2007). Burkhardt et al. (2003), in a study examining Wh-movment and NP-movement in unaccusative verb constructions, found slower than normal activation of Wh-phrases in relative clause structures and slower than normal activation of object-NP traces in the unaccusative structures in an 
online sentence processing task. They put forth the claim that even though brain damage to the vicinity of Broca's area affects dependency relations, an inability to access information in traces or establish proper coindexation is not a result of such damage. Rather, Berkhardt et al. (2003) argued, the results suggest that these dependency relations are affected because the basic syntactic processes used to instantiate them have been slowed down. However, the researchers also suggested that once syntactic activation is underway, all associated mechanisms will take place, including establishing longdistance dependencies.

Dickey, Choy, and Thompson (2007) proposed a different account of the above observation. In an eye-tracking study examining the autonomic processing of Whmovement, Dickey et al. (2007) found that the participants with aphasia's online processing of the movement dependency in Wh-questions was relatively unimpaired. The results suggested that when listening to yes/no questions and Wh-questions, PWAs engage in the same rapid, automatic processing as unimpaired controls, thus contradicting the claim that PWAs have slower than normal processing of movement dependencies.

Burkhardt, Avrutin, Pinango, and Ruigendijk (2008) maintain the view of slowerthan-normal syntactic processing in agrammatic Broca's aphasia. They presented data from an online comprehension study of Dutch reflexive constructions and found that the agrammatic deficit was closely tied to the formation of the syntactic structure. In particular, the data indicated that the Dutch participants were not able to identify reflexive-antecedent dependencies in the same manner as normal unimpaired controls. Thus, Burkhardt et al. (2008) argued that the comprehension problems seen in 
agrammatism are caused by a processing limitation affecting the temporal constraints of syntactic structure formation. The data in Burkhardt et al. (2008) suggest that agrammatism is highly selective in that it affects the formation of the proper syntactic structure, leading to the conclusion that the PWA's failure to construct the complete syntactic tree is the result of a slower-than-normal syntactic system. The researchers explained that slower than normal syntactic structure building could result in a temporarily pruned syntax tree which results in the specific comprehension and production problems seen in agrammatism.

\section{Idioms and Aphasia}

Idioms present special challenges for persons with aphasia as idioms frequently have meanings that go beyond the syntactic and semantic structure of a sentence. It is commonly stated in the aphasia literature that PWA have preserved automatic speech: exclamations, swearing, proper nouns, speech formulas, nursery rhymes, prayers, recited material, counting from 1-10, to name a few (Van Lancker Sidtis, 2006). These utterances are reported to have normal articulation and prosody. Idioms fall under this category. Simply defined, an idiom is a conventionalized complex expression (Everaert, Van Der Linden, Schenk, \& Schreuder, 1995). It is conventionalized because idioms do not follow specific grammatical rules. Idioms or nonliteral language can be simply defined as "what we say is not what we intend to convey" (Van Lancker Sidtis, 2006, p.214). What that statement presupposes is that nonliteral utterances suspend the regular, routine associations of referent meanings and grammar and are replaced by other different rules, associations, or conventions. Van Lancker Sidtis (2006) argued that literal meaning can be better characterized as an aggregate of lexical meaning and it is one of 
the characteristics that distinguishes nonliteral from literal communication. It is also believed that idiomatic expressions are stored in the mental lexicon as complete units (Jackendoff, 2002).

There is a body of psycholinguistic literature dedicated to the study of aphasic deficits for idiom comprehension (Brumm, 2011; Cacciari, Reati, Colombo, Padovani, Rizzo, \& Papagno, 2006; Papagno \& Caporali, 2007; Papagno, Tabossi, Colombo, \& Zampetti, 2004; Papagno \& Genoni, 2004; Thompkins, Boada, \& McGarry, 1992). Researchers have attempted to provide explanations for preserved residual language following left hemisphere damage. Van Lancker Stidtis (2006) summarized findings by Smith (1966) and Smith and Burklund (1966) in which a right-handed individual afflicted by an infiltrating brain tumor in his left cerebral hemisphere underwent a left hemispherectomy. The surgery resulted in a profound aphasia with preserved wellarticulated expletives, sentence stems, and discourse elements. These well-articulated elements, according to Smith (1966) and Smith and Burklund (1966), lent support to a possible right-hemisphere dominance for non propositional speech and nonliteral meanings. Furthermore, Hillert (2004) conducted a study with 3 brain damaged participants: one participant with Wernicke's aphasia, one participant with global aphasia, and one right-hemisphere damaged patient. The results supported the hypothesis that there is a separate lexical entry for idiomatic meaning and this meaning is accessed independently of the literal meaning. It was concluded that literal and nonliteral meanings are spared in left-hemisphere and right-hemisphere damaged adults.

Other research on the processing of nonliteral language has shown contradictory evidence to what is reported. In a case study relative to a patient with a deep dyslexia and 
chronic agrammatic aphasia, Nenonen et al. (2002) found that their participant had to syntactically parse and retrieve the words from the lexicon during idiom comprehension. Interestingly, their participant was able to read idiomatic noun phrases despite the dyslexia and agrammatism. Nenonen et al. (2006) reasoned that noun phrase idioms are more holistically stored as full units while verb phrase idioms require syntactic parsing due to complex morphosyntactic encoding such as argument structures, tense, and person. Similarly, Papagno et al. (2004) found similar results in a group of 11 patients with aphasia. Two of the participants presented with a Broca's aphasia and nine presented with a fluent aphasia. The results revealed that PWA have difficulty comprehending idiomatic meanings. Papagno et al. (2004) argued that both literal and nonliteral phrases are processed in parallel and there is a bias towards the literal meaning. A follow-up study with 10 aphasic participants further confirmed that idioms are difficult for left hemisphere damaged patients and that these difficulties seem to be caused by the inability to suppress the literal interpretation of the phrase (Papagno et al., 2004).

Cacciari et al. (2006) studied the processing of ambiguous idioms in 15 aphasic participants: six with Broca's aphasia, five with Wernicke's aphasia, and four with amnestic aphasia. The results demonstrated that the aphasia group was significantly more impaired than the control group. Cacciari et al. (2006) reasoned that the impairment in accessing the nonliteral meaning could be attributed to a deficit in identifying the idiom itself or even an impairment in suppressing the literal meaning to access the nonliteral meaning. 
The prior work reported was based mainly on off-line processing studies. There have been numerous neuroimaging studies on the processing of idioms (Brumm, 2011; Hillert \& Buracas, 2009; Mashal, Faust, Hendler, \& Mark, 2008; Oliveri, Romero Lauro, \& Papagno, 2004; Rizzo, Sandrini, \& Papagno, 2007; Romero Lauro, Tettamanti, Cappa, \& Papagno, 2008; Zempleni, Renken, Hacks, \& Hoogduin, 2007). These imaging studies have focused on normal, non-brain-damaged individuals. Altogether, the studies cited have demonstrated bilateral neural involvement during idiomatic comprehension, including those areas involved in literal language comprehension (i.e. left inferior frontal gyrus and middle temporal lobe areas).

Brumm (2011) conducted an on-line and off-line processing study on idioms in both non-brain damaged adults and in adults with Broca's aphasia. The purpose of the studies was to bridge the gap between on-line and off-line processing and comprehension of idiomatic expressions. The on-line processing study consisted of 7 adults with a single unilateral CVA and a group of age-matched and education-matched unimpaired participants. The participants were presented with 60 idiomatic expressions of the format VP NP without any plausible literal interpretations. The off-line experiment consisted of the same participants as the on-line task. The participants were presented with 20 idiomatic expressions embedded into auditory sentences that biased the idiomatic phrase toward either a figurative or literal interpretation. Comprehension questions were paired with each stimulus. 
Brumm (2011) found that the results of the on-line task indicated restricted lexical access for only the highly predictable idiomatic expressions. When compared to normal controls, Brumm (2011) found that figurative meanings for the high predictable idiomatic phrases were also accessed, but the timing of the access was delayed and only appeared at the end of the disambiguating phrase. Thus, lexical processing is disordered in PWA during idiomatic phrase comprehension. In terms of the off-line processing task, the lefthemisphere-damaged participants had greater difficulty with the off-line task as compared to the normal controls. Bias towards the literal meaning of the idiomatic phrase was demonstrated by the participants with aphasia and replicated the comprehension difficulties reported in the literature for idiomatic processing in persons with aphasia (Brumm, 2011). However, the results of the off-line task failed to replicate the report that access to idiomatic meanings is somewhat spared, as reported in Cacciari et al. (2006).

\section{Verb Particle Constructions and Aphasia}

To date, there is little research on verb particle production in persons with aphasia. Kohen, Milsark, and Martin (2011) examined the ability of PWAs to repeat sentences containing verb particles. The authors report that there has been previous work that has focused on prepositions and how these are produced and comprehended in persons with aphasia; however, there has been little to no research on verb particles and how they differ from prepositional phrases. The purpose of their study was to investigate the effects of increased syntactic and semantic argument structure complexity on sentence repetition focusing on verb particles and prepositions. Specifically, the authors focused on the English verb particle construction and prepositional transitive constructions. These are illustrated below (from Kohen et al., 2011) 
(1) The driver turned off the lights.

(2) The secretary crossed out the names.

(3) The driver turned off the road.

(4) The secretary crossed over the bridge.

The phrases in boldface signify verb particle constructions and those in italics signify transitive prepositional constructions. The authors argue that prepositional transitive constructions have a more intricate syntactic structure than verb particle constructions and they are semantically more complex, as verb particle constructions form a unitary predicate with three distinct semantic elements as opposed to four distinct semantic elements in transitive prepositional constructions. Therefore, it is expected that the sentence types, despite being superficially similar, will show a difference in processing complexity in which the prepositional transitive type will demonstrate greater processing cost (Kohen et al., 2011). Furthermore, the authors expected that the effects of greater complexity on sentence production would be demonstrated in persons with reduced short term memory capacity. Thus, Kohen et al. (2011) hypothesized that verb particles would be repeated correctly more often than prepositions, and sentences containing verb particles would be repeated more successfully than prepositional transitive sentences.

Eight right-handed monolingual English speakers with chronic aphasia resulting from left-hemisphere neurological damage participated in their study. All participants were at least 36 months post onset stroke with a mean age of 56 years and had at least a high school education. The authors reported that all participants had received varying amounts of speech therapy; however, none were receiving treatment for agrammatism at the time of the study. The authors diagnosed the participants with aphasia using the 
Western Aphasia Battery. Severity levels of agrammatism were based on the 10-point fluency scale outlined in the WAB for the following subtests: Scoring Fluency, Grammatical Competence, and Paraphasias of Spontaneous Speech Tasks (Kohen et al., 2011). Four participants scored 4.5 or below and were rated as severely agrammatic, two participants scored 5.5 on the fluency subtest and were rated as moderately agrammatic, and two participants scored above 6.0 and were rated non-agrammatic.

The stimuli consisted of 30 paired transitive sentences equally divided into verbparticle and prepositional transitive constructions that were balanced for length, lexical content, and frequency. The authors reported a bias against their results: frequency counts indicated that prepositional transitive sentences contained words of higher frequency than words in the verb particle sentences. The sentences were constructed to allow for identical subjects and verbs to be followed by either a prepositional phrase or a verb particle and direct object noun. Kohen et al. (2011) provide the following example:

(5) The driver is turning off the lights.

(6) The driver is turning off the road.

The participants listened to the stimuli said aloud by the clinician and were asked to repeat all 60 sentences presented in randomized order.

Kohen et al (2011) found that verb particles were repeated correctly more often than prepositions during sentence repetition. Furthermore, verb particle sentences were repeated correctly significantly more than prepositional transitive sentences, thus supporting their hypothesis. However, the researchers found no difference between the sentence types in those participants with high WAB scores, suggesting that the difference in processing complexity was most likely to be observed in agrammatic Broca's aphasia. 
Moreover, the researchers were not clear whether the results of the experiment were attributed to syntax, semantics, or both.

Upon reviewing the stimuli that the researchers presented to the participants, Kohen et al. (2011) used idiomatic and directional phrasal verbs in their stimuli. Some examples of these are provided below:

(7) The woman is checking out the book (idiomatic).

(8) The man is looking up the address (idiomatic).

(9) The boy is washing off the dirt (directional).

(10) The man is knocking down the wall (directional).

It is useful to study the various classes of verb particles independently in order to investigate which classes, if any, are the most difficult for PWA to produce in speech or whether, as Kohen et al. (2011) stated, they are retrieved as single units in the lexicon. It would be expected that verb particles would present a challenge to PWA due to their idiomatic meanings and the ability of the object noun phrase to move between the verb and its particle, a characteristic not examined in Kohen et al. (2011). Perhaps the verb particle constructions were easier for the participants with aphasia to repeat because the structure was in its deep structure form (i.e. without overt movement of the constituents). Thus, it would be useful to study the movement of the NP object phrase to determine whether or not this creates a processing burden. 


\section{Summary and Rationale}

As previously mentioned, verb particle constructions are composed of a verb and a preposition-like particle. This particle exhibits movement depending on the argument structure of the verb (i.e. whether the verb is transitive or intransitive). When the verb is intransitive, the particle remains at the right-hand position. When the verb is transitive, the particle may move to either the left or the right, unless the complement is an object pronoun in which case the verb particle remains at the right-hand position. Moreover, if the complement of the verb is heavy (i.e. an object relative clause) the particle remains at the left hand position. Two opposing syntactic analyses of verb particle constructions have been included to further show the complexity of these constructions.

Broca's aphasia is an acquired linguistic deficit caused by damage to the prefrontal cortex of the brain near Broca's area, typically due to left hemisphere CVA or traumatic brain injury. Broca's aphasia is characterized by reduction or suppression of language production with word retrieval impairments, and agrammatism. Persons with agrammatism also often demonstrate asyntactic comprehension. Because of these deficits, PWA have difficulty producing and comprehending complex sentences, particularly when the word order differs from the canonical deep structure order.

Idioms were once thought to be stored as whole units within the lexicon with the respective idiomatic meaning being accessed in the right hemisphere. Recent neuroimaging studies have demonstrated a bilateral neural involvement during idiomatic comprehension. This bilateral involvement also includes those areas involved in literal 
language comprehension. In terms of left-hemisphere damage and idiom comprehension, empirical data on the off-line processing of idiomatic meaning suggests a literal bias towards idiomatic expressions.

Processing studies in aphasia have demonstrated that the processing of verbs in Broca's aphasia is relatively intact; however, problems arise when the verbs are semantically more complex. In terms of sentence processing by these individuals, empirical data demonstrate slower than normal processing of complex sentences, such as Wh-questions and reflexivity. Verb production studies have demonstrated that PWAs have problems with verb movement in sentences. Using a syntactic framework, it has been shown that verb movement affects tense inflection and negation. The argument structure of the verb is also a factor in that the more complex the verb's argument structure is, the more difficult the verb will be for the PWA to produce. This difficulty with movement and complex argument structures could present a problem for PWA in producing verb particle constructions.

To date, there are no published studies examining how verb particle constructions are comprehended by persons with aphasia. However, research on verb particle production in PWA has revealed that verb particle constructions are easier for PWA to repeat than prepositional phrases. The aim of the present work is to increase knowledge in this area in order to shed light into the processing of complex argument structures and syntactic movement. Most of the idiomatic comprehension studies have looked at sentential idioms but have not looked into one of the most common expressions in 
English: the verb particle. Thus, increased knowledge in this area may be useful in improving existing techniques for aphasia treatment and creating novel treatment strategies to target this class of verbs.

\section{Plan of Study and Experimental Questions}

The purpose of the study is to examine how persons with aphasia comprehend different verb particle constructions according to the semantic transparency of the verb particle constructions and in the semantic classes put forth by Jackendoff (2002). The study will involve a picture-matching task. The task will compare the processing of verb particle constructions in PWA and in typical young and older non-brain damaged adults. The experimental task will focus on the following three classes of verb particle constructions: idiomatic verb particles, directional verb particles, and aspectual verb particles. Additionally, movement of the object NP will also be examined in order to determine if such movement creates a processing burden on the aphasic group.

The following research questions will be addressed:

1) Will there be a significant difference between PWAs and non-braindamaged adults in comprehending verb particle constructions? It is predicted that there will be a significant difference in comprehension between PWAs and non-brain-damaged adults.

2) Will there be a significant difference between the typical older adults and the PWAs relative to comprehending specific types of verb particles (idiomatic, aspectual, directional)? It is predicted that PWAs will have more difficulty processing idiomatic verb particle constructions than typical older adults. Given this hypothesis, the 
directional verb particles should present the least difficulty for PWAs. Typical adults are not expected to show significant differences between each category.

3) Will there be a significant difference in the processing time of verb particle constructions with movement of the object NP between PWAs and typical adults? An increase in processing time in PWAs is expected in the V NP Prt condition as opposed to V Prt NP condition. A difference in processing time between the V NP Prt condition and V Prt NP is not expected in typical adults.

4) Considering the error type of responses by PWAs only, will PWAs select a picture representing the meaning of the verb itself significantly more than the meaning of the entire verb particle construction? It is hypothesized that PWAs will have a bias towards the literal meaning of the verb and will select pictures representing the verb significantly more than the meaning of the entire verb particle construction. Such a difference in error type is not expected in the typical adult groups. 


\section{CHAPTER II}

\section{Method}

\section{Participants}

The participants consisted of 27 monolingual English speaking adults recruited from the State of Florida. Participants were placed into three groups based on age and presence of brain damage. Group $1(\mathrm{n}=7)$ consisted of persons with a Broca's type aphasia as the result of left cerebrovascular accident confirmed by a neurologist between the ages of 51 and 74. Group $2(n=10)$ consisted of non-brain damaged older adults between the ages of 56 and 74 . Group $3(n=10)$ consisted of non-brain damaged young adults between the ages of 22 and 36. All participants were right-handed (aphasic participants were right-handed prior to stroke). The following table summarizes the groups of participants. See Appendix A for full demographic information for each participant as well as scores on each subtest of the WAB-R.

\section{Table 2.1 Demographic Summary}

Demographic information of each group is presented below. The maximum score obtainable on the MoCA is 30 points. The maximum score achievable on the WAB-R is 100 .

\begin{tabular}{|c|c|c|c|c|c|c|c|c|c|c|c|}
\hline \multicolumn{10}{|c|}{ Descriptive Statistics for Demographic Information } \\
\hline Group & $\begin{array}{c}\text { Number of } \\
\text { Participants }\end{array}$ & $\begin{array}{c}\text { Mean } \\
\text { Age }\end{array}$ & \multicolumn{2}{|c|}{ Years of Education } & \multicolumn{3}{|c|}{ MoCA Scores } & \multicolumn{4}{c|}{ WAB-R Scores } \\
\cline { 4 - 13 } & Mean & SD & Range & Mean & SD & Range & Mean & SD & Range \\
\hline $\begin{array}{c}\text { Group } \\
1\end{array}$ & 7 & 58.14 & 16 & 2.94 & $12-20$ & 20 & 1.99 & $17-23$ & 75.23 & 11.03 & $64-93$ \\
\hline $\begin{array}{c}\text { Group } \\
2\end{array}$ & 10 & 63.98 & 17.2 & 2.10 & $14-20$ & 28 & 1.36 & $25-30$ & N/A & N/A & N/A \\
\hline $\begin{array}{c}\text { Group } \\
3\end{array}$ & 10 & 28.46 & 18 & 2.05 & $13-20$ & N/A & N/A & N/A & N/A & N/A & N/A \\
\hline
\end{tabular}

A Kruskal-Wallis test was used to compare the distribution of years of education across groups. No significant difference in the distribution of years of education was found between groups $(\mathrm{p}>.05)$. A Mann-Whitney $U$ conducted on age for the older 
typical adults and the PWA revealed a significant difference between the two groups $(\mathrm{U}=$ $57.0, \mathrm{p}=.033$ ). There appeared to be more participants in the 60s range in Group 2 (older normal) than in Group 1 (aphasic adults) who were in the 50s range.

\section{Pre-Experimental Testing}

Hearing screenings for the participants were conducted according to the Guidelines for audiologic screening of the American Speech-Language-Hearing Association (ASHA) (ASHA, 1997). Younger typical participants underwent screening throughout the speech frequencies at $25 \mathrm{~dB} \mathrm{HL}$ at $1000 \mathrm{~Hz}, 2000 \mathrm{~Hz}$, and $4000 \mathrm{~Hz}$. A modified hearing screening for older adults through the speech frequencies was conducted at $40 \mathrm{~dB} \mathrm{HL}$ at $1000 \mathrm{~Hz}, 2000 \mathrm{~Hz}$, and $4000 \mathrm{~Hz}$ to the two older adult groups. These frequencies have been recommended in the literature for screening older adults for hearing impairment (Weinstein, 2011; Yueh, Shapiro, MacLean, \& Shekelle, 2003). The pass criteria are based on responses to pure-tone air-conduction stimuli at $40 \mathrm{~dB} \mathrm{HL}$ at

$1000 \mathrm{~Hz}, 2000 \mathrm{~Hz}$, and $4000 \mathrm{~Hz}$ in both ears. All participants passed a hearing screening through the speech frequencies to ensure hearing is within normal/functional limits.

A language background questionnaire was given to all participants to confirm native English language proficiency (See Appendix B). Participants were asked the age of acquisition of the English language and whether or not a second language other than English was acquired. If a second language other than English was acquired, the participant was asked to state the proficiency level and age of acquisition of the second language. Participants who acquired their native language before or near preschool age (approximately 3 to 5 years of age) and who acquired a second language other than English on or after adolescence were included in the study. 
The Montreal Cognitive Assessment (MoCA) (Nasreddine, 2016) was administered to participants in Groups 1 and 2. The MoCA was administered to the typical older adults to ensure that all participants in this group had the appropriate cognitive prerequisites to perform the experimental tasks. This test was administered to the PWA to investigate whether performance on this task was correlated to performance on the experimental task. The MoCA is a rapid screening assessment for mild cognitive dysfunction. It assesses attention and concentration, executive functions, memory, language, visuoconstructional skills, conceptual thinking, calculations, and orientation. The total possible score is 30 points, and a score above 26 is considered normal.

The Western Aphasia Battery Revised (WAB-R) (Kertesz, 2006) was administered to the participants with aphasia (Group 1) to determine severity of aphasic involvement. The WAB-R is an individually administered assessment for adults with acquired neurological disorders. The instrument assesses the linguistic skills most frequently affected by aphasia and provides differential diagnosis information. It is composed of the following sections: spontaneous speech, auditory verbal comprehension, repetition, and naming and word finding. The total score for each subsection is used to compute the Aphasia Quotient (AQ). Severity of aphasic involvement is determined by the AQ. The maximum score achievable on the WAB-R AQ is 100. A score below 93.8 yields an impairment consistent with aphasia. See Appendix A for each participant's individual AQ score. 


\section{General Procedures}

The study was approved by the Institutional Review Board of Florida International University. All participants were residents of Florida from the following counties: Miami-Dade, Broward, Palm Beach, Orange, and Pinellas Counties. Data collection for all groups took place at Florida International University Speech Skills Lab located AHC-3 407, Florida Atlantic University, The Aphasia House at University of Central Florida, University of South Florida, or in the participant's home under controlled laboratory conditions. The aphasic group was recruited from outpatient centers, university clinics, and aphasia support groups within Florida by means of referral sampling. The typical older adult group was selected by means of chain-random sampling from the community. The typical younger adult group was selected by means of chainrandom sampling from Florida International University. Pre-experimental testing was administered in the following order: hearing screening, language background questionnaire, MoCA, and WAB-R. Pre-experimental testing took about 45 to 50 minutes per participant. The experimental task took about 45 to 60 minutes per participant. The total time per participant for the entire study was about 1.5 to 2 hours.

Upon obtaining verbal and written consent, the participants underwent preexperimental testing to ensure they meet the inclusionary criteria. For all groups, a language background questionnaire and a hearing screening were administered. For Groups 1 and 2, the MoCA was administered after the hearing screening. Participants in Group 1 were given the WAB-R after the MoCA. Participants in group 3 were administered the language background questionnaire and a hearing screening. Breaks were provided if necessary after each pre-experimental task. 


\section{Experimental Task}

\section{Materials/Stimuli}

The stimuli consisted of 30 sentences containing idiomatic verb particle constructions (e.g. The girls kicked out the boys), 30 sentences containing directional verb particle constructions (e.g. The student picked up the pencil), 30 sentences containing aspectual verb particle constructions (e.g. The baby drank up the milk), and 90 filler sentences. Each independent variable (idiomatic, directional, and aspectual verb particle construction) alternated in object NP placement. That is, half of the experimental stimuli were of the structure V Prt NP and the other half were of the structure V NP Prt, as illustrated below:

(1) V Prt NP: The girls kicked out the boy.

(2) V NP Prt: The girls kicked the boy out.

Additionally, all stimulus sentences were presented on a computer screen using SuperLab (Version 5; Cedrus Corporation, 2014). The stimulus sentences were audiorecorded using Praat (Boersma \& Weenink, 2016). A sample picture is provided below illustrating the sentence above. See Appendix C for a list of the stimuli used. 


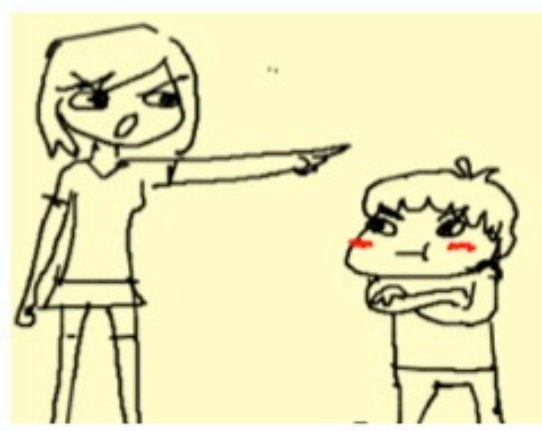

1

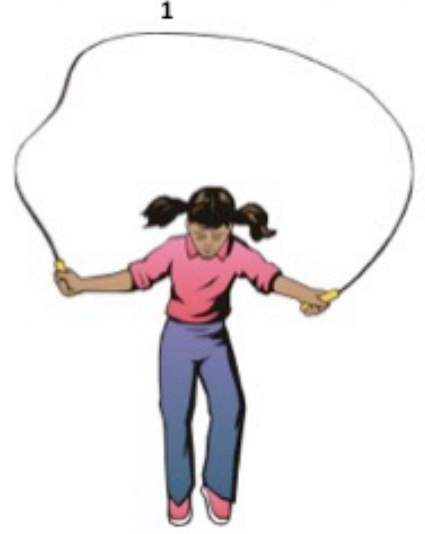

3

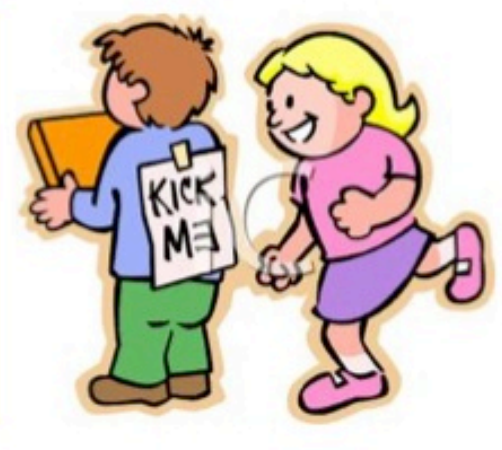

2

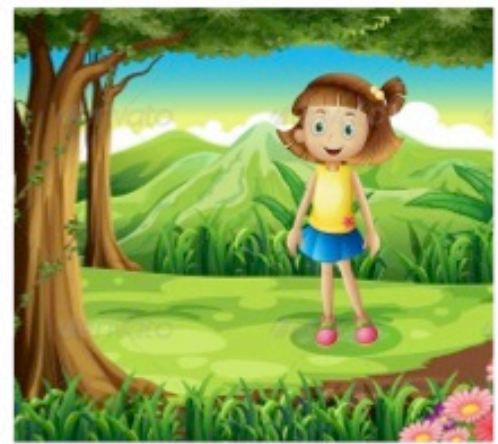

4

Figure 2.1 Sample stimuli for the sentence: The girl kicked the boy out.

Picture 1 demonstrates the correct meaning of the verb particle. Picture 2 illustrates the literal meaning of the verb. Picture 3 represents an unrelated foil. Picture 4 represents the meaning of the particle "out".

As demonstrated in Figure 2.1, four pictures were presented to the participants for each sentence on a computer screen side by side depicting four scenes: a target picture and three complementary foils. The target picture depicted the exact meaning of the verb particle construction. One of the foils depicted the meaning of the verb, another depicted the meaning of the particle, and a third depicted an unrelated scene. In Figure 2.1, the meaning of the particle construction is depicted in picture 1, the meaning of the verb "kick" is depicted in picture 2, the meaning of the particle "out" is depicted in picture three, and the unrelated scene is depicted in picture 3. 
The examiner presented instructions to the participant prior to starting the task. Participants were told to select the picture that best matches the sentence by pressing any of the color-coded keys on the computer's keyboard. The keyboard was color-coded as follows: yellow keys for picture 1, blue keys for picture 2, green keys for picture 3, and red keys for picture 4. After presenting the participant with instructions, five sample sentences were presented to aid the participant in learning the task. The audio played first followed by the picture immediately after. All participants were able to match the keys to the picture successfully. Reaction times for these as well as correct/incorrect responses were collected. Reaction times were measured from the time the audio recording ended to the time the participant pressed a key. After a key was pressed, the timer reset and the next sentence was presented aurally followed by the picture. Reaction time was measured in milliseconds.

\section{Procedures}

The entire experimental task consisted of a receptive picture-matching task counterbalanced for each participant. Participants listened to a total of 180 sentences split between two sessions, approximately 30 minutes in length, containing 90 sentences each. Breaks were given after approximately 30 minutes or 90 sentences, whichever occurred first, during the experimental task.

The participants sat before a computer screen. For the first half of the experiment, the examiner provided the directions followed by five sample sentences. A prompt appeared on the screen indicating a break before starting the second half of the experimental task. The investigator gave the following instructions: "You will listen to sentences and you will be shown pictures on the screen. Select the picture that best 
matches the sentence by pressing these buttons. We will do 5 practice sentences." After the practice sentences, the investigator instructed the participants to begin the task. After 90 sentences or approximately 30 minutes, a prompt appeared instructing participants to take a break. The participants were given the option of taking as long as they wanted. Once the participant was ready to resume the task, the investigator instructed the participant to press any key to continue.

\section{Instrumentation}

The picture matching task was run on Cedrus SuperLab Version 5 (Cedrus Corporation, 2014). SuperLab is an experiment-building software designed for psychology experiments. The program allows researchers to build experiments without relying on scripting or programming. The program supports picture files, movies, Rapid Serial Visual Representation (RSVP) of text, self-paced reading, and sound files. The program allows for collection of reaction time data. The Cedrus SuperLab Version 5 and program was run on a 13-inch MacBook Air Early 2014 running OS X 10.9.5.

\section{Data Analysis}

The collected data was in the form of ratio and interval data. Reaction times in milliseconds and the number of correct and incorrect responses made on an item in the task were recorded. The independent variables consisted of group as the between subjects variable and two within subject variables: type of verb particle construction (idiomatic, directional, and aspectual) and noun phrase movement. The dependent variables were reaction times and error type. Reaction times were determined for all responses. Error type was analyzed in terms of whether the participant selected a picture depicting the meaning of the verb, the particle, or an unrelated scene. 
Differences in comprehending verb particle constructions between PWAs and both groups of non-brain-damaged adults were identified by comparing overall reaction times (in milliseconds) and the overall total number of correct responses between groups. Differences between the typical older adults and the PWAs relative to comprehending specific types of verb particles (idiomatic, aspectual, directional) were calculated by comparing reaction times and total number of correct responses between groups. Differences in the processing time and accuracy of response relative to movement of the object NP between PWAs and both groups of typical adults were identified by comparing reaction times and total number of correct responses between groups. When considering errors produced, the number of errors between the three verb forms-idiomatic, aspectual, directional - were compared within each group. Additional error pattern analysis was conducted for significant findings.

Statistical analyses were conducted on the outcomes of reaction times in milliseconds and accuracy data between groups. A series of Kruskal-Wallis analyses were used to calculate statistical significances between groups. This non-parametric test was used due to the uneven number of participants between groups and the small number of participants per group. The same statistical test was used to analyze the accuracy data between groups. Post hoc testing in the form of Tukey's test was used to determine significance between groups relative to the particle and movement data if significance was observed relative to Kruskal-Wallis findings.

A one-way ANOVA was used to analyze the error data within each group to determine any differences in error production between the verb particle construction forms. Descriptive analysis was used to analyze the error data for each group if the 
ANOVA findings were significant. Each participant's error response was coded as representing the meaning of the verb particle (Correct), the meaning of the verb or incomplete action (verb), the particle (particle), or the unrelated scene (unrelated). 


\section{CHAPTER III}

Results

The purpose of the study was to examine the processing of verb particle constructions in English in typical young and older adults and in adults with Broca's aphasia. The problem to be addressed is whether English verb particle constructions are difficult for persons with aphasia to comprehend. Average reaction times in milliseconds and number of accurate responses committed on each trial were analyzed between groups based on the experimenter's research questions. See Appendix D for raw data tables.

\section{Overall Performance}

The first research question addressed whether there was a significant difference between PWAs and either non-brain-damaged adult group in comprehending verb particle constructions. The overall reaction times of each of the three groups was analyzed by calculating the average reaction time data across verb construction form (idiomatic, aspectual, and directional) and movement (V Prt NP and V NP Prt) per participant. A Kruskal-Wallis test conducted on these data revealed a significant difference across groups $(\mathrm{H}(2)=11.419, \mathrm{p}=.003)$. Post-hoc Tukey's HSD tests conducted on this significant finding revealed significant differences between the aphasic group (Group 1) and the older normal group (Group 2) $(\mathrm{p}=.003)$ and between the aphasic group (Group 1) and the younger normal group (Group 3) in overall reaction time $(p=.0005)$. No significant difference was found between the older normal group (Group 2 ) and the younger normal group (Group 3$)$ in overall reaction time $(p>.05)$. Figure 3.1 illustrates the overall reaction time performance on the picture matching task for all three groups. 


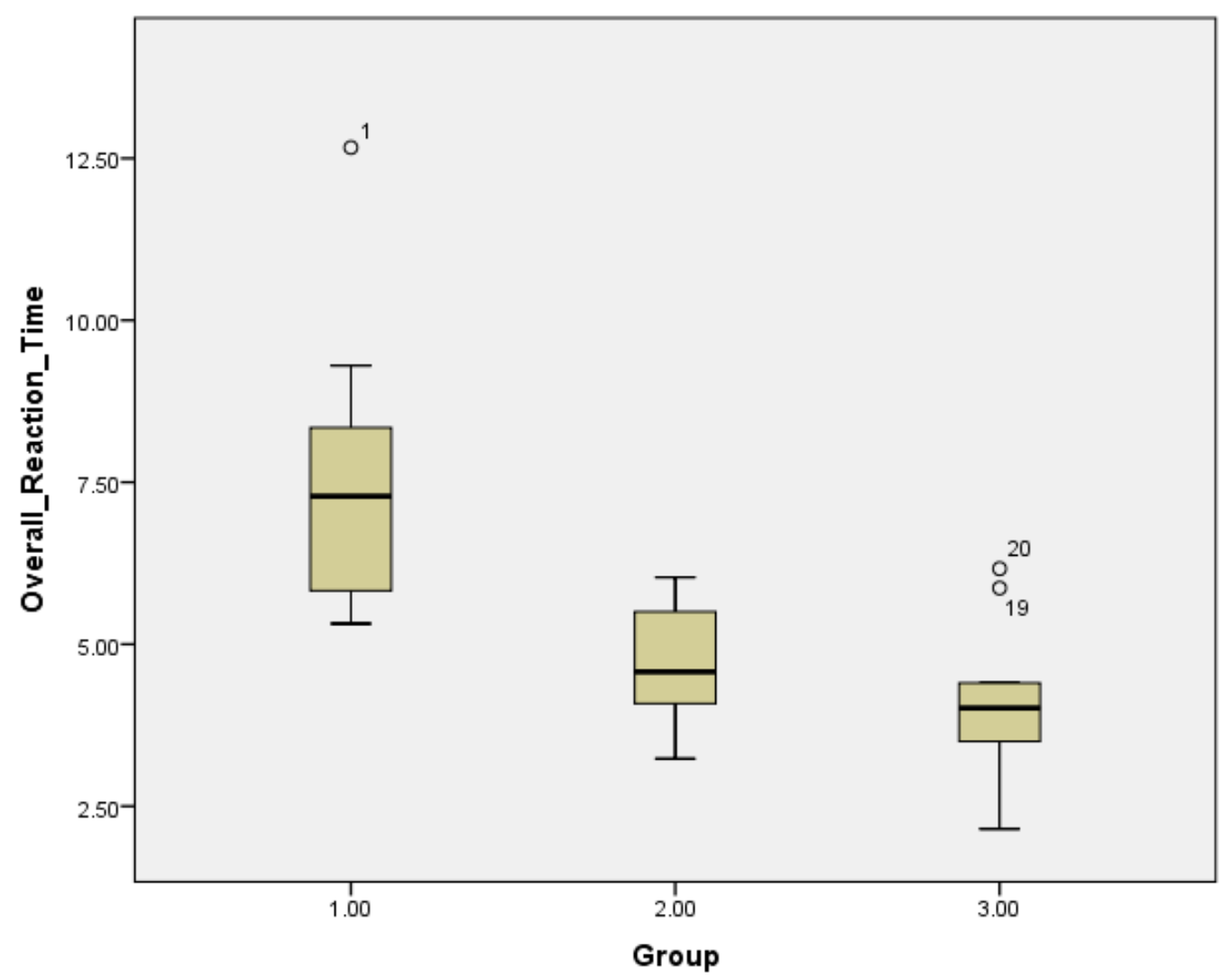

Figure 3.1 Overall Reaction Times in millisecond by Group

The overall number of correct responses across verb construction form (idiomatic, aspectual, and directional) and movement (V Prt NP and V NP Prt) per participant were calculated for each participant. A Kruskal-Wallis test conducted on these data revealed no significant differences between groups $(\mathrm{P}>.05)$. Overall correct response on the experimental task for each group can be seen in Table 3.1.

Table 3.1. Means, Standard Deviations, and Ranges for Correct Responses for overall performance and verb construction form for all three groups

\begin{tabular}{|c|c|c|c|c|c|c|c|c|c|c|c|c|c|c|c|c|c|c|}
\hline \multicolumn{19}{|c|}{ Accuracy Data } \\
\hline \multirow{2}{*}{ Group } & \multicolumn{3}{|c|}{ Overall } & \multicolumn{3}{|c|}{ Aspectual } & \multicolumn{3}{|c|}{ Directional } & \multicolumn{3}{|c|}{ Idiomatic } & \multicolumn{3}{|c|}{ VPrt NP } & \multicolumn{3}{|c|}{ VNP Prt } \\
\hline & Mean & SD & Range & Mean & SD & Range & Mean & SD & Range & Mean & SD & Range & Mean & SD & \begin{tabular}{|l} 
Range \\
\end{tabular} & Mean & SD & \begin{tabular}{|l|} 
Range \\
\end{tabular} \\
\hline 1 & \begin{tabular}{|l|}
66.3 \\
\end{tabular} & 8.8 & 53-78 & 14 & 3.2 & $10-19$ & 26 & 3.3 & $21-29$ & 25 & 3.2 & $21-29$ & 33.9 & 3.5 & \begin{tabular}{|l|}
$27-38$ \\
\end{tabular} & 32.4 & 6.6 & $20-40$ \\
\hline 2 & \begin{tabular}{|l|l|}
68.7 \\
\end{tabular} & 5.6 & $60-72$ & 12.9 & 3.9 & $8-18$ & 27.5 & 2.1 & $24-30$ & 28.3 & \begin{tabular}{|l|}
1.3 \\
\end{tabular} & $27-30$ & 34.1 & 3.2 & \begin{tabular}{|l|}
$29-38$ \\
\end{tabular} & 34.6 & 2.5 & $30-37$ \\
\hline 3 & 68.2 & 4 & $60-73$ & 11.9 & 2.6 & $9-16$ & 28.4 & 1.5 & $26-30$ & 28 & \begin{tabular}{|l|}
1.6 \\
\end{tabular} & $25-30$ & 34.1 & 2.2 & $30-36$ & 34.1 & 2.3 & $30-38$ \\
\hline
\end{tabular}




\section{Verb Construction Forms}

The second research question examined whether there was a significant difference between the typical adults and the PWAs relative to comprehending the specific types of verb particle constructions (idiomatic, aspectual, directional). Reaction times for each form (aspectual, directional, and idiomatic) were calculated by determining average reaction time of each construction form across movement type per participant. A Kruskal-Wallis test conducted on these data revealed a significant difference between groups for each form: aspectual $(\mathrm{H}(2)=10.651 ; \mathrm{p}=.005)$, directional $(\mathrm{H}(2)=11.331 ; \mathrm{p}$ $=.003)$, and idiomatic $(\mathrm{H}(2)=13.237 ; \mathrm{p}=.001)$. Post-hoc Tukey's HSD tests conducted on these significant findings revealed significant differences between the aphasic group (Group 1) and the older adult group (Group 2) in the reaction time for all three verb construction forms: aspectual $(p=.005)$, directional $(p=.007)$, idiomatic $(p=.015)$. Tukey's HSD tests also revealed significant differences between the aphasic group (Group 1) and the younger normal group (Group 3) in the reaction time for all three verb construction forms: aspectual $(p=.002)$, directional $(p=.001)$, idiomatic $(p=.001)$. No significant differences were found between the older normal group and the younger normal group in reaction time for any of the construction forms $(\mathrm{p}>.05)$. Figures 3.2 , 3.3, and 3.4 illustrate the differences in reaction times per group for each of the forms analyzed. 


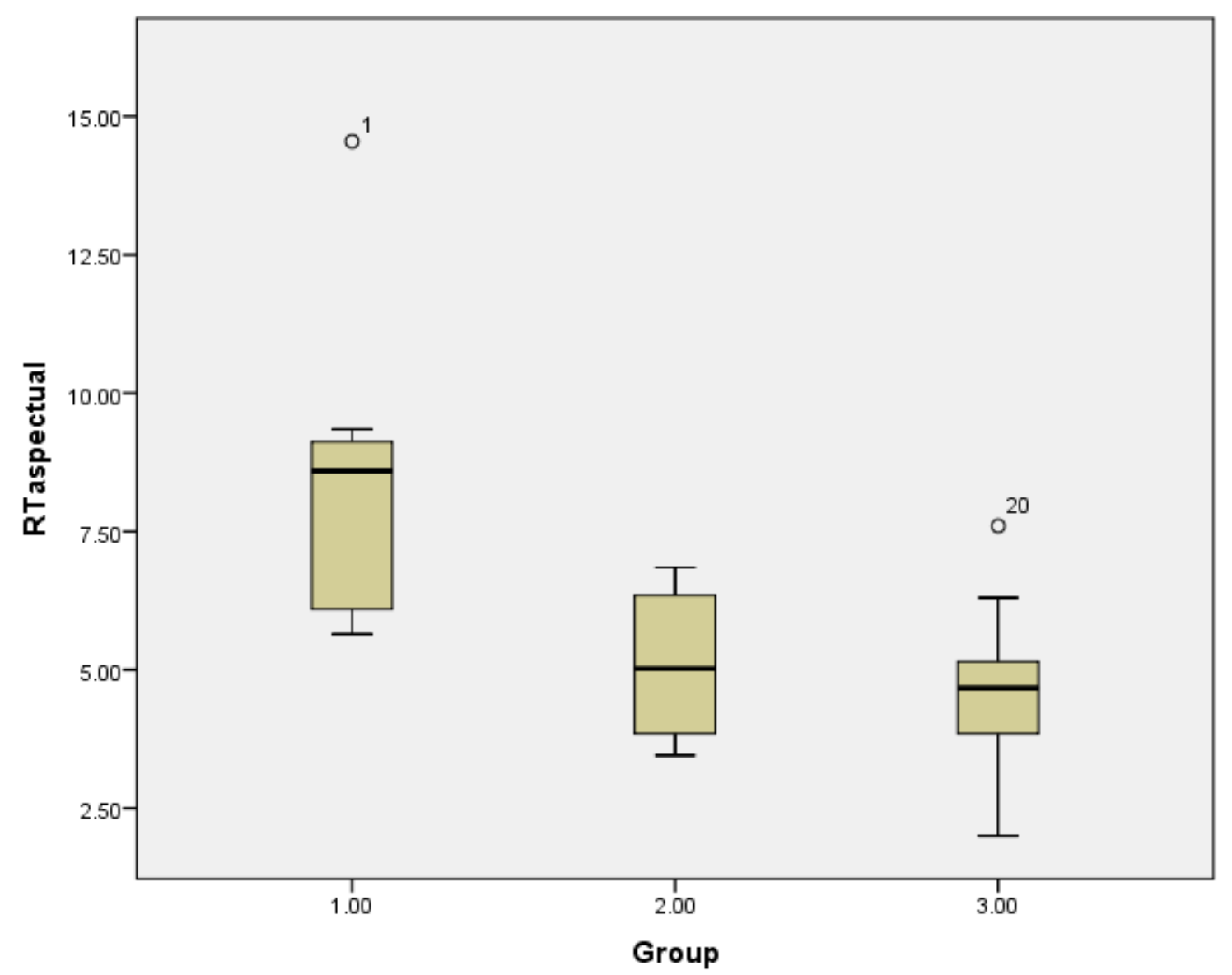

Figure 3.2 Reaction Times in milliseconds by Group for Aspectual Verb Particles 


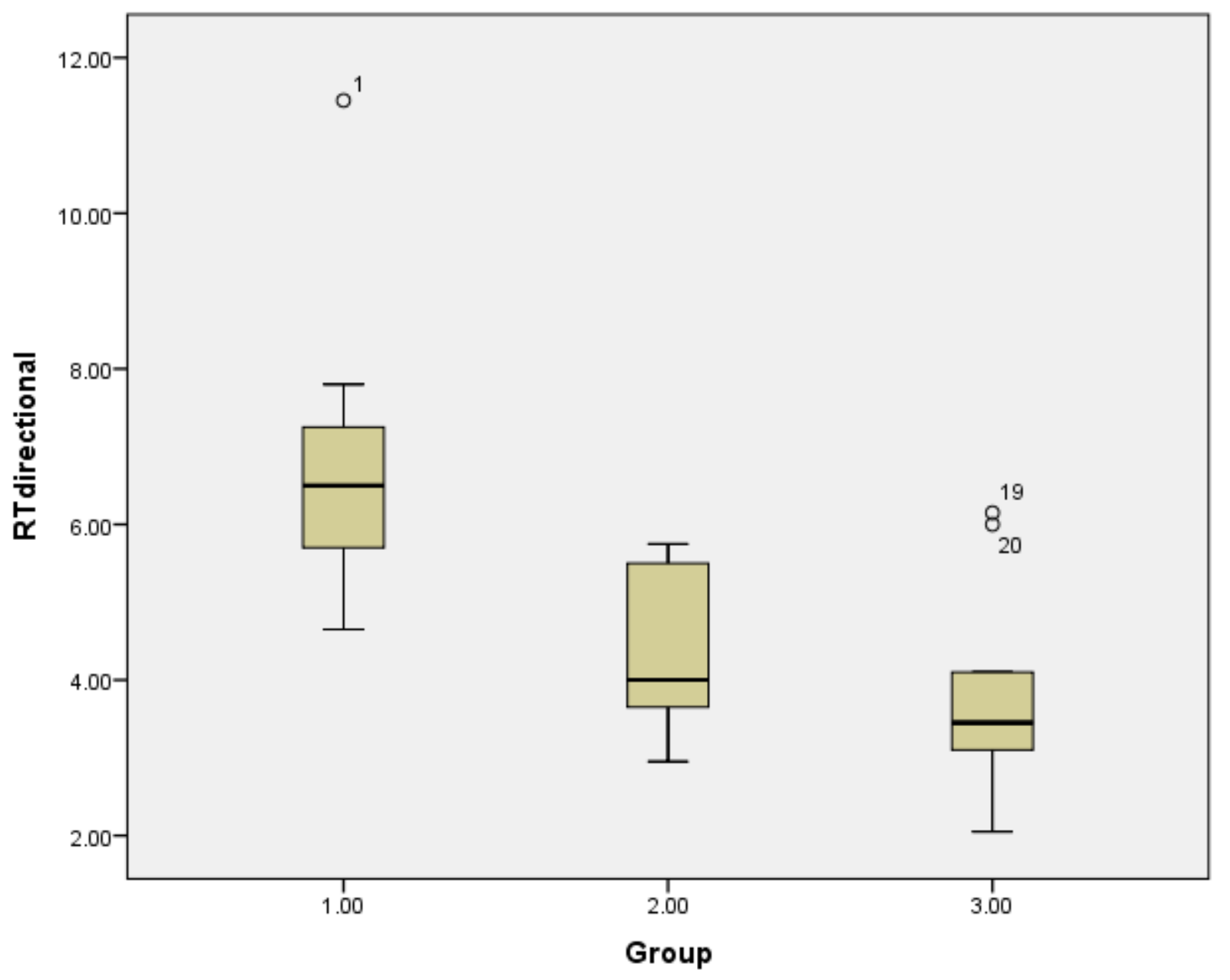

Figure 3.3 Reaction Times in milliseconds by Group for Directional Verb Particles 


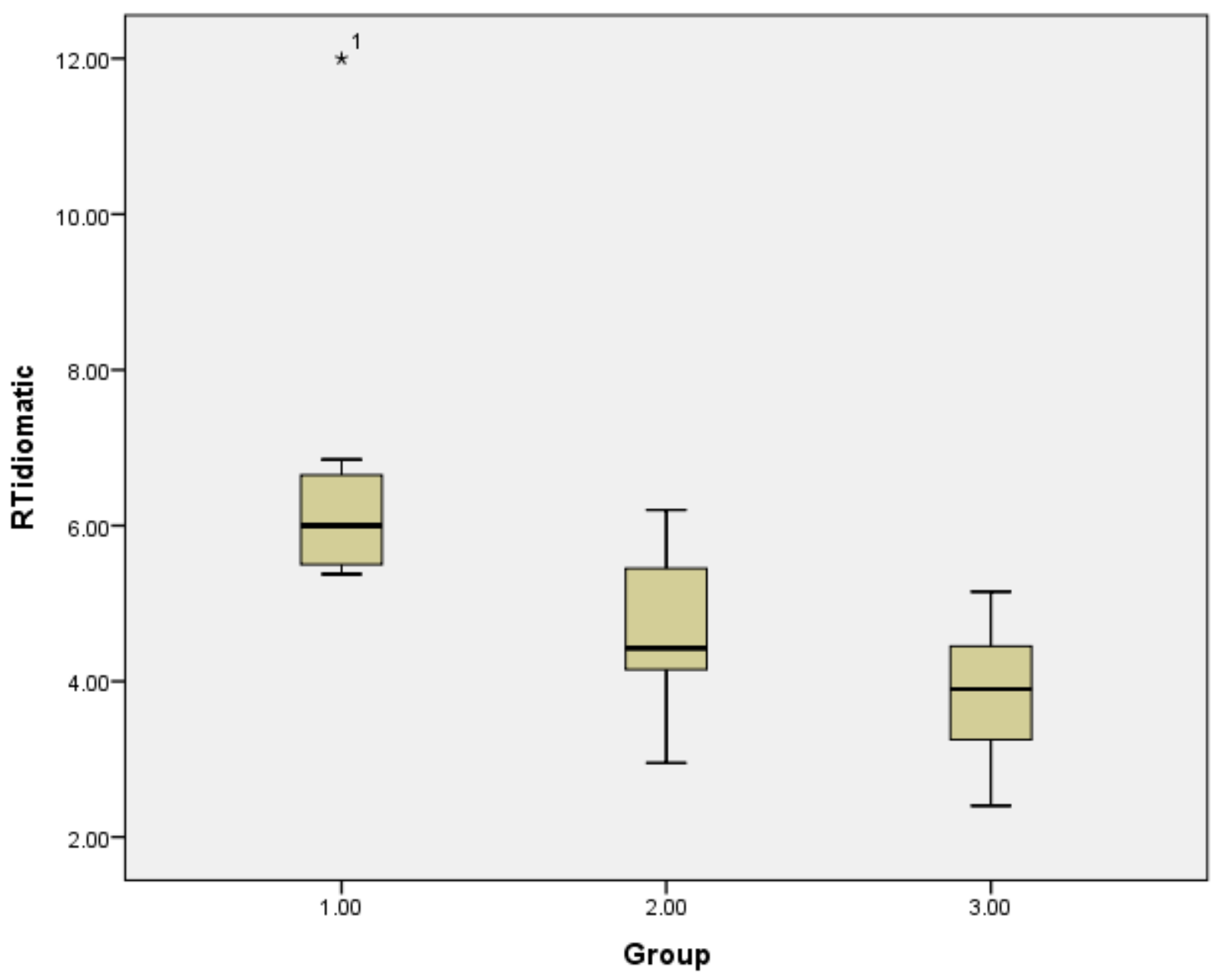

Figure 3.4 Reaction Times in milliseconds by Group for Idiomatic Verb Particles

Within group analyses were conducted on the reaction time data, comparing the three verb construction forms for each group. Three one-way repeated measure analysis of variances (ANOVAs), one for each group, were used to analyze these data. For the PWA, the results revealed a significant finding $(\mathrm{F}(2,12)=7.331 ; \mathrm{p}<.01)$, with pairwise Bonferroni comparisons yielding a significant difference between aspectual vs. directional forms $(\mathrm{p}=.024)$ and a trend towards significance between aspectual vs. idiomatic forms $(\mathrm{p}=.081)$. The aphasic group were significantly slower on the aspectual than directional stimuli and trending towards slower performance on aspectual than 
idiomatic. There was no significant difference in reaction time between directional and idiomatic. Figure 3.5 illustrates the differences in reaction time for each verb construction for group 1.

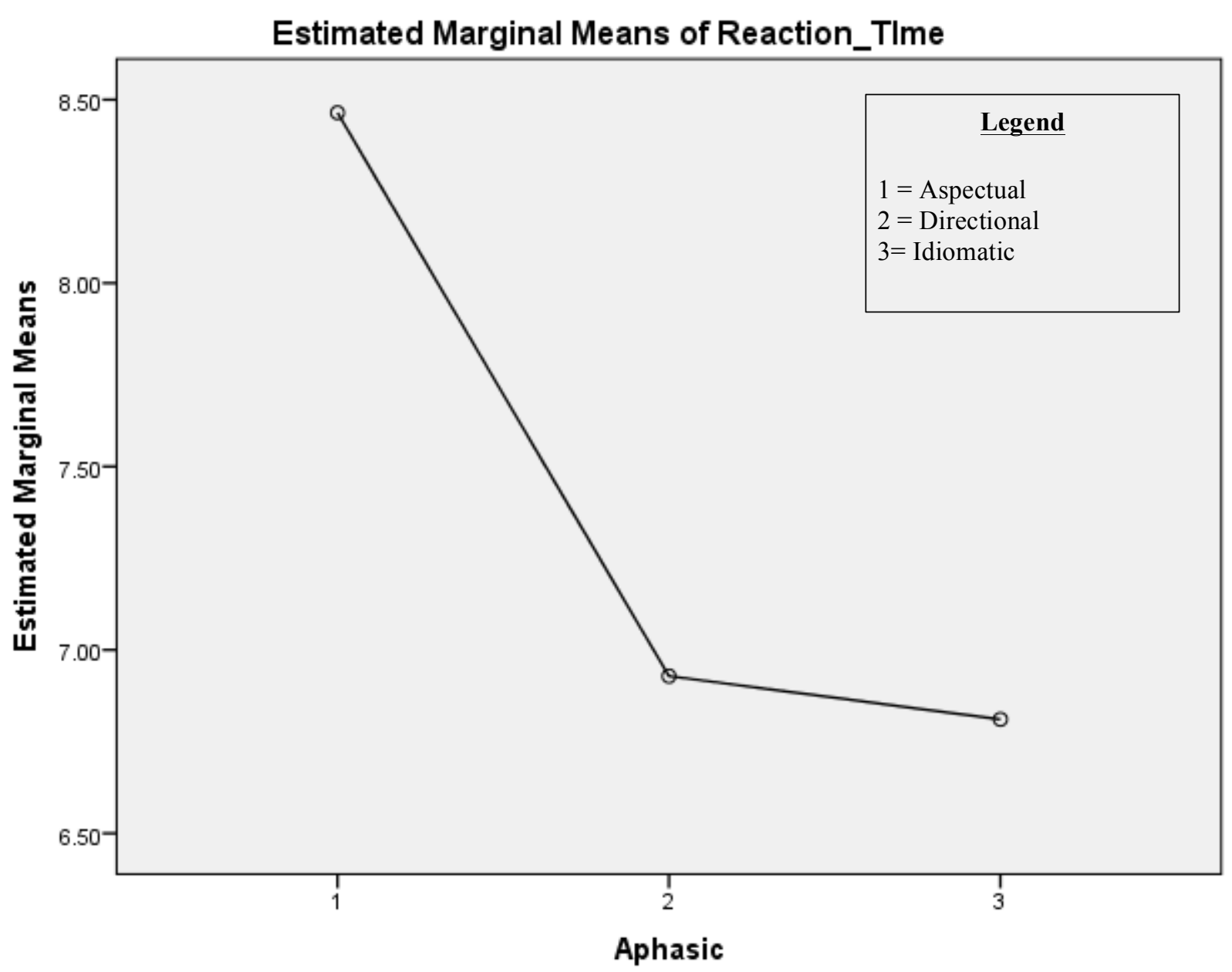

Figure 3.5 Reaction time for the three verb construction types for the Group with Aphasia

For the typical older adults, the results revealed a trend towards significance $(\mathrm{p}=.081)$ only. However, for the younger typical adults, the results revealed a significant finding $(\mathrm{F}(2,18)=7.552 ; \mathrm{p}<.01$, with pairwise Bonferroni comparisons yielding a significant difference between the aspectual vs. directional forms $(\mathrm{p}=.008)$ and a trend 
towards significance between aspectual and idiomatic forms $(\mathrm{p}=.096)$. The young adults were significantly slower on the aspectual than the directional stimuli and trending towards slower performance on aspectual than idiomatic stimuli. There was no significant difference in reaction time between directional and idiomatic. Thus, the aphasic adults showed a similar pattern to the younger adults relative to the verb construction forms on reaction time. Figure 3.6 illustrates the differences in reaction time for each verb construction for group 3.

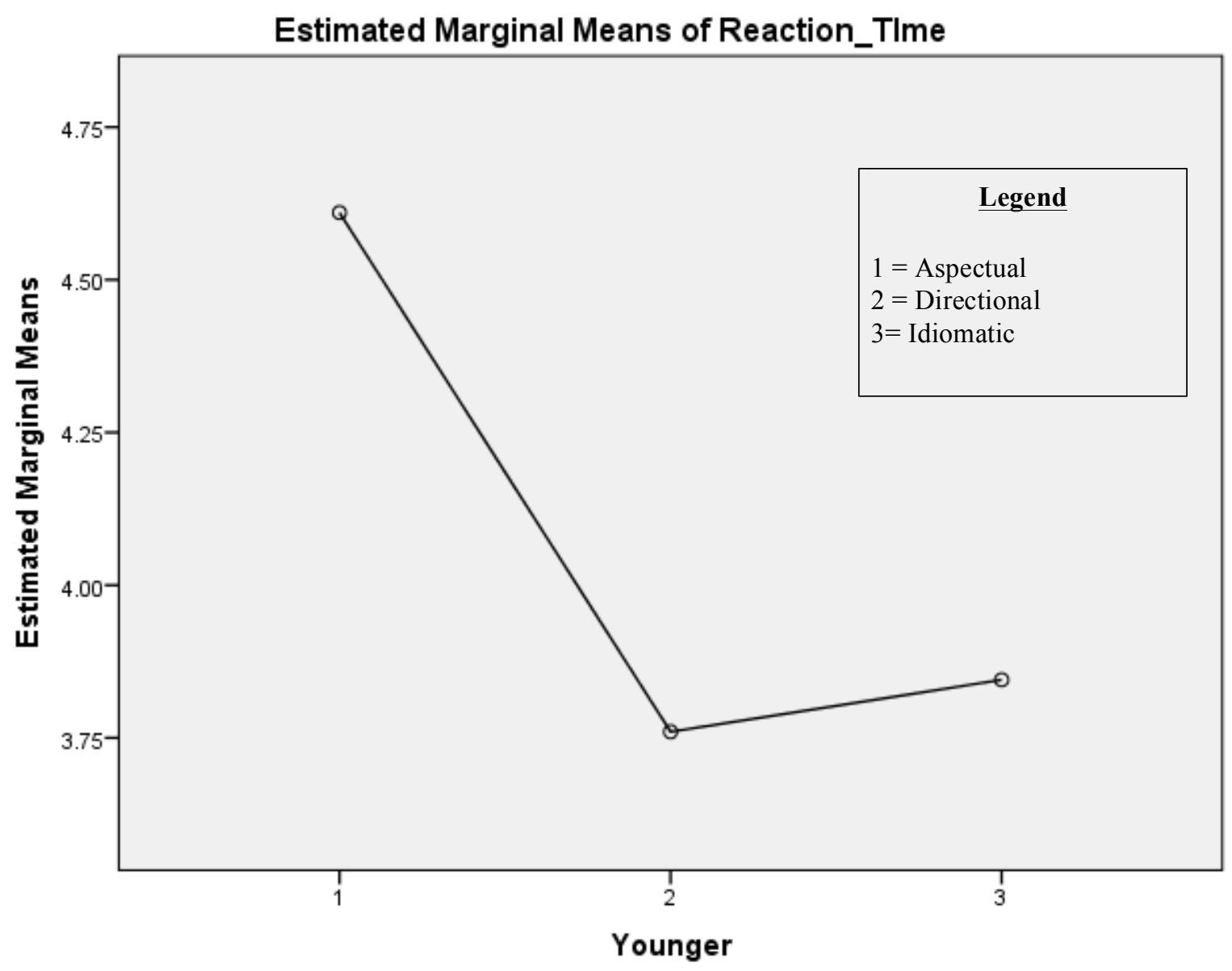

Figure 3.6 Reaction time for the three verb construction types for the typical younger group 
The number of correct responses for each construction type was calculated for each group and analyzed between groups for each form (aspectual, directional, idiomatic). Kruskal-Wallis tests conducted on the accuracy data for each construction revealed no significant differences between groups for any of the construction forms (aspectual $\mathrm{p}>.05$; directional $\mathrm{p}>.05$; idiomatic $\mathrm{p}>.05$ ). However, for the idiomatic

form, there was a trend toward significance $(\mathrm{p}=.061)$, with the aphasic group showing less accuracy for this verb construction than the other two groups. See Table 3.1 for accuracy data on verb construction type.

\section{Movement Analysis}

The next research question considered if there was a significant difference in the processing time of verb particle constructions specifically related to movement of the object NP between PWAs and the two typical adult groups. Average reaction times were calculated for each movement condition across construction type per participant. Thus, the average reaction times for V Prt NP was calculated by averaging the RT across the three forms - aspectual, directional, idiomatic - per participant. The same procedure was repeated on the V NP Prt condition. These reaction times were then compared between the three groups. A Kruskal-Wallis test conducted on these data revealed significant differences between groups for each movement condition: $V \operatorname{Prt} N P(H(2)=13.470 ; p=$ $.001)$, V NP Prt $(\mathrm{H}(2)=10.501 ; \mathrm{p}=.005)$. Post-hoc Tukey's HSD tests revealed significant differences in reaction times for the V Prt NP condition between Group 1 and Group $2(\mathrm{p}=.011)$ and between Group 1 and Group $3(\mathrm{p}=.001)$. There was no significant difference in reaction time for the V Prt NP condition between Group 2 and Group $3(\mathrm{p}>.05)$. Tukey's HSD test also revealed significant differences in reaction 
times for the V NP Prt condition between Group 1 and Group $2(\mathrm{p}=.002)$ and between Group 1 and Group $3(\mathrm{p}=.001)$. There was no significant difference between Group 2 and Group $3(\mathrm{p}>.05)$. Figures 3.7 and 3.8 illustrate the differences in reaction times per group for each movement condition analyzed.

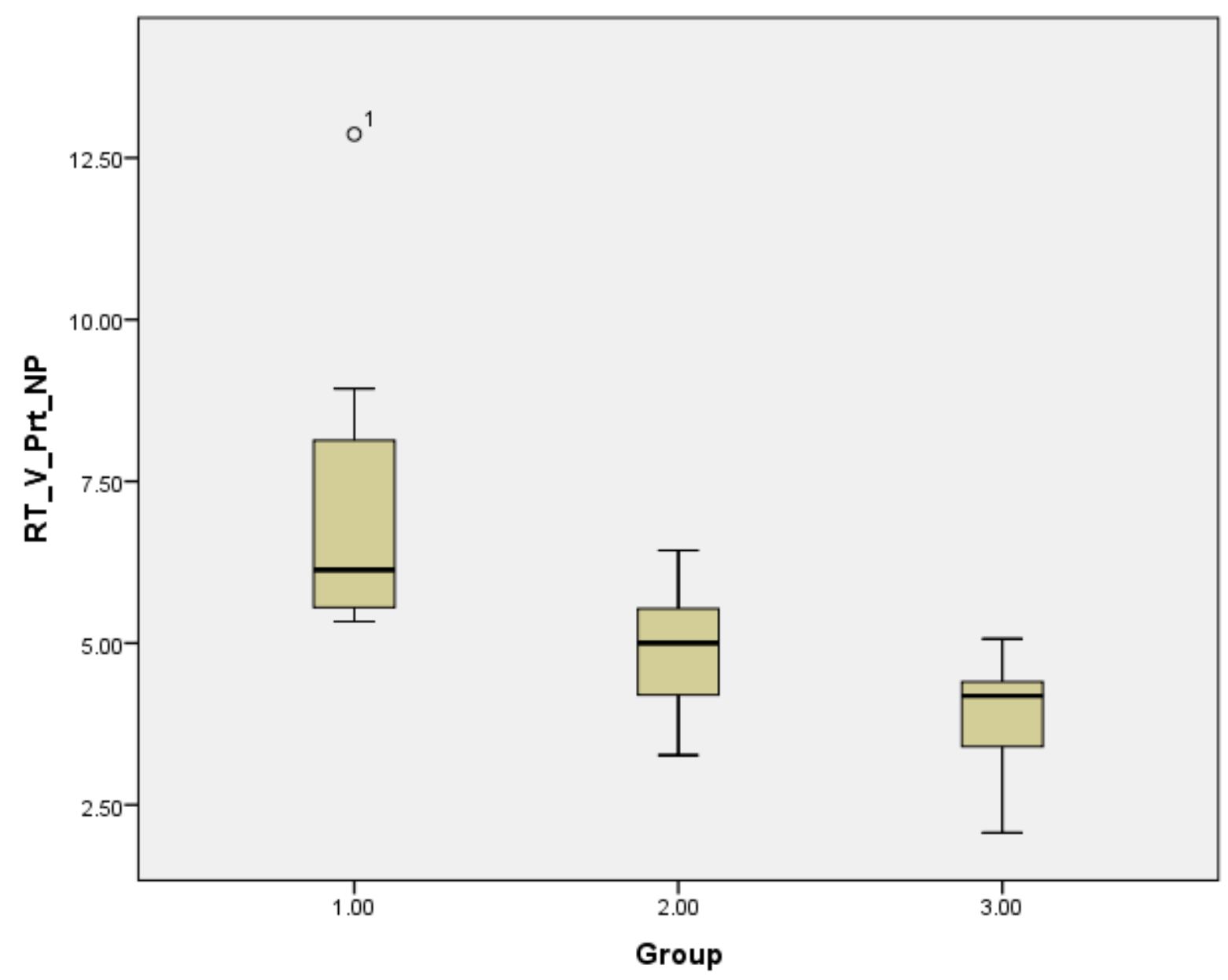

Figure 3.7 Reaction Times in milliseconds by Group for the Condition V Prt NP 


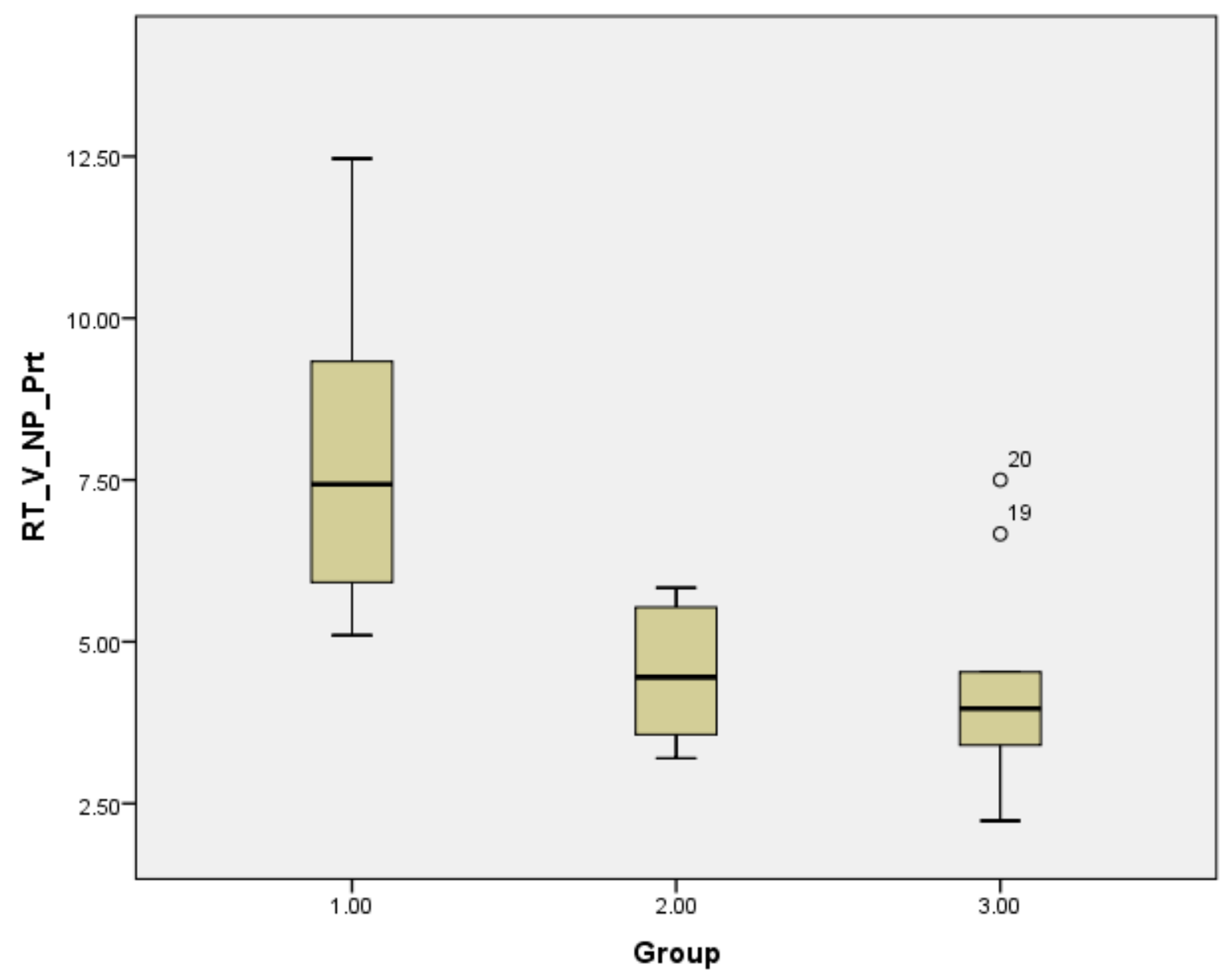

Figure 3.8 Reaction Time in milliseconds by Group for the Condition V NP Prt Within group analyses were conducted on the reaction time data for the two movement conditions for each group. Related t-tests, one for each group, were used to analyze these data. There were no significant findings for any of the groups ( $p>05)$.

The number of correct responses for each movement condition was calculated by adding the correct responses for each condition (V Prt NP and V NP Prt). Kruskal-Wallis tests conducted on these data revealed no significant differences between groups for either condition (V Prt NP $p>.05$; V NP Prt $p>.05$ ). See Table 3.3 below for accuracy data on the movement analysis. 
Table 3.3 Means, standard deviations, and ranges for correct responses for movement of the verb particle per verb construction form for the three groups

\begin{tabular}{|c|c|c|c|c|c|c|c|c|c|c|c|c|c|c|c|c|c|c|c|c|c|c|c|c|}
\hline \multicolumn{25}{|c|}{ Accuracy Data of Movement of Particle } \\
\hline \multirow{3}{*}{ Group } & \multicolumn{6}{|c|}{ Aspectual } & \multicolumn{6}{|c|}{ Directional } & \multicolumn{6}{|c|}{ Idiomatic } & \multicolumn{6}{|c|}{ Overall Movement Data } \\
\hline & \multicolumn{3}{|c|}{ V Prt NP } & \multicolumn{3}{|c|}{ VNPPrt } & \multicolumn{3}{|c|}{ V Prt NP } & \multicolumn{3}{|c|}{ VNP Prt } & \multicolumn{3}{|c|}{ V Prt NP } & \multicolumn{3}{|c|}{ VNP Prt } & \multicolumn{3}{|c|}{ V Prt NP } & \multicolumn{3}{|c|}{ VNP Prt } \\
\hline & Mean & SD & Range & Mean & \begin{tabular}{|l|l}
$S D$ & $R$ \\
\end{tabular} & Range & Mean & \begin{tabular}{|l|l}
$S D$ & $F$
\end{tabular} & Range & Mean & SD & Range & Mean & SD & Range & Mean & SD & Range & Mean & SD & Range & Mean & SD & Range \\
\hline 1 & 7 & 1.5 & $4-8$ & 7 & 2.6 & $6-11$ & 13.6 & 1.1 & $12-15$ & 12.4 & 2.6 & $8-15$ & 13.3 & 1.5 & $11-15$ & 13 & 2 & $9-15$ & 33.9 & 3.5 & $27-38$ & 32.4 & 6.6 & $20-40$ \\
\hline 2 & 6.3 & 2 & $4-10$ & 6.6 & 2.1 & \begin{tabular}{|l|}
$4-11$ \\
\end{tabular} & 13.6 & \begin{tabular}{|l|}
1.2 \\
\end{tabular} & $11-15$ & 13.9 & \begin{tabular}{|l|}
1.1 \\
\end{tabular} & $12-15$ & 14.2 & 0.8 & $13-15$ & \begin{tabular}{|l|}
14.1 \\
\end{tabular} & 0.7 & $13-15$ & 34.1 & 3.2 & $29-38$ & 34.6 & 2.5 & $30-37$ \\
\hline 3 & 5.9 & 1.4 & $4-8$ & 6 & \begin{tabular}{l|l}
$4-8$ \\
\end{tabular} & $13-15$ & 14.2 & \begin{tabular}{|l|l|}
1.4 & \\
\end{tabular} & 13-15 & 14.2 & 0.92 & $13-15$ & 14 & 0.9 & $12-15$ & 13.9 & 0.7 & $13-15$ & 34.1 & 2.2 & $30-36$ & 34.1 & 2.3 & $30-38$ \\
\hline
\end{tabular}

\section{Error Analysis}

The final research question considered whether the three groups showed a difference in error production between the three verb construction forms. If a significant difference occurred for any group, error patterns were further examined relative to the different incorrect foils, specifically considering if the participant selected a picture representing the meaning of the verb itself, the particle itself, or an unrelated picture more than the meaning of the entire verb particle construction. Three separate one-way ANOVAs, one ANOVA for each group, were conducted to compare the number of errors for each verb particle construction form within each group. These analyses were conducted to determine if there was a significant difference in error pattern between the verb particle forms for each group. Each one-way ANOVA revealed significant differences in error production within each group $(\operatorname{Group} 1 \mathrm{~F}(2,12)=134.414 ; \mathrm{p}<.05$; Group $2 \mathrm{~F}(2,18)=136.931 ; \mathrm{p}<.05 ;$ Group $3 \mathrm{~F}(2,18)=281.81 ; \mathrm{p}<.05)$. Post hoc analysis with Bonferroni adjustment revealed significantly more error responses on the aspectual form than on the other two error types for all three groups $(p<.05)$. Figures 3.9, 3.10, and 3.11 illustrate the differences in error production for groups 1,2 , and 3 , respectively. 


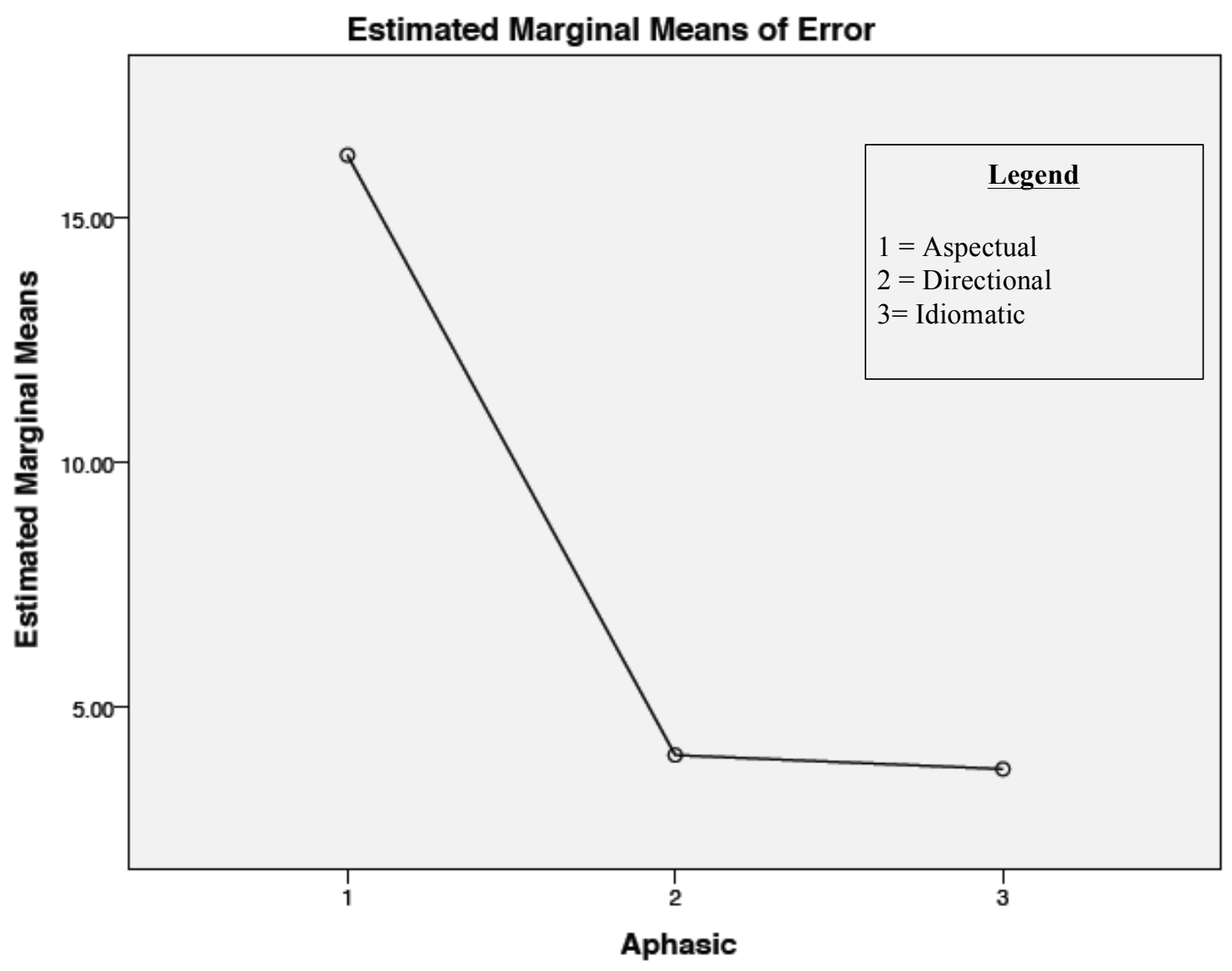

Figure 3.9 Error Production for the three verb construction types for the Group with Aphasia 


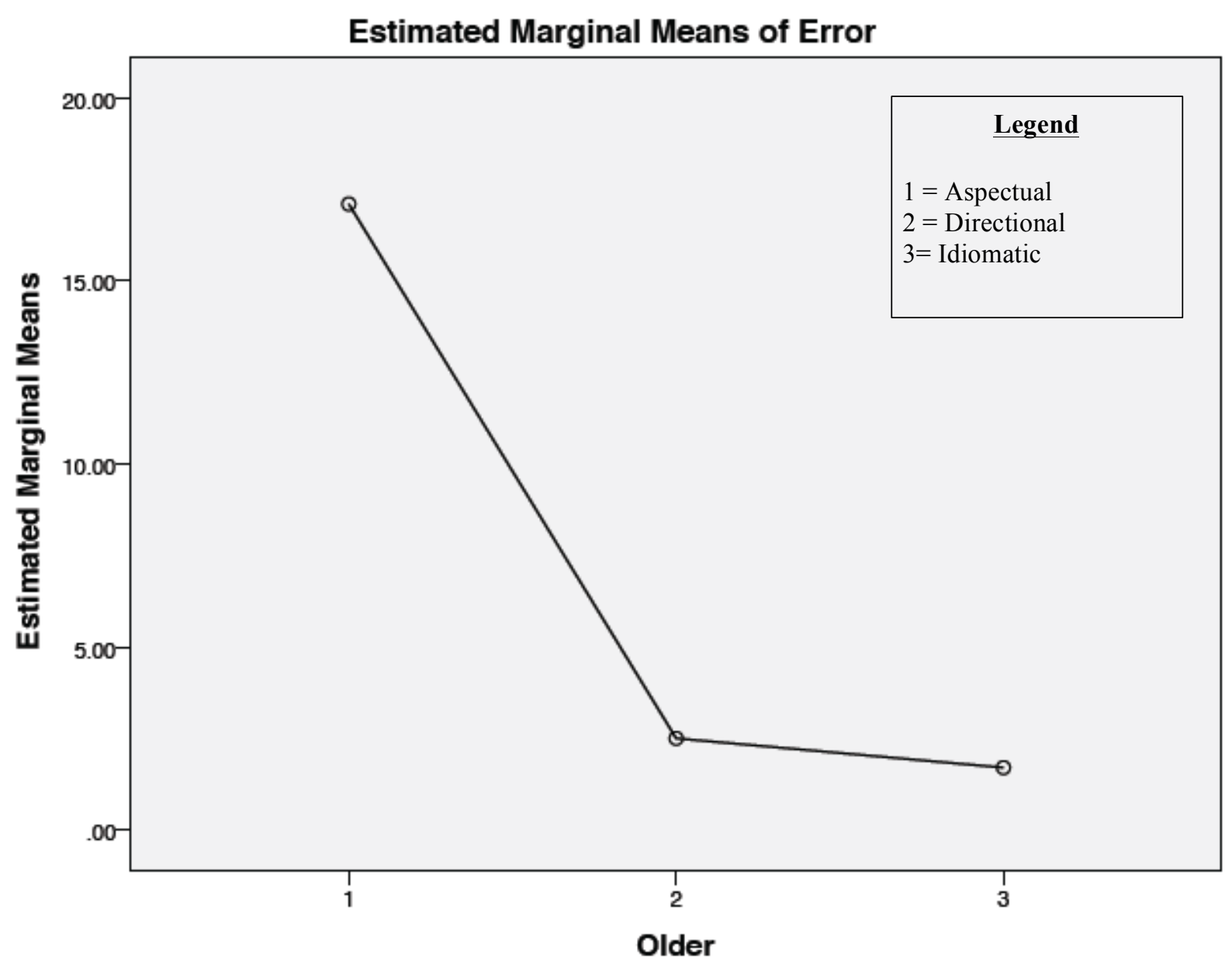

Figure 3.10 Error Production for the three verb construction types for the typical older Group 


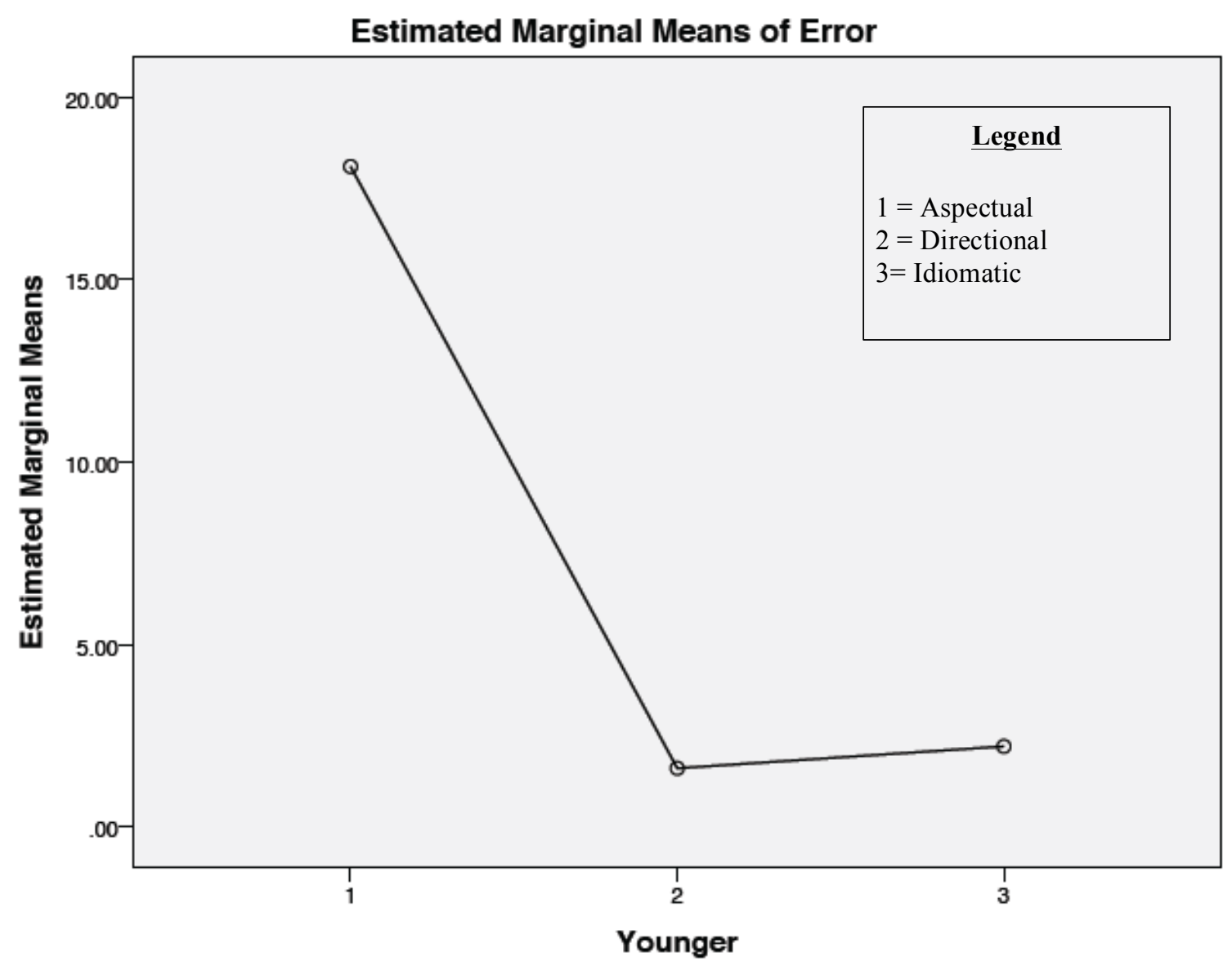

Figure 3.11 Error Production for the three verb construction types for the typical younger group

As indicated, of the three construction forms, the aspectual type contained the greatest number of errors across all three groups. Although some errors were committed on the idiomatic and directional forms, the instances of the errors were too few to warrant any important findings. Thus, a descriptive qualitative analysis examining error types in the aspectual verb construction was conducted on error production for all three groups. 
The analysis of error types in Group 1 revealed that when errors were committed, $91 \%$ of the errors consisted of a picture depicting the meaning of the verb being selected as opposed to $7.2 \%$ and $1.8 \%$ of the errors consisting of a picture depicting the meaning of the particle or unrelated foil, respectively. Additionally, movement had little influence on the type of errors overall: in the V Prt NP condition, $90 \%$ of the errors consisted of a picture representing a verb, $8.3 \%$ of the errors consisted of a picture depicting the meaning of the particle, and $1.67 \%$ of the errors consisted of a picture depicting an unrelated foil; in the V NP Prt condition, $92 \%$ of the errors consisted of a picture depicting the verb, $5.9 \%$ of the errors consisted of a picture representing the particle, and $2 \%$ of the errors consisted of a picture representing an unrelated foil. Table 3.4 summarizes the error patterns for the aspectual verb construction in Group 1. 
Table 3.4 Error Patterns for the aspectual verb construction in Group 1

\begin{tabular}{|c|c|c|c|c|c|c|c|}
\hline \multicolumn{8}{|c|}{ Meanings Selected per Participant per Picture } \\
\hline \multirow[t]{2}{*}{ Stimuli } & \multicolumn{7}{|c|}{ Participants } \\
\hline & VB & SJ & $\mathrm{JB}$ & $\mathrm{HB}$ & EP & DG & AS \\
\hline Aspectual_V_Prt_NP (01, His friend ate up the spaghetti.jpg) & Correct & Correct & Correct & Correct & Correct & verb & Correct \\
\hline Aspectual_V_Prt_NP (02, My dad raked up the leaves.jpg) & verb & verb & Correct & verb & Correct & verb & Correct \\
\hline Aspectual_V_Prt_NP (03, My mother finished up the dress.jpg) & Correct & Correct & Correct & Correct & verb & verb & Correct \\
\hline Aspectual_V_Prt_NP (04, My mother heated up the leftovers.jpg) & Correct & Correct & Correct & Correct & Correct & verb & Correct \\
\hline Aspectual_V_Prt_NP (05, My mother swept up the floor.jpg) & particle & particle & Correct & verb & Correct & Correct & Correct \\
\hline Aspectual_V_Prt_NP (06, The baby drank up the milk.jpg) & verb & verb & Correct & verb & Correct & verb & verb \\
\hline Aspectual_V_Prt_NP (07, The cold froze up the lake.jpg) & verb & verb & unrelated & verb & verb & verb & verb \\
\hline Aspectual_V_Prt_NP (08, The fire burned up the trees.jpg) & verb & verb & verb & Correct & verb & verb & verb \\
\hline Aspectual_V_Prt_NP (09, The researcher sealed up the vials.jpg) & particle & verb & verb & verb & verb & verb & verb \\
\hline Aspectual_V_Prt_NP (10, The shopkeeper closed up his store.jpg) & verb & verb & verb & verb & Correct & Correct & verb \\
\hline Aspectual_V_Prt_NP (11, The student opened up the book.jpg) & verb & Correct & verb & verb & verb & verb & verb \\
\hline Aspectual_V_Prt_NP (12, The student ripped up the paper.jpg) & verb & Correct & verb & Correct & Correct & particle & Correct \\
\hline Aspectual_V_Prt_NP $(13$, The sun dried up the rain.jpg) & particle & Correct & Correct & verb & Correct & Correct & Correct \\
\hline Aspectual_V_Prt_NP (14, The teacher cleaned up his desk.jpg) & particle & verb & verb & verb & verb & verb & verb \\
\hline Aspectual_V_Prt_NP (15, The woman wiped up the mess.jpg) & Correct & verb & Correct & Correct & Correct & verb & Correct \\
\hline Aspectual_V_NP_Prt (01, His friend ate the spaghetti up.jpg) & Correct & verb & verb & Correct & verb & Correct & Correct \\
\hline Aspectual_V_NP_Prt (02, My dad raked the leaves up.jpg) & verb & verb & verb & Correct & verb & verb & verb \\
\hline Aspectual_V_NP_Prt (03, My mother finished the dress up.jpg) & Correct & Correct & Correct & Correct & particle & Correct & Correct \\
\hline Aspectual_V_NP_Prt (04, My mother heated the leftovers up.jpg) & Correct & Correct & Correct & verb & Correct & verb & Correct \\
\hline Aspectual_V_NP_Prt (05, My mother swept the floor up.jpg) & verb & verb & Correct & particle & Correct & Correct & Correct \\
\hline Aspectual_V_NP_Prt (06, The baby drank the milk up.jpg) & verb & verb & Correct & Correct & verb & verb & verb \\
\hline Aspectual_V_NP_Prt (07, The cold froze the lake up.jpg) & verb & verb & verb & verb & verb & unrelated & verb \\
\hline Aspectual_V_NP_Prt (08, The fire burned the trees up.jpg) & verb & verb & verb & verb & Correct & verb & Correct \\
\hline Aspectual_V_NP_Prt (09, The researchers sealed the vials up.jpg) & particle & verb & verb & Correct & verb & verb & Correct \\
\hline Aspectual_V_NP_Prt (10, The shopkeeper closed his store up.jpg) & verb & verb & verb & verb & Correct & Correct & Correct \\
\hline Aspectual_V_NP_Prt (11, The student opened the book up.jpg) & Correct & Correct & verb & Correct & verb & Correct & Correct \\
\hline Aspectual_V_NP_Prt (12, The student ripped the paper up.jpg) & Correct & Correct & Correct & Correct & Correct & Correct & Correct \\
\hline Aspectual_V_NP_Prt (13, The sun dried the rain up.jpg) & particle & Correct & Correct & Correct & Correct & Correct & Correct \\
\hline Aspectual_V_NP_Prt (14, The teacher cleaned his desk up.jpg) & verb & Correct & Correct & verb & verb & Correct & verb \\
\hline Aspectual_V_NP_Prt (15, The woman wiped the mess up.jpg) & Correct & verb & Correct & verb & Correct & verb & Correct \\
\hline
\end{tabular}

In Group 2, $100 \%$ of the errors consisted of a picture depicting the meaning of the

verb. Movement of the particle had no influence on error type. Table 3.5 summarizes the

error patterns for the aspectual verb construction in Group 2. 
Table 3.5 Error Patterns for the aspectual verb construction in Group 2

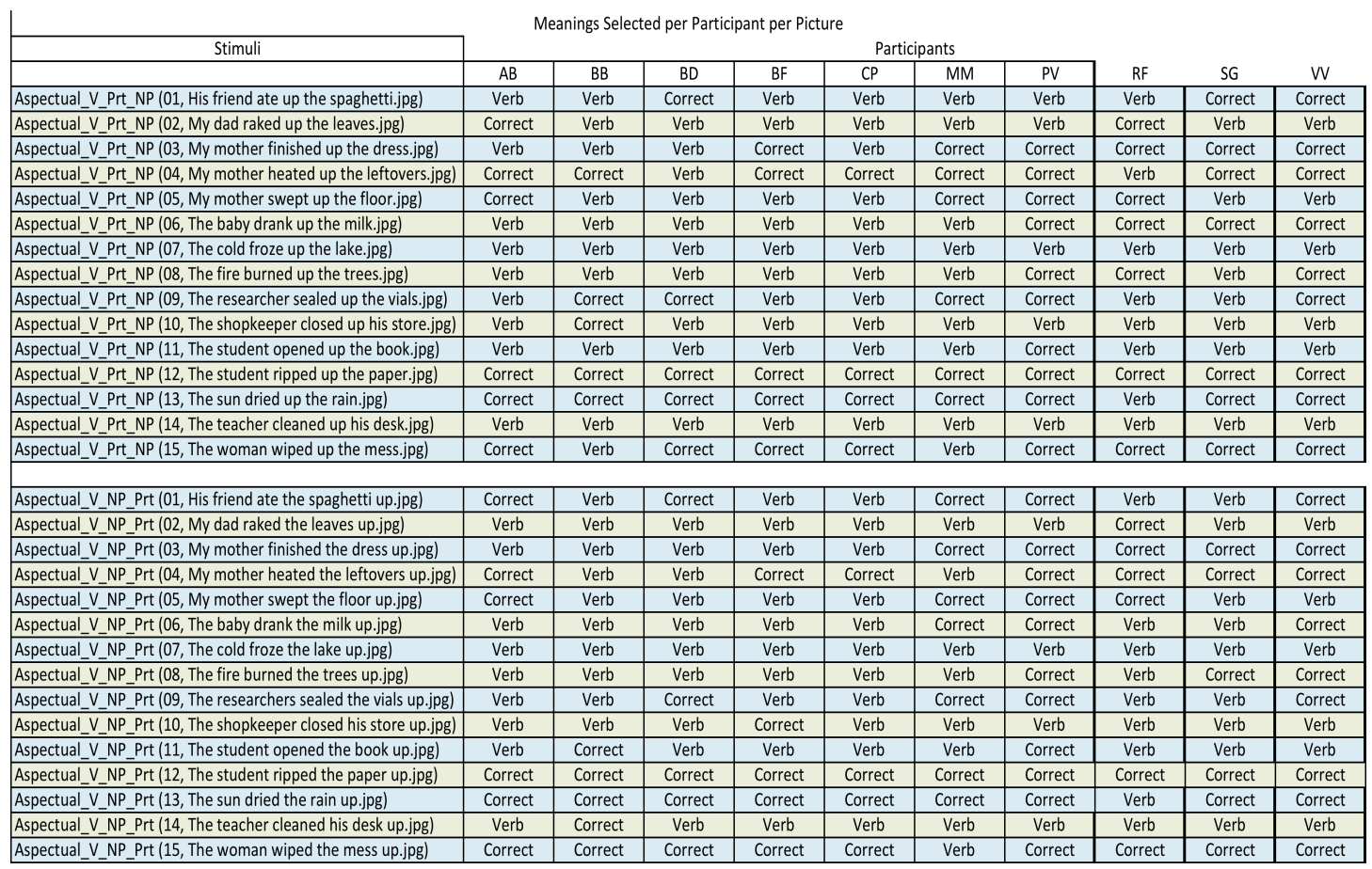

In Group 3, 100\% of the errors consisted of choosing the picture depicting the

meaning of the verb. Movement of the particle had no influence on error type. Table 3.6

summarizes the error patterns for the aspectual verb construction in Group 3. 
Table 3.6 Error Patterns for the aspectual verb construction in Group 3

\begin{tabular}{|c|c|c|c|c|c|c|c|c|c|c|}
\hline \multicolumn{11}{|c|}{ Meanings Selected per Participant per Picture } \\
\hline Stimuli & \multicolumn{10}{|c|}{ Participants } \\
\hline Aspectual_V_Prt_NP (01, His friend ate up the spaghetti.jpg) & Correct & Correct & Verb & Verb & Verb & Correct & Verb & VP & Verb & VP \\
\hline Aspectual_V_Prt_NP (03, My mother finished up the dress.jpg) & Verb & Verb & Verb & Verb & Correct & Correct & Correct & Verb & Correct & Verb \\
\hline Aspectual_V_Prt_NP (04, My mother heated up the leftovers.jpg) & Correct & Correct & Correct & Verb & Correct & Correct & Correct & Correct & Correct & Correct \\
\hline Aspectual_V_Prt_NP (05, My mother swept up the floor.jpg) & Verb & Verb & Verb & Verb & Verb & Verb & Verb & Correct & Verb & Correct \\
\hline Aspectual_V_Prt_NP (08, The fire burned up the trees.jpg) & Verb & Verb & Verb & Verb & Verb & Verb & Verb & Verb & Verb & Correct \\
\hline Aspectual_V_Prt_NP (09, The researcher sealed up the vials.jpg) & Correct & Verb & Correct & Verb & Verb & Correct & Verb & Verb & Correct & Verb \\
\hline Aspectual_V_Prt_NP (10, The shopkeeper closed up his store.jpg) & Verb & Verb & Verb & Verb & Verb & Correct & Verb & Correct & Verb & Verb \\
\hline Aspectual_V_Prt_NP (11, The student opened up the book.jpg) & Correct & Correct & Verb & Verb & Verb & Verb & Verb & Verb & Correct & Verb \\
\hline Aspectual_V_Prt_NP (12, The student ripped up the paper.jpg) & Correct & Correct & Correct & Correct & Correct & Correct & Correct & Verb & Correct & Correct \\
\hline Aspectual_V_Prt_NP (13, The sun dried up the rain.jpg) & Correct & Correct & Correct & Correct & Correct & Correct & Correct & Correct & Correct & Correct \\
\hline Aspectual_V_Prt_NP (14, The teacher cleaned up his desk.jpg) & Verb & Verb & Verb & Verb & Verb & Verb & Verb & Correct & Verb & Verb \\
\hline Aspectual_V_NP_Prt (03, My mother finished the dress up.jpg) & Verb & Verb & Correct & Correct & Correct & Correct & Verb & Verb & Correct & Correct \\
\hline Aspectual_V_NP_Prt (04, My mother heated the leftovers up.jpg) & Correct & Correct & Correct & Verb & Correct & Verb & Correct & Verb & Correct & Correct \\
\hline Aspectual_V_NP_Prt (05, My mother swept the floor up.jpg) & Verb & Verb & Verb & Verb & Verb & Verb & Verb & Verb & Correct & Verb \\
\hline Aspectual_V_NP_Prt (06, The baby drank the milk up.jpg) & Correct & Correct & Verb & Verb & Verb & Correct & Verb & Verb & Verb & Correct \\
\hline Aspectual_V_NP_Prt (07, The cold froze the lake up.jpg) & Verb & Correct & Verb & Verb & Verb & Verb & Verb & Verb & Verb & Verb \\
\hline Aspectual_V_NP_Prt (08, The fire burned the trees up.jpg) & Verb & Verb & Verb & Correct & Verb & Verb & Verb & Verb & Verb & Correct \\
\hline Aspectual_V_NP_Prt (09, The researchers sealed the vials up.jpg) & Correct & Verb & Correct & Verb & Verb & Correct & Verb & Correct & Correct & Verb \\
\hline Aspectual_V_NP_Prt (10, The shopkeeper closed his store up.jpg) & Verb & Verb & Verb & Verb & Verb & Correct & Verb & Correct & Correct & Verb \\
\hline Aspectual_V_NP_Prt (11, The student opened the book up.jpg) & Correct & Correct & Verb & Verb & Verb & Verb & Verb & Verb & Verb & Verb \\
\hline Aspectual_V_NP_Prt (12, The student ripped the paper up.jpg) & Correct & Correct & Correct & Correct & Correct & Correct & Correct & Correct & Verb & Correct \\
\hline Aspectual_V_NP_Prt (13, The sun dried the rain up.jpg) & Correct & Correct & Correct & Correct & Correct & Correct & Correct & Verb & Correct & Correct \\
\hline Aspectual_V_NP_Prt (14, The teacher cleaned his desk up.jpg) & Verb & Verb & Verb & Verb & Verb & Verb & Verb & Correct & Verb & Verb \\
\hline
\end{tabular}

\section{Correlations}

\section{Spearman Rho Correlations were conducted to examine relationships between}

age, education, and performance on the MoCA and the experimental task data across

findings for the aphasic adults and the typical older adults. Table 3.7 below summarizes

the correlations between age, education, and MoCA scores and overall reaction time and

overall accuracy. 
Table 3.7 Spearman Rho Correlations

\begin{tabular}{|l|c|c|c|c|}
\hline \multirow{4}{*}{ Spearman's Rho Correlation } \\
\hline & \multicolumn{2}{|c|}{$\begin{array}{c}\text { Overall Reaction } \\
\text { Time }\end{array}$} & \multicolumn{2}{c|}{ Overall Accuracy } \\
\cline { 2 - 5 } & $\mathrm{r}_{\mathrm{s}}$ & $\mathrm{p}$ & $\mathrm{r}_{\mathrm{s}}$ & $\mathrm{p}$ \\
\hline Education & 0.067 & 0.798 & 0.308 & 0.229 \\
\hline Age & -0.127 & 0.626 & 0.081 & 0.757 \\
\hline MoCA & -0.429 & 0.086 & 0.178 & 0.494 \\
\hline
\end{tabular}

As can be observed, although not significant, there was a moderate negative relationship between MoCA scores and overall reaction time, $r_{\mathrm{s}}=-.429$, thus indicating that the higher the score on the MoCA, the lower the reaction time on the experimental task. 


\section{CHAPTER IV}

\section{Discussion}

\section{Introduction}

The purpose of the study was to examine the processing of verb particle constructions in English in typical young and older adults and in adults with Broca's aphasia. The main research question to be considered was whether verb-particle constructions pose difficulty in comprehension for persons with aphasia. In order to answer this broad question, the analyses addressed whether there would be significant differences between PWAs and young and older non-brain-damaged adults in comprehending verb particle constructions. Specifically, the examiner addressed whether there would be significant differences between typical older and younger adults and PWAs relative to comprehending specific types of verb particles (idiomatic, aspectual, directional) and whether there would be significant differences in the processing time of verb particle constructions with movement of the object NP between PWAs and typical older and younger adults. Additionally, the examiner explored within group differences for error production relative to verb construction type and specific error patterns for each group.

\section{Overall Performance}

The first research question addressed whether there would be an overall significant difference between PWAs and young and older non-brain-damaged adults in comprehending verb particle constructions relative to reaction time and accuracy of performance. It was predicted that there will be a significant difference in comprehension between PWAs and both groups of non-brain-damaged adults. The results of the picture- 
matching task confirmed this hypothesis. The aphasic group performed significantly slower overall than the older normal and younger groups. This difference in reaction times in persons with aphasia is to be expected (Burkhardt et al., 2008; Burkhardt et al., 2003; Dickey et al., 2007). This finding is remarkable because although the sentences presented to the individuals with aphasia were simple in structure, slower than normal processing was still observed. According to Burkhardt et al. (2008), this slowing down may be due to slower than normal syntactic structure building, in which the person with aphasia has difficulty constructing the underlying syntactic structure. Thus, considering Friedmann's $(2001 ;$ 2006) Tree Pruning Hypothesis, it may be theorized that the slower than normal syntactic processing is due to the aphasic individual having difficulty accessing higher nodes in the syntactic tree (Burkhardt et al., 2008). According to analyses by Johnson (1991), Pesetsky (1995), Jackendoff (2002), Kayne (1985), Aarts (1989) and den Dikken (1995), movement of the verb is required into a higher branch on the syntactic tree. Further evidence is provided if an analysis of verb particle constructions is such that they are syntactically parsed as they are being processed. Thus, this would support Kayne (1985), Aarts (1989) and den Dikken (1995) who postulate that verb particles are heads of syntactic phrases rather than whole lexical units.

The results may also be explained in light of the meaning of the verb particles themselves. It has been shown that the semantic weight of the verbs may also cause a delay in processing in persons with aphasia (Morean, 2012). In this analysis, the reaction 
times of all forms in each movement condition were collapsed and compared. Thus, it is highly probable that the semantic opaqueness or transparency also could have affected the processing times for the participants with aphasia.

Interestingly, no overall significant differences were observed between the young and older non-brain damaged groups relative to overall reaction time or accuracy, suggesting that both younger and older adults process these constructions in a similar fashion. This observation is surprising in light of the fact that research indicates that processing of syntactic forms is slowed with age (Craik \& Salthouse, 2008; Kemper, 1986). Kemper (1986) found that young adults were able to accurately imitate or paraphrase sentences involving embedded gerunds, that-caluses, wh-cluases, and relative clauses regardless of length position, or type of embedded clauses. Older adults were found to be unable to paraphrase or imitate long constructions correctly especially those in which the embedded clause was sentence initial. Therefore Kemper (1986) concludes that there is an age-related decline in processing abilities due to the increased processing demands of long or sentence initial constructions. Perhaps verb particle constructions consist of simple argument structures, although not studied in the present work, which could be playing a role the way they are being processed, thus being easier to retrieve regardless of a subtly declining system.

\section{Verb Construction Forms}

Reaction times were compared to determine if there would be a significant difference between PWAs and typical adults in comprehending the types of verb particle constructions (aspectual, directional, idiomatic). It was predicted that PWAs would have more difficulty processing idiomatic verb particle constructions than typical older adults. 
Given this hypothesis, the directional verb particles should present the least difficulty for PWAs. The rationale behind this prediction is that directional verb particles are the most transparent semantically and, therefore, should be retrieved quicker than idiomatic or aspectual verb particles whose meanings tend to be more opaque. Typical adults were not expected to show significant differences between each category.

The results revealed significant differences in the processing of the different forms between persons with aphasia and the two groups of typical adults. Specifically, the aphasic group was significantly slower than the other two groups for each verb construction type. No statistically significant differences were found between the older and younger normal groups for any of the constructions. Within groups analyses revealed that the aphasic group were significantly slower in comprehending aspectual verb forms than directional. Additionally, persons with aphasia demonstrated a trend toward slower processing of aspectual verb forms than idiomatic verb forms. Surprisingly, the younger adult group also demonstrated a similar pattern as the aphasic group. Younger adults were slower in comprehending aspectual verb forms than directional verb forms and a trend towards significance was also observed between aspectual and idiomatic indicating slower performance on aspectual verb constructions as compared to idiomatic verb constructions. Interestingly, there was no significant difference in accuracy of responses between the three groups for any of the verb constructions. However, there was a trend towards significance for the idiomatic construction; the aphasic group tended to be noticeably less accurate than the other two groups on this construction.

The verb construction form data lends support to the analyses of McIntyre (2002) and Larsen (2014) in regards to aspectual verb particles. Larsen (2014) argues that 
aspectual verb particles must be treated as idiomatic and that these retain abstract spatial meaning. McIntyre (2002) proposed that aspectual verb particles add its own semantic contribution and like Larsen (2014), also denote abstract spatial meaning. Therefore, any aspectual relations these types of particles denote are from the spatial relations they designate (Larsen, 2014). Therefore, aspectual verb particles may be re-analyzed as type of verb particles having a more idiosyncratic meaning. The results for the aphasic participants in the current study support findings on idiom comprehension in persons with aphasia (Papagno et al., 2004; Cacciari et al., 2006; Nenonen et al., 2006). It has been shown that verb phrase idioms require syntactic parsing during comprehension due to morphosyntactic encoding such as tense, argument structures, and person (Nenonen et al., 2006). Taking Nenonen et al. (2006) into account, this would explain why the aphasic participants were slower in comprehending aspectual verb particles. Additionally, it would also explain the younger adult data. It may well be the case that the particle in these constructions provides a processing cost resulting in slower processing in the younger typical group. Moreover, this type of construction may also be becoming obsolete for the younger typical adult group.

In terms of accuracy data, the results also lend support to the literature on idiom processing as described above. The trend towards less accuracy in the idiomatic verb forms can be explained in light of access to nonliteral meaning in persons with aphasia. Cacciari et al. (2006) reasoned that the impairment in accessing the nonliteral meaning may be due to a deficit in either identifying the idiom itself or an impairment in suppressing the literal meaning to access the nonliteral meaning. The trend toward 
decreased accuracy in the idiomatic verb construction may be due to a deficit in identifying the idiom.

\section{Movement Analysis}

Movement of the object noun phrase and processing time was examined in all groups. An increase in processing time in PWAs was predicted in the V NP Prt condition as opposed to V Prt NP condition. A difference in processing time between the V NP Prt condition and V Prt NP was not expected in typical adults. The results demonstrated a difference in processing time for both movement conditions between persons with aphasia and non-brain damaged adults. The aphasic group was slower than the typical adult groups in terms of processing the syntactic forms. Movement of the object noun phrase had no significant effect on processing time. Furthermore, there were no significant differences between groups for response accuracy relative to syntactic movement. Thus, movement had no effect on the participants' correct responses.

It has been shown in the literature that constructions requiring movement of constituents slow down processing in persons with aphasia (Burkhardt et al. 2008; Burkhardt et al. 2003). Furthermore, the aphasic involvement affects the ability to syntactically construct the sentence during processing. Burkhardt (2008) suggested that this slower-than-normal syntactic building is the result of a temporarily pruned syntax tree. The results of the movement analysis support the literature on slower-than-normal syntactic building during sentence comprehension.

Neuroimaging studies have shown that verb movement and wh-movement involves Broca's area (Shetreet and Friedmann, 2014; Rogalsky, Almeida, Sprouse, and Hickok, 2015). Shetreet and Friedmann (2014) compared wh-movement and verb 
movement in healthy adults aged 22 to 41 . The investigators found a distinction between wh-movement and verb movement: wh-movement involves Broca's area as well as bilateral posterior temporal regions, left precentral gyrus, and left cerebellum as opposed to verb movement that involves Broca's area. Thus, given these findings, movement of the verb should pose a problem for the aphasic during comprehension; however, such is not the case in the present work. It may be the case that movement of the verb is minimal in the constructions presented to the participants. It may also be the case that the participants with aphasia have access to other brain regions responsible for syntactic processing and could therefore process the moved structures without any difficulty. Imaging studies examining the processing of verb particle constructions will aid in understanding movement in these structures.

\section{Error Analysis}

The final question addressed whether the three groups showed a difference in error production between the three verb construction forms. An analysis of error production within group for the three verb constructions was conducted and revealed that all three groups produced significantly more errors on the aspectual verb form than the other two forms. It was hypothesized in Question 4 that PWAs will have a bias towards the literal meaning of the verb and would select pictures representing the verb more than the meaning of the entire verb particle construction. Such a difference in error type is not expected in the typical adult groups. The hypothesis held true for the aphasic group. However, surprisingly, the typical adult groups also showed a bias towards the verb form, particularly in the aspectual form of the verb. Statistical analyses further demonstrated 
that there was a significant difference in all three groups with regards to error pattern: the aspectual verb construction has significantly more errors than the directional and idiomatic verb constructions.

Research on idiom comprehension in persons with aphasia has shown that there is a literal bias towards the meaning of the idiom (Brumm, 2011; Cacciari et al., 2006; Nenonen, 2006; Papagno et al., 2004). However, the results of the present work appear to contradict these previous observations. Although the participants with aphasia selected a picture that represented the literal meaning of the verb more often for the aspectual form, such was not the case for the directional and idiomatic verb forms. In fact, the data shows that fewer to no errors were made in the idiomatic and directional verb constructions. If errors occurred, the meaning of the verb itself was selected; however the occurrences of these were too few to make any significant generalizations. Moreover, the typical adults groups performed similarly to the aphasic group, selecting the picture that represents the verb more often than the picture representing the meaning of the verb particle construction. Thus, the results indicate that the aspectual feature of the verb is weaker given that the aphasic adults and both non-brain damaged groups showed similar error patterns. This result appears to be in congruence with Larsen's (2014) analysis of verb particles in which he argued that particles categorized as aspectual do not denote an aspect feature but rather denote metaphorical spatial relations. Further elaboration on this hypothesis suggests that the particle in this construction may even be relic of a past aspectual construction given that in its modern use, the particle is redundant, according to Jackendoff (2002). 


\section{General Discussion}

The present work is the first of its kind to examine both how the categories of verb-particle constructions put forth by Jackendoff (2002) and particle movement affects comprehension in persons with aphasia. To date, there has been one published study on verb particle constructions that studied the ability for persons with aphasia to repeat sentences containing verb particle constructions (Kohen et al., 2011). The results of their study found that verb particle constructions were easier to repeat than transitive prepositional sentences; however, it was unclear whether this facility was due to syntax, semantics, or both. The present study presented a receptive language task to the participants with aphasia. This receptive task is a pure form of examining comprehension of these constructions.

The verb particle constructions in the present work were analyzed in terms of their semantic form (aspectual, idiomatic, and aspectual) and in terms of movement of the verb particle (whether the particle immediately follows the verb or the object noun phrase). These verb particle constructions were examined in persons with aphasia (PWA) and in non-brain damaged adults. The current findings suggest that verb particle constructions pose some difficulty for persons with aphasia to comprehend although this difficulty is not too different from typical adults, particularly when the meaning of the verb particle is more opaque. Furthermore, the results seem to point to more syntactic parsing of the verb particle construction in persons with aphasia; movement of the object noun phrase, however, had no effect on processing cost. Syntactic parsing of verb particle constructions refutes the claim that verb particle constructions form a unitary predicate as presented in Kohen et al. (2011). Although argument structures were not studied in the 
present work, perhaps the ease in repetition has more to do with the semantic complexity of the argument structures within the sentences presented rather than the syntactic or semantic structure of the verb particles themselves given the findings of the present work. Bastiaanse et al. (2002) and Bastiaanse and van Zonnefeld (2004) support the notion that verbs that are more complex in terms of their argument structure are harder to produce than simpler verbs. It may well be the case that verb particle constructions fall into the latter category as presented in Kohen et al. (2011).

\section{Limitations of the Study}

There are some limitations of the present work. The biggest limitation was the uneven number of participants, particularly for the aphasic group and the other two groups. The examiner had difficulty finding monolingual participants with aphasia who were nonfluent in nature and could perform the experimental task. Additionally, the sample size was small, with small numbers of participants per group (7 in group 1, 10 in group 2, and 10 in group 3). This increased the chances of outliers and skewed data sets. Moreover, there was a small number of stimulus sentences presented to each participant, 30 sentences total of each type, which were divided in half based on movement type. Due to the small numbers, reaction times of error trials were included in the overall data set. A larger stimulus set would have allowed to remove reaction times for error trials and accurately calculate which forms and constructions were processed faster. Finally, some of the pictures chosen to represent the sentences were not exact matches but rather pictures that best fit the overall meaning of the verb particle and not necessarily the 
whole sentence. Thus, participants were surprised at first when presented with a picture that did not quite fit with the sentence that they heard which led to possible increases in reaction times for some trials.

\section{Implications for Further Research}

The present work analyzed the syntax and semantics of verb particle constructions using the semantic categories put forth by Jackendoff (2002) and the syntactic analyses by Dikken (1995), Kayne (1985), Aarts' (1989), Johnson (1991) and Pesetsky (1995). In light of the present findings, it would be useful to analyze the meanings of verb particle constructions as existing in a continuum. This continuum can be studied in persons with aphasia relative to their transparency and opaqueness and how different syntactic constructions affect their processing (i.e. Wh-questions, relative clauses, passive constructions).

Moreover, verb particles should also be studied relative to production by persons with aphasia utilizing the same or similar syntactic constructions as in the present work. The study conducted by Koehn et al. (2011) found that verb particle constructions were easiest for persons with aphasia to repeat. The results of the present work appear to shed light as to why this is the case. Further studies may look at the impact of movement on production of verb particles as well as semantic transparency and opaqueness. This could highlight which syntactic form is easier for the aphasic adult to produce given the current findings. 


\section{Summary and Conclusions}

The results of the present study demonstrated that the aphasic group was slower in overall processing of verb particle constructions than typical younger and older adults. However, no significant differences in response accuracy were found between groups. In terms of verb construction forms, the aphasic group was significantly slower than both typical adult groups for each condition type. Within groups analysis revealed that the aphasic group were significantly slower in comprehending aspectual verb forms than directional verb forms and demonstrated a trend toward slower processing of aspectual verb forms. The younger adult group demonstrated a similar pattern as the aphasic group but the older typical group showed no processing differences between the three forms. In terms of accuracy, there was no significant difference between groups; however, the aphasic group was noticeably less accurate on the idiomatic construction than the other two groups. Relative to a movement analysis, the aphasic group was slower than the typical adult groups with regards to processing the syntactic forms. However, movement of the object noun phrase had no significant effect on processing time. Additionally, movement had no effect on participants' response accuracy. Error analysis within each group revealed significantly more errors on the aspectual verb form than the other two forms for all three groups. Specifically, when committing an error, all groups selected a picture representing the literal meaning of the verb more often than the meaning of the verb particle.

The results of the present work support the notion that verb particle constructions are syntactically parsed during comprehension. Semantically, verb particle constructions exist on a continuum from semantically opaque to semantically transparent. Rather than 
classifying verb particles as being idiomatic or directional, an accurate semantic classification would be an opaque class that includes those particles with idiosyncratic meanings and a transparent class which would include those with more directional meanings as the particle would have a meaning similar to that of a preposition. The implications for the field of linguistics would be to consider a general syntax of verb particles such that the verb and its particle are generated separately. This would require cross-linguistic studies of verb particles primarily in the Germanic languages as well as in other languages containing these constructions. In agrammatic aphasia and agrammatism therapy, it is important to consider the deep structure of syntactic constructions. The literature supports the notion that derived structures, such as questions, relative clauses, and even verb particle constructions, become burdensome for the aphasic. Thus, it is important to select treatments that target base structures and guide the aphasic individual up the syntax tree. Additionally, selecting targets that are semantically transparent also will be helpful in rehabilitation. 


\section{References}

Aarts, B. (1989). Verb-preposition constructions and small clauses in English. Journal of Linguistics, 25(2), 277-290.

American Speech-Language-Hearing Association. (1997). Guidelines for audiologic screening [Guidelines]. Available from www.asha.org/policy retrieved 8 March 2016.

Ardila, A. (2014). Aphasia Handbook. Unpublished manuscript, Florida International University.

Baker, M. (1997). On particles in universal grammar: A review of den Dikken (1995). Natural Language \& Linguistic Theory, 15(3), 641-666.

Barde, L. H. F., Schwartz, M. F., \& Boronat, C. B. (2006). Semantic weight and verb retrieval in aphasia. Brain and Language, 97(3), 266-278.

Bastiaanse, R., Rispens, J., Ruigendijk, E., Rabadan, O.J., \& Thompson, C. K. (2002). Verbs: some properties and their consequences for agrammatic Broca's aphasia. Journal of Neurolinguistics, 15, 239-264.

Bastiaanse, R. \& van Zonnefeld, R. (2004). Broca's aphasia, verbs and the mental lexicon. Brain and Language, 90, 198-202.

Behrens, H. (1998). How difficult are complex verbs? Evidence from German, Dutch, and English. Linguistics, 36, 679-712.

Blais, M., \& Gonnerman, L.M. (2013). Explicit and implicit semantic processing of verbparticle constructions by French-English bilinguals. Bilingualism, 16(4), 829-846.

Boersma, P. \& Weenink, D. (2016). Praat: doing phonetics by computer [Computer program]. Version 6.0.14., retrieved 8 March 2016 from http://www.praat.org/ 
Breedin, S. D., Saffran, E. M., \& Schwartz, M. F. (1998). Semantic factors in verb retrieval: An effect of complexity. Brain and Language, 63(1), 1-31.

Brum, K. P. (2011). Digging beneath the surface behavioral and neural indices of lexical access during idiom comprehension in aphasia: A multi-modal approach (Order No. 3487397). Available fom ProQuest Dissertations \& Theses A\&I; ProQuest Dissertations \& Theses Global. (912997715).

Burkhardt, P., Avrutin, S., Pinango, M. M., \& Ruigendijk, E. (2008). Slower-than-normal syntactic processing in agrammatic Broca's aphasia: Evidence from Dutch. Journal of Neurolinguistics, 21(2), 120-137.

Burkhardt, P., Pinango, M. M., \& Wong, K. (2003). The role of the anterior left hemisphere in real-time sentence comprehension: Evidence from spit intransitivity. Brain and Language, 86(1), 9-22.

Cacciari, C., Reati, F., Colombo, M. R., Padovani, R., Rizzo, S., \& Papagno, C. (2006). The comprehension of ambiguous idioms in aphasic patients. Neuropsychologia, 44, 1305-1314.

Condon, N. (2008). How cognitive linguistic motivations influence the learning of phrasal verbs. In F. Boers \& S. Lindstromberg (Eds.), Cognitive linguistic approaches to teaching vocabulary and phraseology, 133-157. Berlin: Mouton de Gruyter.

Crutchley, A. (2007). Comprehension of idiomatic verb + particle constructions in 6- to 11-year old children. First Language, 27(3), 203-226.

Den Dikken, M. (1995). Particles: On the syntax of verb-particle, triadic, and causative constructions. New York: Oxford University Press.

Dickey, M. W., Choy, J. W. J., \& Thompson, C. K. (2007). Real-time comprehension of wh-movement in aphasia: Evidence from eye-tracking while listening. Brain and Language, 100(1), 1-22. 
Dillard, A. (2014). Non-native speaker attentional capacity and the processing of English phrasal verb constructions. MI: ProQuest LLC.

Evaert, M., Van Der Linden, V., Schenk, Screuder, R. O. (1995). Introduction. In Evaert, M., Van Der Linden, V., Schenk, Screuder, R. O. (Eds.), Idioms: Structural and Psychological Perpectives (pp. 1-13). NJ: Lawrence Erlbaum Associates, Inc.

Friedmann, N. (2001). Agrammatism and the psychological reality of the syntactic tree. Journal of Psycholinguistic Research, 30, 71-90.

Friedmann, N. (2006). Generalizations on variations in comprehension and production: a further source of variation and a possible account. Brain and Language, 96, 151153.

Garrett, K. L. \& Lasker, J. P. (2013). Adults with severe aphasia and apraxia of speech. In D. R. Beukelman \& P. Mirenda (Eds.), Augmentative \& alternative communication: Supporting children \& adults with complex communication needs ( $4^{\text {th }}$ ed., 405-445). Baltimore, MD: Paul H. Brookes Publishing Co.

Gonnerman, L. M., \& Hayes, C. R. (2005). The professor chewed the students...out: Effects of dependency, length, and adjacency on word order preferences in sentences with verb-particle constructions.

Goodglass, H. (1993). Understanding Aphasia. San Diego, CA: Academic Press, Inc.

Grodzinsky, Y. (1988). Syntactic representations in agrammatic aphasia: The case of prepositions. Language and Speech, 31(2), 115-134.

Hallowell, B. \& Chapey, R. (2008). Introduction to language intervention strategies in adult aphasia. In R. Chapey (Ed.), Language intervention strategies in aphasia and related neurogenic communication disorders $\left(5^{\text {th }}\right.$ ed., pp. 3-19). Baltimore, MD: Lippincott Williams \& Wilkins.

Helm-Estabrooks, N., Albert, M. L., \& Nicholas, M. (2014). Manual of Aphasia and Aphasia Therapy Third Edition. TX: PRO-ED, Inc. 
Hillert, D. (2004). Spared access to idiomatic and literal meanings: a single case approach. Brain and Language, 89, 207-215.

Hillert, D. \& Buracas, G. (2009). The neural substrates of spoken idiom comprehension. Language and Cognitive Processes, 24, 1370-1391.

Hough, M. S. (2007). Episodes of word retrieval failures in aphasia. Journal of Medical Speech-Language Pathology, 15(3), 319-326.

Hough, M. S., Downs, C. R., Cranford, J. L., \& Givens, G. D. (2003). Measures of auditory processing in aphasia: Behavioral and electrophysiological analysis. Aphasiology, 17(2), 159-172.

Jackendoff, R. (1995). The boundaries in the lexicon. In M. Everaert, E. van der Linden, A. Shenk, \& R. Schreuder (Eds.), Idioms: Structural and Psychological Perspectives, 133-166. NJ: Lawrence Erlbaum.

Jackendoff, R. (2002). English Particle Constructions, the lexicon, and the autonomy of syntax. In N. Dehe, R. Jackendoff, A. McIntyre, S. Urban (Eds.), Verb-Particle Explorations (pp. 67-94) NY: Mouton de Gruyter.

Johnson, K. (1991). Object Positions. Natural Language \& Linguistic Theory, 9(4), 577636.

Kayne, R. S. (1985). Principles of particle constructions. In J. Gueron, H.-G. Obenauer, \& J.-Y. Pollock (eds.), Grammatical representation, 101-140. Dordrecht: Foris Publications Holland.

Kegl, J. (1995). Levels of representation and units of access relevant to agrammatism. Brain and Language, 50(2), 151-200.

Kemper, S. (1986). Imitation of complex syntactic constructions by elderly adults. Applied Psycholinguistics, 7, 277-288. 
Kertesz, A. (1982). The Western Aphasia Battery. New York: Grune \& Stratton.

Kim, M. \& Thompson, C. K. (2000). Patterns of comprehension and production of nouns and verbs in agrammatism: Implications for lexical organization. Brain and Language, 74(1), 1-25.

Kohen, F., Milsark, G., \& Martin, N. (2011). Effects of syntactic and semantic argument structure on sentence repetition in agrammatism: things we can learn from particles and prepositions. Aphasiology, 25, 736-747.

Larsen, D. (2014). Particles and particle-verb constructions in English and other Germanic languages. MI: ProQuest LLC.

Laufer, B. (1997). The lexical plight in second language reading. In J. Coady \& T. Hutchkin (eds.), Second language vocabulary acquisition: A rationale for pedagogy, 20-34. Cambridge: Cambridge University Press.

Lopez, D., Louis, E., Miles, J., Thompson, E., \& Walker, K. (2011, September). The production of the verb particle construction with full and reduced relative clauses. Paper presented at the New Trends in Experimental Psycholinguistics conference, Madrid, Spain.

Mashal, N., Faust, M., Hendler, T., \& Mark, J.-B. (2008). Hemispheric differences in processing the literal interpretation of idioms: Converging evidence from behavioral and fMRI studies. Cortex, 44, 848-860.

McIntyre, A. (2002). Idiosyncrasy in particle verbs. In N. Dehe, R. Jackendoff, A. McIntyre, S. Urban (Eds.), Verb-Particle Explorations, 95-118. NY: Mouton de Gruyter.

Morean, D. F. (2012). Effects of semantic weight on verb recognition and retrieval in aphasia: Implications for the lexical-conceptual structure of verbs. MI: ProQuest LLC.

Nasreddine, Z. (2016). Montreal Cognitive Assessment. Available from http://www.mocatest.org retrieved 20 March 2016. 
Neagu, M. (2007). English verb particles and their acquisition. A cognitive approach. Revista Espanola De Linguistica Aplicada, 20, 121-138.

Nenonen, M., Niemi, J., \& Laine, M. (2002). Representation and processing of idioms: evidence from aphasia. Journal of Neurolinguistics, 15, 43-58.

Nolte, J. (2009). The human brain: An introduction to its functional anatomy $\left(6^{\text {th }}\right.$ ed.) Philadelphia, PA: Mosby Elsevier.

Oliveri, M., Romero Lauro, L. J., \& Papagno, C. (2004). Left but not right temporal involvement in opaque idiom comprehension: A repetitive transcranial magnetic stimulation study. Journal of Cognitive Neuroscience, 16(5), 848-855.

Papagno, C. \& Caporali, A. (2007). Testing idiom comprehension in aphasic patients: The effects of task and idiom type. Brain and Language, 100(2), 208-220.

Papagno, C. \& Genoni, A. (2004). The role of syntactic competence in idiom comprehension: a study on aphasic patients. Journal of Neurolinguistics, 17, 371382.

Papagno, C., Tabossi, P., Colombo, M. R., \& Zampetti, P. (2004). Idiom comprehension in aphasic patients. Brain and Language, 89, 226-234.

Pesetsky, D. M. (1995). Zero syntax: Experiencers and Cascades. Cambridge, MA: The MIT Press.

Pollock, J. Y. (1989). Verb movement, Universal Grammar and the structure of IP. Linguistic Inquiry, 20, 365-424.

Rizzo, S., Sandrini, M., \& Papagno, C. (2007). The dorsolateral prefrontal cortex in idiom interpretation: An rTMS study. Brain Research Bulletin, 71, 523-528. 
Rochon, E., Saffran, E. M., Berndt, R. S., \& Schwartz, M. F. (2000). Quantitative analysis of aphasic sentence production: Further development and new data. Brain and Language, 72, 193-218.

Rogalsky, C., Almeida, D., Sprouse, J., \& Hickok, G. (2015). Sentence processing selectivity in Broca's area: evident for structutre but not syntactic movement. Language, Cognition, and Neuroscience 30:10, 1326-1338.

Romero Lauro, L. J., Tettamanti, M., Cappa, S. F., \& Papagno, C. (2008). Idiom comprehension: A prefrontal task? Cerebral Cortex, 18, 162-170.

Shapiro, L. P., Gordon, B., Hack, N., \& Killackey, J. (1993). Verb-argument structure processing in complex sentences in Broca's and Wernicke's aphasia. Brain and Language, 45(3), 423-447.

Shetreet, E., \& Friedmann, N. (2014). The processing of different syntactic structures: fMRI investigation of the linguistic distinction between wh-movement and verb movement. Journal of Neurolinguistics, 27, 1-17.

Sugisaki, K., \& Snyder, W. (2002). Preposition stranding and the compounding parameter: a developmental perspective. Proceedings of the Annual Boston University Conference on Lanuage Development, 26(2),677-688.

SuperLab [Computer Software]. (2014). Retrieved from http://superlab.com/

Tompkins, C., Boada, R., \& McGarry, K. (1992). The access and processing of familiar idioms by brain-damaged and normally aging adults. Journal of Speech and Hearing Research, 35, 626-637.

Thompson, C. K. (2003). Unaccusative verb production in agrammatic aphasia: The argument structure complexity hypothesis. Journal of Neurolinguistics, 16, 151167.

Thompson, C. K. \& Bastiaanse, R. (2012). Introduction to Agrammatism. In C. Thompson \& R. Bastiaanse (Eds.), Perspectives on Agrammatism (pp. 1-16). New York: Psychology Press. 
Torres-Martinez, S. (2015). A constructionist approach to the teaching of phrasal verbs. English Today, 31(3), 46-58.

Turgeon, Y. \& Macoir, J. (2008). Classical and contemporary assessment of aphasia and acquired disorders of language. In B. Stemmer \& H.A. Whitaker (Eds.), Handbook of the neuroscience of language (pp. 3-11). San Diego, CA: Academic Press.

Van Lancker Sidtis, D. (2006). Where in the brain is nonliteral language? Metaphor and Symbol, 21, 213-244.

Weinstein, B. E. (2011). Screening for otologic functional impairments in the elderly: Whose job is it anyway? Audiology Research, 1, 42-48.

Wray, A., \& Perkins, M. R. (2000). The functions of formulaic language: An integrated model. Language and Communication, 20(1), 1-28.

Yueh, B., Shapiro, N., MacLean, C.H., \& Shekelle, P. G. (2003). Screening and management of adult hearing loss in primary care: Scientific review. JAMA, 289, 1976-85.

Zempleni, M.-Z., Renken, R., Hoeks, J. C. J., Hoogduin, J. M., \& Stowe, L. A. (2007). Semantic ambiguity processing in sentence context: Evidence from event-related fMRI. Neuroimage, 34, 1270-1279. 


\section{Appendix A}

Participant Demographic Information

Group 1: Participants with Aphasia

\begin{tabular}{|l|l|r|r|r|r|}
\hline \multicolumn{1}{|c|}{ Initials } & Gender & \multicolumn{1}{c|}{ Age } & WAB-R AQ & Education & \multicolumn{1}{c|}{ MOCA } \\
\hline EP & M & 61.34 & 87.8 & 20 & 21 \\
\hline JB & M & 55.91 & 72.3 & 17 & 19 \\
\hline DG & M & 56.03 & 63.6 & 13 & 20 \\
\hline AS & F & 54.76 & 92.5 & 12 & 23 \\
\hline SJ & F & 52.85 & 69.8 & 19 & 18 \\
\hline VB & F & 74.25 & 65.2 & 15 & 17 \\
\hline HB & F & 51.85 & 75.4 & 16 & 19 \\
\hline
\end{tabular}

\begin{tabular}{|c|c|c|c|c|c|c|c|c|}
\hline \multicolumn{7}{|c|}{ WAB-R Subtest Scores per Participant } \\
\hline Initials & Gender & Age & Date of Onset & Spontaneous Speech Score & Auditory Verbal Comprehension Score & Repetition Score & Naming and Word Finding Score & WAB-R AQ \\
\hline EP & M & 61.34 & Apr-16 & 18 & 10 & 9.2 & 6.7 \\
\hline JB & M & 55.91 & Feb-15 & 10 & 9.45 & 8.4 & 8.3 \\
\hline DG & M & 56.03 & Jun-15 & 11 & 7.2 & 7 & 72.3 \\
\hline AS & F & 54.76 & Apr-04 & 18 & 9.55 & 9.4 & 6.6 \\
\hline SJ & F & 52.85 & Sep-15 & 10 & 8.9 & 8.6 & 9.3 & 7.4 \\
\hline VB & F & 74.25 & May-07 & 10 & 8.8 & 8 & 9.6 \\
\hline HB & F & 51.85 & May-08 & 13 & 9.4 & 7.3 & 5.8 \\
\hline
\end{tabular}

Group 2: Older Normals

\begin{tabular}{|c|c|c|c|c|}
\hline Initials & Gender & Age & Education & MOCA \\
\hline MM & $\mathrm{F}$ & 61.13 & 17 & 29 \\
\hline$C P$ & $\mathrm{~F}$ & 61.43 & 17 & 28 \\
\hline EF & $\mathrm{F}$ & 56.77 & 14 & 28 \\
\hline BB & $\mathrm{F}$ & 56.9 & 19 & 27 \\
\hline VV & $\mathrm{F}$ & 70.78 & 19 & 27 \\
\hline WD & M & 70.69 & 14 & 27 \\
\hline PV & M & 74.01 & 19 & 27 \\
\hline RF & M & 62.81 & 17 & 27 \\
\hline$A B$ & M & 63.47 & 20 & 30 \\
\hline SG & M & 61.82 & 16 & 25 \\
\hline
\end{tabular}


Group 3: Younger Normals

\begin{tabular}{|l|l|r|r|}
\hline \multicolumn{1}{|c|}{ Initials } & \multicolumn{1}{c|}{ Gender } & \multicolumn{1}{c|}{ Age } & Education \\
\hline KB & F & 25.06 & 19 \\
\hline IC & F & 29.23 & 17 \\
\hline LC & F & 36.4 & 20 \\
\hline TN & F & 35.1 & 18 \\
\hline LCL & F & 27.14 & 18 \\
\hline JR & M & 23.6 & 13 \\
\hline JM & M & 29.39 & 20 \\
\hline CD & M & 26.09 & 19 \\
\hline RR & M & 22.26 & 17 \\
\hline JM & M & 30.37 & 19 \\
\hline
\end{tabular}


Appendix B

\section{BACKGROUND QUESTIONNAIRE}

\section{Personal Information}

1. Please indicate your date of birth:

2. What is your Place of Birth?

3. If place of Birth is not U.S., how long have you been living in the U.S.?

$\circ$ Less than 9 years

- 10-19 years

○ 20-29 years

o 30-39 years

○ More than 40 years

4. What is your highest level of education achieved?

$\circ$ High School/GED

- Vocational/technical school

○ Some college

- Bachelor's degree

- Master's degree

- Doctoral degree

○ Professional degree (MD. JD, etc.)

5. How many languages do you speak?
○ 1
○ 2 
$\begin{array}{ll}\text { ○ } & 3 \\ \text { ○ } & \text { More than } 3\end{array}$

6. Which is your primary language?

○ English

○ Spanish

- French

- Haitian Creole

$\circ$ Other (please specify):

7. When did you begin acquiring your first language?

- Between $2-3$ years of age

- In grade school

○ In junior high/high school

$\circ$ In college

8. When did you begin acquiring your second language?

- Between 2-3 years of age

○ In grade school

$\circ$ In junior high/high school

$\circ$ In college 


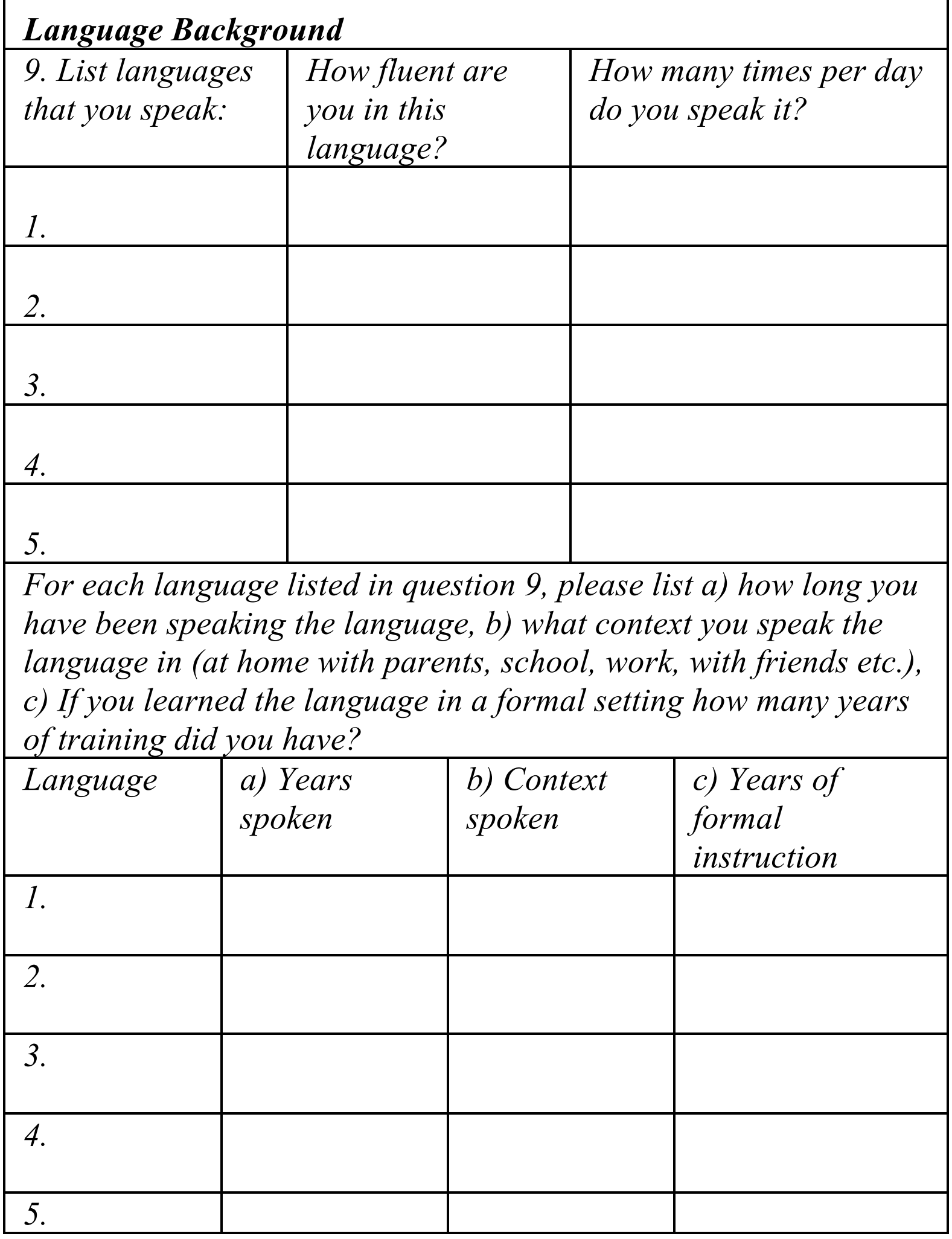




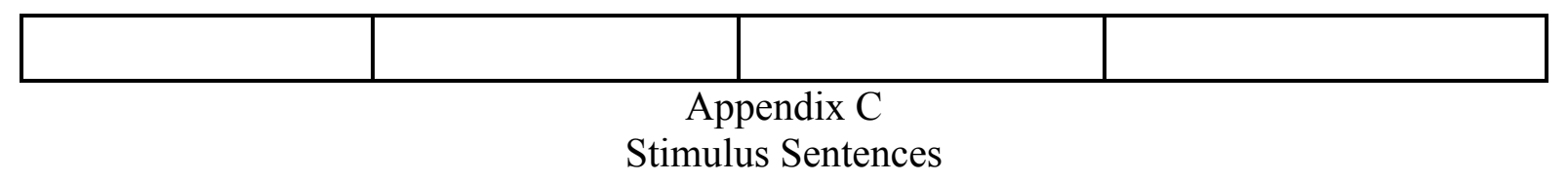

\section{Sample Sentences}

Stimulus Sentences

The cat is sleeping.

The apple is red.

The boy is crying.

The man is reading,

The woman is cooking.

\section{Target Sentences}

Condition: VP Prt NP

\begin{tabular}{|c|c|c|}
\hline Idiomatic & Directional & Aspectual \\
\hline $\begin{array}{l}\text { My grandmother cut out the } \\
\text { coupons. }\end{array}$ & $\begin{array}{l}\text { The student picked up the } \\
\text { pencil. }\end{array}$ & $\begin{array}{l}\text { The student ripped up the } \\
\text { paper. }\end{array}$ \\
\hline The girl kicked out the boy. & $\begin{array}{l}\text { My mother sent out the } \\
\text { package. }\end{array}$ & The sun dried up the rain. \\
\hline $\begin{array}{l}\text { The parents dropped off the } \\
\text { student. }\end{array}$ & $\begin{array}{l}\text { The tornado flattened down } \\
\text { the buildings. }\end{array}$ & $\begin{array}{l}\text { My mother finished up her } \\
\text { dress. }\end{array}$ \\
\hline $\begin{array}{l}\text { The parents picked up their } \\
\text { son. }\end{array}$ & The dog dug out his bone. & The baby drank up the milk. \\
\hline $\begin{array}{l}\text { The translator looked up the } \\
\text { word. }\end{array}$ & $\begin{array}{l}\text { The cat scared away the } \\
\text { birds. }\end{array}$ & The fire burned up the trees. \\
\hline $\begin{array}{l}\text { His secretary handed in the } \\
\text { document. }\end{array}$ & $\begin{array}{l}\text { The man threw away the } \\
\text { garbage. }\end{array}$ & $\begin{array}{l}\text { The teacher cleaned up his } \\
\text { desk. }\end{array}$ \\
\hline $\begin{array}{l}\text { The woman tried on the } \\
\text { dress. }\end{array}$ & $\begin{array}{l}\text { The bulldozer knocked } \\
\text { down the houses. }\end{array}$ & $\begin{array}{l}\text { The shopkeeper closed up } \\
\text { his store. }\end{array}$ \\
\hline $\begin{array}{l}\text { The boss took over the } \\
\text { meeting. }\end{array}$ & $\begin{array}{l}\text { The cats knocked over a } \\
\text { vase. }\end{array}$ & $\begin{array}{l}\text { The student opened up his } \\
\text { book. }\end{array}$ \\
\hline $\begin{array}{l}\text { The agent clued in his } \\
\text { partner. }\end{array}$ & $\begin{array}{l}\text { The camper laid down the } \\
\text { tarp. }\end{array}$ & $\begin{array}{l}\text { His friend ate up the } \\
\text { spaghetti. }\end{array}$ \\
\hline $\begin{array}{l}\text { My brother knocked out } \\
\text { two assignments. }\end{array}$ & $\begin{array}{l}\text { The cook mixed in the } \\
\text { ingredients. }\end{array}$ & The cold froze up the lake. \\
\hline The boys blew up the car. & $\begin{array}{l}\text { The volunteer scooped up } \\
\text { the trash. }\end{array}$ & $\begin{array}{l}\text { The researcher sealed up the } \\
\text { vials. }\end{array}$ \\
\hline $\begin{array}{l}\text { The police broke up the } \\
\text { party. }\end{array}$ & $\begin{array}{l}\text { Your son set down the } \\
\text { plates. }\end{array}$ & $\begin{array}{l}\text { My mother swept up the } \\
\text { floor. }\end{array}$ \\
\hline $\begin{array}{l}\text { The soldier handed over his } \\
\text { weapon. }\end{array}$ & $\begin{array}{l}\text { My mother sewed on the } \\
\text { button. }\end{array}$ & $\begin{array}{l}\text { The woman wiped up the } \\
\text { mess. }\end{array}$ \\
\hline $\begin{array}{l}\text { The woman fought off the } \\
\text { burglar. }\end{array}$ & $\begin{array}{l}\text { The child threw down the } \\
\text { toy. }\end{array}$ & $\begin{array}{l}\text { My mother heated up the } \\
\text { leftovers. }\end{array}$ \\
\hline The soldier barked out the & Your dad slammed on the & My dad raked up the leaves. \\
\hline
\end{tabular}


orders.

brakes.

Condition: VP NP Prt

\begin{tabular}{|c|c|c|}
\hline Idiomatic & Directional & Aspectual \\
\hline $\begin{array}{l}\text { My grandmother cut the } \\
\text { coupons out. }\end{array}$ & $\begin{array}{l}\text { The student picked the } \\
\text { pencil up. }\end{array}$ & $\begin{array}{l}\text { The student ripped the } \\
\text { paper up. }\end{array}$ \\
\hline The girl kicked the boy out. & $\begin{array}{l}\text { My mother sent the package } \\
\text { out. }\end{array}$ & The sun dried the rain up. \\
\hline $\begin{array}{l}\text { The parents dropped the } \\
\text { student off. }\end{array}$ & $\begin{array}{l}\text { The tornado flattened the } \\
\text { buildings down. }\end{array}$ & $\begin{array}{l}\text { My mother finished her } \\
\text { dress up. }\end{array}$ \\
\hline $\begin{array}{l}\text { The parents picked their son } \\
\text { up. }\end{array}$ & The dog dug his bone out. & The baby drank the milk up. \\
\hline $\begin{array}{l}\text { The translator looked the } \\
\text { word up. }\end{array}$ & $\begin{array}{l}\text { The cat scared the birds } \\
\text { away. }\end{array}$ & The fire burned the trees up. \\
\hline $\begin{array}{l}\text { His secretary handed the } \\
\text { document in. }\end{array}$ & $\begin{array}{l}\text { The man threw the garbage } \\
\text { away. }\end{array}$ & $\begin{array}{l}\text { The teacher cleaned his } \\
\text { desk up. }\end{array}$ \\
\hline $\begin{array}{l}\text { The woman tried the dress } \\
\text { on. }\end{array}$ & $\begin{array}{l}\text { The bulldozer knocked the } \\
\text { houses down. }\end{array}$ & $\begin{array}{l}\text { The shopkeeper closed his } \\
\text { store up. }\end{array}$ \\
\hline $\begin{array}{l}\text { The boss took the meeting } \\
\text { over. }\end{array}$ & $\begin{array}{l}\text { The cats knocked a vase } \\
\text { over. }\end{array}$ & $\begin{array}{l}\text { The student opened his } \\
\text { book up. }\end{array}$ \\
\hline $\begin{array}{l}\text { The agent clued his partner } \\
\text { in. }\end{array}$ & $\begin{array}{l}\text { The camper laid the tarp } \\
\text { down. }\end{array}$ & $\begin{array}{l}\text { His friend ate the spaghetti } \\
\text { up. }\end{array}$ \\
\hline $\begin{array}{l}\text { My brother knocked two } \\
\text { assignments out. }\end{array}$ & $\begin{array}{l}\text { The cook mixed the } \\
\text { ingredients in. }\end{array}$ & The cold froze the lake up. \\
\hline The boys blew the car up. & $\begin{array}{l}\text { The volunteer scooped the } \\
\text { trash up. }\end{array}$ & $\begin{array}{l}\text { The researcher sealed the } \\
\text { vials up }\end{array}$ \\
\hline $\begin{array}{l}\text { The police broke the party } \\
\text { up. }\end{array}$ & $\begin{array}{l}\text { Your son set the plates } \\
\text { down. }\end{array}$ & $\begin{array}{l}\text { My mother swept the house } \\
\text { up. }\end{array}$ \\
\hline $\begin{array}{l}\text { The soldier handed his } \\
\text { weapon over. }\end{array}$ & $\begin{array}{l}\text { My mother sewed the } \\
\text { button on. }\end{array}$ & $\begin{array}{l}\text { The woman wiped the mess } \\
\text { up. }\end{array}$ \\
\hline $\begin{array}{l}\text { The woman fought the } \\
\text { burglar off. }\end{array}$ & $\begin{array}{l}\text { The child threw the toy } \\
\text { down. }\end{array}$ & $\begin{array}{l}\text { My mother heated the } \\
\text { leftovers up. }\end{array}$ \\
\hline $\begin{array}{l}\text { The soldier barked the } \\
\text { orders out. }\end{array}$ & $\begin{array}{l}\text { Your dad slammed the } \\
\text { brakes on. }\end{array}$ & My dad raked the leaves up. \\
\hline
\end{tabular}




\section{Distractor Sentences}

\begin{tabular}{|c|c|c|}
\hline \multicolumn{3}{|l|}{ Prepositional Phrases } \\
\hline The man went to the store. & $\begin{array}{l}\text { The cow jumped over the } \\
\text { moon. }\end{array}$ & $\begin{array}{l}\text { The salesman talked on the } \\
\text { phone. }\end{array}$ \\
\hline $\begin{array}{l}\text { The cat came inside the } \\
\text { house. }\end{array}$ & The rooster sat on the fence. & $\begin{array}{l}\text { The secretary typed on the } \\
\text { computer. }\end{array}$ \\
\hline The boys played in the yard. & The pig rolled in the mud. & $\begin{array}{l}\text { The student read in the } \\
\text { library. }\end{array}$ \\
\hline $\begin{array}{l}\text { The child hid under the } \\
\text { blanket. }\end{array}$ & $\begin{array}{l}\text { The woman checked on the } \\
\text { food. }\end{array}$ & The dog ran in the park. \\
\hline The dog slept on the bed. & $\begin{array}{l}\text { The children looked down } \\
\text { the bridge. }\end{array}$ & $\begin{array}{l}\text { The businessman ran to the } \\
\text { office. }\end{array}$ \\
\hline $\begin{array}{l}\text { The children played on the } \\
\text { computer. }\end{array}$ & $\begin{array}{l}\text { The neighbor knocked on } \\
\text { the door. }\end{array}$ & $\begin{array}{l}\text { The clerk filed the } \\
\text { documents. }\end{array}$ \\
\hline $\begin{array}{l}\text { The couple ate in a } \\
\text { restaurant. }\end{array}$ & $\begin{array}{l}\text { The businessman blew on } \\
\text { the coffee. }\end{array}$ & $\begin{array}{l}\text { The children jumped in the } \\
\text { yard. }\end{array}$ \\
\hline $\begin{array}{l}\text { The children went to the } \\
\text { movies. }\end{array}$ & $\begin{array}{l}\text { The fans cheered for the } \\
\text { team. }\end{array}$ & $\begin{array}{l}\text { The kitten bumped into the } \\
\text { wall. }\end{array}$ \\
\hline $\begin{array}{l}\text { The teacher read in the } \\
\text { library. }\end{array}$ & $\begin{array}{l}\text { The baby pointed to the } \\
\text { letter. }\end{array}$ & The nanny lay on the bed. \\
\hline $\begin{array}{l}\text { The man walked in the } \\
\text { park. }\end{array}$ & $\begin{array}{l}\text { The woman sewed in the } \\
\text { house. }\end{array}$ & $\begin{array}{l}\text { The boys listened to the } \\
\text { teacher. }\end{array}$ \\
\hline The pots were on the stove. & $\begin{array}{l}\text { The mailman sat on the } \\
\text { porch. }\end{array}$ & $\begin{array}{l}\text { The boat sailed in the } \\
\text { ocean. }\end{array}$ \\
\hline $\begin{array}{l}\text { The plates were on the } \\
\text { table. }\end{array}$ & $\begin{array}{l}\text { The nanny cooked in the } \\
\text { kitchen. }\end{array}$ & $\begin{array}{l}\text { The dolphin swam by the } \\
\text { shore. }\end{array}$ \\
\hline The dog ran into the house. & $\begin{array}{l}\text { The dentist wrote on the } \\
\text { chart. }\end{array}$ & The birds flew in the sky. \\
\hline $\begin{array}{l}\text { The policeman searched } \\
\text { inside the car. }\end{array}$ & $\begin{array}{l}\text { The therapist checked on } \\
\text { her patient. }\end{array}$ & $\begin{array}{l}\text { The spider climbed up the } \\
\text { wall. }\end{array}$ \\
\hline The candle was on the shelf. & $\begin{array}{l}\text { The maid cleaned in the } \\
\text { garage. }\end{array}$ & The rain fell on the plants. \\
\hline
\end{tabular}




\begin{tabular}{|c|c|c|}
\hline $\begin{array}{l}\text { The students studied the } \\
\text { chapter yesterday. }\end{array}$ & $\begin{array}{l}\text { The candles burned all night } \\
\text { long. }\end{array}$ & $\begin{array}{l}\text { The writer finished the } \\
\text { horror novel. }\end{array}$ \\
\hline $\begin{array}{l}\text { The teacher taught the } \\
\text { chemistry lesson. }\end{array}$ & $\begin{array}{l}\text { The man changed the flat } \\
\text { tire. }\end{array}$ & $\begin{array}{l}\text { The detective found the } \\
\text { evidence yesterday. }\end{array}$ \\
\hline The boys threw the big ball. & $\begin{array}{l}\text { The teacher graded the } \\
\text { homework assignment. }\end{array}$ & $\begin{array}{l}\text { The miller made flour last } \\
\text { night. }\end{array}$ \\
\hline $\begin{array}{l}\text { The cat chased the golden } \\
\text { retriever. }\end{array}$ & $\begin{array}{l}\text { The girls ate some } \\
\text { chocolate cake. }\end{array}$ & $\begin{array}{l}\text { The farmer milked the cows } \\
\text { yesterday. }\end{array}$ \\
\hline $\begin{array}{l}\text { The plumber fixed the } \\
\text { broken pipes. }\end{array}$ & $\begin{array}{l}\text { The nanny changed the } \\
\text { baby's diaper. }\end{array}$ & $\begin{array}{l}\text { The man wore the long } \\
\text { coat. }\end{array}$ \\
\hline $\begin{array}{l}\text { The baby broke the TV } \\
\text { yesterday. }\end{array}$ & $\begin{array}{l}\text { The secretary sent the email } \\
\text { yesterday. }\end{array}$ & $\begin{array}{l}\text { The woman took her big } \\
\text { purse. }\end{array}$ \\
\hline $\begin{array}{l}\text { The cook fried the sweet } \\
\text { potatoes. }\end{array}$ & $\begin{array}{l}\text { The musician tuned his } \\
\text { guitar yesterday. }\end{array}$ & $\begin{array}{l}\text { The baby drank the apple } \\
\text { juice. }\end{array}$ \\
\hline $\begin{array}{l}\text { The milkman left the jars } \\
\text { yesterday. }\end{array}$ & $\begin{array}{l}\text { The actor memorized all his } \\
\text { lines. }\end{array}$ & $\begin{array}{l}\text { The dog chased the black } \\
\text { cat. }\end{array}$ \\
\hline $\begin{array}{l}\text { The woman played the } \\
\text { grand piano. }\end{array}$ & $\begin{array}{l}\text { The maid cleaned the dirty } \\
\text { mantle. }\end{array}$ & $\begin{array}{l}\text { The couple drank wine last } \\
\text { night. }\end{array}$ \\
\hline $\begin{array}{l}\text { The guitarist composed a } \\
\text { song yesterday. }\end{array}$ & $\begin{array}{l}\text { The heat melted the ice } \\
\text { cubes. }\end{array}$ & $\begin{array}{l}\text { The mechanic fixed the car } \\
\text { yesterday. }\end{array}$ \\
\hline $\begin{array}{l}\text { The runner won the } \\
\text { marathon race. }\end{array}$ & $\begin{array}{l}\text { The teenager broke the } \\
\text { computer yesterday. }\end{array}$ & $\begin{array}{l}\text { The chef fried the green } \\
\text { tomatoes. }\end{array}$ \\
\hline $\begin{array}{l}\text { The librarian organized the } \\
\text { old bookshelf. }\end{array}$ & $\begin{array}{l}\text { The shelf held twenty old } \\
\text { books. }\end{array}$ & $\begin{array}{l}\text { The student drank the soda } \\
\text { yesterday. }\end{array}$ \\
\hline $\begin{array}{l}\text { The student made a study } \\
\text { guide. }\end{array}$ & $\begin{array}{l}\text { The babysitter drank herbal } \\
\text { tea yesterday. }\end{array}$ & $\begin{array}{l}\text { The woman ironed her } \\
\text { striped dress. }\end{array}$ \\
\hline $\begin{array}{l}\text { The pilot landed the plane } \\
\text { safely. }\end{array}$ & $\begin{array}{l}\text { The mother bought a long } \\
\text { dress. }\end{array}$ & $\begin{array}{l}\text { The man cut the woman's } \\
\text { hair. }\end{array}$ \\
\hline The child wanted a red bike. & The car had a flat tire. & $\begin{array}{l}\text { The writer finished the short } \\
\text { story. }\end{array}$ \\
\hline
\end{tabular}




\section{Appendix D}

Raw Data

Group 1: Participants with Aphasia

\begin{tabular}{|c|c|c|c|c|c|c|}
\hline \multirow{3}{*}{ Initials } & \multicolumn{6}{|c|}{ Total Reaction Times (In Seconds) } \\
\cline { 2 - 7 } & \multicolumn{2}{|c|}{ Aspectual } & \multicolumn{2}{c|}{ Directional } & \multicolumn{2}{c|}{ Idiomatic } \\
\cline { 2 - 7 } & V Prt NP & V NP Prt & V Prt NP & V NP Prt & V Prt NP & V NP Prt \\
\hline EP & 14.4 & 14.7 & 12.1 & 10.8 & 12.1 & 11.9 \\
\hline JB & 5.2 & 6.1 & 5.2 & 4.7 & 5.6 & 6.4 \\
\hline DG & 10.3 & 6.9 & 5.2 & 8.2 & 6.5 & 7.2 \\
\hline AS & 5.6 & 12.2 & 5 & 8 & 6.1 & 6.8 \\
\hline SJ & 6.2 & 6.8 & 7.2 & 5.7 & 5 & 5.8 \\
\hline VB & 10.1 & 8.6 & 6.3 & 9.3 & 10.4 & 11.1 \\
\hline HB & 6.2 & 5.2 & 4.5 & 4.8 & 5.9 & 5.3 \\
\hline
\end{tabular}

\begin{tabular}{|c|c|c|c|c|c|c|}
\hline \multirow{3}{*}{ Initials } & \multicolumn{6}{|c|}{ Number Correct } \\
\cline { 2 - 7 } & \multicolumn{2}{|c|}{ Aspectual } & \multicolumn{2}{c|}{ Directional } & \multicolumn{2}{c|}{ Idiomatic } \\
\cline { 2 - 7 } & V Prt NP & V NP Prt & V Prt NP & V NP Prt & V Prt NP & V NP Prt \\
\hline EP & 7 & 9 & 13 & 15 & 13 & 14 \\
\hline JB & 8 & 8 & 15 & 14 & 13 & 12 \\
\hline DG & 8 & 3 & 13 & 8 & 12 & 9 \\
\hline AS & 8 & 11 & 15 & 14 & 15 & 15 \\
\hline SJ & 6 & 6 & 13 & 14 & 15 & 14 \\
\hline VB & 4 & 6 & 12 & 10 & 11 & 13 \\
\hline HB & 8 & 6 & 14 & 12 & 14 & 14 \\
\hline
\end{tabular}


Group 2: Older Normals

\begin{tabular}{|c|c|c|c|c|c|c|}
\hline \multirow{3}{*}{ Initials } & \multicolumn{6}{|c|}{ Total Reaction Times (In Seconds) } \\
\cline { 2 - 7 } & \multicolumn{2}{|c|}{ Aspectual } & \multicolumn{2}{|c|}{ Directional } & \multicolumn{2}{c|}{ Idiomatic } \\
\cline { 2 - 7 } & V Prt NP & V NP Prt & V Prt NP & V NP Prt & V Prt NP & V NP Prt \\
\hline MM & 6.2 & 6.5 & 5.9 & 5.6 & 4.3 & 4.5 \\
\hline CP & 6.1 & 6.7 & 5.5 & 5.5 & 7.7 & 4.7 \\
\hline EF & 3.1 & 3.8 & 3.7 & 3.6 & 3.8 & 2.9 \\
\hline BB & 4.9 & 4.6 & 3.9 & 3.4 & 4 & 4.5 \\
\hline VV & 4.8 & 5.8 & 4.2 & 4.3 & 4.8 & 4.1 \\
\hline WD & 4.1 & 3.6 & 3.5 & 3.7 & 8.6 & 3.4 \\
\hline PV & 5.8 & 5.3 & 6.2 & 5.3 & 5.4 & 4.8 \\
\hline RF & 4.4 & 4.3 & 4 & 3.5 & 4.2 & 4.1 \\
\hline AB & 6.4 & 7.3 & 4.8 & 4.7 & 5.4 & 5.5 \\
\hline SG & 3.5 & 4.1 & 3.1 & 2.8 & 3.2 & 2.7 \\
\hline
\end{tabular}

\begin{tabular}{|c|c|c|c|c|c|c|}
\hline \multirow{3}{*}{ Initials } & \multicolumn{6}{|c|}{ Number Correct } \\
\cline { 2 - 7 } & \multicolumn{2}{|c|}{ Aspectual } & \multicolumn{2}{c|}{ Directional } & \multicolumn{2}{c|}{ Idiomatic } \\
\cline { 2 - 7 } & V Prt NP & V NP Prt & V Prt NP & V NP Prt & V Prt NP & V NP Prt \\
\hline MM & 6 & 7 & 14 & 15 & 15 & 15 \\
\hline CP & 4 & 4 & 13 & 12 & 13 & 14 \\
\hline EF & 5 & 5 & 13 & 13 & 14 & 14 \\
\hline BB & 5 & 5 & 14 & 14 & 13 & 14 \\
\hline VV & 9 & 9 & 15 & 15 & 14 & 14 \\
\hline WD & 4 & 7 & 11 & 13 & 14 & 13 \\
\hline PV & 10 & 11 & 13 & 13 & 15 & 13 \\
\hline RF & 7 & 6 & 15 & 15 & 14 & 14 \\
\hline AB & 6 & 6 & 14 & 14 & 15 & 15 \\
\hline SG & 7 & 6 & 14 & 15 & 15 & 15 \\
\hline
\end{tabular}


Group 3: Younger Normals

\begin{tabular}{|c|c|c|c|c|c|c|}
\hline \multirow{3}{*}{ Initials } & \multicolumn{6}{|c|}{ Total Reaction Times (In Seconds) } \\
\cline { 2 - 7 } & \multicolumn{2}{|c|}{ Aspectual } & \multicolumn{2}{c|}{ Directional } & \multicolumn{2}{c|}{ Idiomatic } \\
\cline { 2 - 7 } & V Prt NP & V NP Prt & V Prt NP & V NP Prt & V Prt NP & V NP Prt \\
\hline KB & 4.6 & 4.7 & 3.6 & 4.1 & 4.1 & 3.8 \\
\hline IC & 5.8 & 6.8 & 5.3 & 7 & 4.1 & 6.2 \\
\hline LC & 6.8 & 8.4 & 3.7 & 8.3 & 4 & 5.8 \\
\hline TN & 4.6 & 5 & 3.8 & 4.4 & 4.4 & 4.2 \\
\hline LCL & 4.7 & 3.7 & 3.8 & 3.6 & 4.7 & 4.2 \\
\hline JR & 4.4 & 3.3 & 3.4 & 2.8 & 2.4 & 4.7 \\
\hline JM & 1.9 & 2.1 & 2 & 2.1 & 2.3 & 2.5 \\
\hline CD & 5.9 & 4.4 & 3.5 & 2.8 & 3.5 & 3 \\
\hline RR & 4.5 & 4.9 & 3 & 3.4 & 3.7 & 4 \\
\hline JM & 2.7 & 3 & 2.3 & 2.3 & 2.6 & 2.7 \\
\hline
\end{tabular}

\begin{tabular}{|c|c|c|c|c|c|c|}
\hline \multirow{3}{*}{ Initials } & \multicolumn{6}{|c|}{ Number Correct } \\
\cline { 2 - 7 } & \multicolumn{2}{|c|}{ Aspectual } & \multicolumn{2}{c|}{ Directional } & \multicolumn{2}{c|}{ Idiomatic } \\
\cline { 2 - 7 } & V Prt NP & V NP Prt & V Prt NP & V NP Prt & V Prt NP & V NP Prt \\
\hline KB & 6 & 8 & 15 & 15 & 14 & 15 \\
\hline IC & 7 & 7 & 14 & 15 & 14 & 13 \\
\hline LC & 5 & 4 & 13 & 13 & 12 & 13 \\
\hline TN & 8 & 8 & 15 & 14 & 13 & 14 \\
\hline LCL & 6 & 5 & 15 & 13 & 15 & 14 \\
\hline JR & 5 & 5 & 15 & 15 & 15 & 15 \\
\hline JM & 4 & 5 & 13 & 13 & 15 & 14 \\
\hline CD & 7 & 6 & 15 & 15 & 14 & 14 \\
\hline RR & 7 & 7 & 14 & 14 & 14 & 13 \\
\hline JM & 4 & 5 & 13 & 15 & 14 & 14 \\
\hline
\end{tabular}

